\title{
Line parameters including temperature dependences of self- and air-broadened line shapes of ${ }^{12} \mathrm{C}^{16} \mathrm{O}_{2}$ : 1.6- $\mu \mathrm{m}$ region
}

\author{
V. Malathy Devi ${ }^{\mathrm{a},}$, , D. Chris Benner ${ }^{\mathrm{a}}$, Keeyoon Sung ${ }^{\mathrm{b}}$, Linda R. Brown ${ }^{\mathrm{b}}$, \\ Timothy J. Crawford ${ }^{\mathrm{b}}$, Charles E. Miller ${ }^{\mathrm{b}}$, Brian J. Drouin ${ }^{\mathrm{b}}$, Vivienne H. Payne, \\ Shanshan Yub ${ }^{b}$, Mary Ann H. Smith ${ }^{c}$, Arlan W. Mantz ${ }^{d}$, Robert R. Gamache ${ }^{\mathrm{e}}$ \\ ${ }^{a}$ Department of Physics, The College of William and Mary, \\ Box 8795, Williamsburg, VA 23187, USA \\ ${ }^{b}$ Jet Propulsion Laboratory, California Institute of Technology, \\ 4800 Oak Grove Drive, Pasadena, CA 91109, USA \\ ${ }^{\circ}$ Science Directorate, NASA Langley Research Center, Hampton, VA 23681, USA \\ ${ }^{d}$ Department of Physics, Astronomy and Geophysics, Connecticut College, \\ New London, CT 06320, USA \\ ${ }^{e}$ Office of the Academic Affairs, Student Affairs, International Relations, University of Massachusetts, \\ One Beacon Street, Boston, MA 02108, USA
}

Number of pages: $\quad \mathbf{4 6}$

Number of Figures: 15

Number of Tables: $\mathbf{8}$

Supplemental files: 1

\author{
${ }^{\text {a }}$ Corresponding author \\ Dr. V. Malathy Devi \\ Phone: 757.864 .5521 \\ Fax: 757-864-4343 \\ e mail: malathy.d.venkataraman@nasa.gov
}




\begin{abstract}
Pressure-broadened line shapes in the $30013 \leftarrow 00001\left(v_{1}+4 v_{2}^{0}+v_{3}\right)$ band of ${ }^{12} \mathrm{C}^{16} \mathrm{O}_{2}$ at $6228 \mathrm{~cm}^{-1}$ are reanalyzed using new spectra recorded with sample temperatures down to $170 \mathrm{~K}$. High resolution, high signal-to-noise (S/N) laboratory measurements of line shapes (Lorentz air- and self-broadened halfwidth coefficients, pressure-shift coefficients and off-diagonal relaxation matrix element coefficients) as a function of gas sample temperatures for various pressures and volume mixing ratios are presented. The spectra were recorded using two different Fourier transform spectrometers (FTS): (1) the McMathPierce FTS located at the National Solar Observatory on Kitt Peak, Arizona (and reported in Devi et al., J Mol Spectrosc 2007;245:52-80) and, (2) the Bruker IFS-125HR FTS at the Jet Propulsion Laboratory in Pasadena, California. The 19 spectra taken at Kitt Peak were all recorded near room temperature while the 27 Bruker spectra were acquired both at room temperature and colder temperatures (170-296 $\mathrm{K})$. Various spectral resolutions (0.004-0.011 cm-1), absorption path lengths (2.46 m-121 m) and $\mathrm{CO}_{2}$ samples (natural and ${ }^{12} \mathrm{C}$-enhanced) were included in the dataset. To maximize the accuracies of the various retrieved line parameters, a multispectrum nonlinear least squares spectrum fitting software program was used to adjust the ro-vibrational constants ( $G, B, D$ etc.) and intensity parameters (including Herman-Wallis terms) instead of directly measuring the individual line positions and intensities. To minimize systematic residuals, line mixing (via off-diagonal relaxation matrix elements) and quadratic speed dependence parameters were included in the analysis. Contributions from other weakly absorbing bands: the $30013 \leftarrow 00001$ and $30012 \longleftarrow 00001$ bands of ${ }^{13} \mathrm{C}^{16} \mathrm{O}_{2}$, the $30013 \leftarrow 00001$ band of ${ }^{12} \mathrm{C}^{16} \mathrm{O}^{18} \mathrm{O}$, hot bands $31113 \leftarrow 01101$ and $32212 \leftarrow 02201$ of ${ }^{12} \mathrm{C}^{16} \mathrm{O}_{2}$, as well as the $40013 \leftarrow 10001$ and the $40014 \leftarrow 10002$ bands of ${ }^{12} \mathrm{C}^{16} \mathrm{O}_{2}$, present within the fitted interval were also measured. Results from previous works and new calculations are compared to present measurements, where appropriate.
\end{abstract}

Key words: $\mathrm{CO}_{2}$, Lorentz width, pressure shift, temperature dependence, relaxation matrix element coefficients, speed dependence 


\section{Introduction}

The present study was undertaken to support space-based observations of carbon dioxide. Both the Orbiting Carbon Observatory-2 (OCO-2) [1-3], launched in 2014, and the Japanese Greenhouse Gases Observing Satellite (GOSAT) [4], launched in 2009, rely on measurements of the absorption of reflected sunlight in the $1.61 \mu \mathrm{m}$ and $2.06 \mu \mathrm{m} \mathrm{CO}$ bands and the $0.76 \mu \mathrm{m} \mathrm{O} \mathrm{O}_{2} \mathrm{~A}$ band. From these measurements, estimates of the column-averaged dry air mole fraction, $X_{\mathrm{CO} 2}$, can be retrieved [e.g., 5,6]. The $X_{\mathrm{CO} 2}$ fields can then be used within atmospheric inversion frameworks to infer sources and sinks of $\mathrm{CO}_{2}$. Systematic errors in the retrievals can introduce regional or airmass-dependent biases in the atmospheric inversions that affect the estimates of the sources and sinks [7]. The goal for the OCO2 mission is to provide atmospheric $X_{\mathrm{CO} 2}$ fields with $0.25 \%$ precision [4] (1 part in 400). This goal places stringent demands on the molecular absorption model used within the retrievals. The accuracy of the molecular absorption model is determined by the accuracy of the line parameters and line shape used, and the critical need for accurate spectroscopic parameters for the near infrared (NIR) $\mathrm{CO}_{2}$ bands has been clearly demonstrated in previous work [8].

This study focuses on accurate measurements of spectroscopic line parameters at $1.6 \mu \mathrm{m}$. The strongest band in this region is the $30013 \leftarrow 00001$ band of ${ }^{12} \mathrm{C}^{16} \mathrm{O}_{2}$ at $6228 \mathrm{~cm}^{-1}$, followed by its first hot band $(31113 \leftarrow 01101)(e, f)$ at $6196 \mathrm{~cm}^{-1}$. Weaker absorption lines of ${ }^{13} \mathrm{C}^{16} \mathrm{O}_{2} \quad(30013 \leftarrow 00001$ and

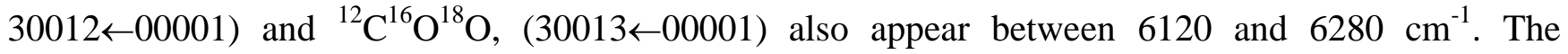
remaining three ${ }^{12} \mathrm{C}^{16} \mathrm{O}_{2}$ bands are weaker: a second hot band $32213 \leftarrow 02201(e, f), 40014 \leftarrow 10002$ and $40013 \leftarrow 10001$. Transitions from minor isotopologues (such as ${ }^{12} \mathrm{C}^{16} \mathrm{O}^{18} \mathrm{O},{ }^{13} \mathrm{C}^{16} \mathrm{O}{ }^{18} \mathrm{O}$ ) also contribute detectable absorption in this wavelength region.

Due to the importance in remote sensing applications, there have been a very large number of measurements reported for $\mathrm{CO}_{2}$ in the $1.6 \mu \mathrm{m}$ region [9-32]. The spectral region between $4600 \mathrm{~cm}^{-1}$ and $7000 \mathrm{~cm}^{-1}$ was previously studied by Toth et al. [13-17] by analyzing a large number of highresolution, high signal to noise $(\mathrm{S} / \mathrm{N})$ spectra recorded using the McMath-Pierce Fourier transform spectrometer (FTS) at Kitt Peak. Those spectra were obtained using samples of $\mathrm{CO}_{2}$ in natural isotopologue abundance, high-purity ${ }^{12} \mathrm{C}$-enriched $\mathrm{CO}_{2},{ }^{13} \mathrm{C}$-enriched $\mathrm{CO}_{2}$ and ${ }^{18} \mathrm{O}$-enriched $\mathrm{CO}_{2}$. The analyses of those data were carried out using a Voigt line shape and a spectrum-by-spectrum fitting procedure. Later, we reinvestigated two of the Fermi tetrad band regions (located at $6228 \mathrm{~cm}^{-1}$ and $6348 \mathrm{~cm}^{-1}$ respectively) $[\mathbf{1 8 , 1 9}]$. Our published results for the $30013 \leftarrow 00001$ and $30012 \longleftarrow 00001$ band regions [18,19] applied the multispectrum fitting technique [33,34] with non-Voigt line shapes: line 
mixing using the off-diagonal relaxation matrix elements [35] and quadratic speed dependence [36]. In Table 1 we give an overview of line shape measurements reported since 2006 for the $30013 \leftarrow 00001$ band, including the studies published after our previous measurements [18] and results by Toth et al. [14] for self-broadened half-width and pressure-shift coefficients. However, all our prior efforts involved gas samples at room temperature, and further laboratory study of pressure broadening as a function of temperature was required for accurate atmospheric remote sensing by OCO-2.

In the present study (PS), we expand our earlier study [18] to include similar high-quality spectra of pure and air-broadened $\mathrm{CO}_{2}$ samples recorded at different gas sample temperatures (170-296 K) and

pressures. The range of measurement conditions was designed to span the range of temperatures and pressures encountered in Earth’s atmosphere.

\section{Table 1 prior studies comes here (landscape format)}

\section{Experimental Details}

A total of 46 spectra were analyzed in this work. Nineteen were recorded [18] at room temperature using the McMath-Pierce FTS at the National Solar Observatory on Kitt Peak, AZ. The 27 additional laboratory spectra were recorded using the Bruker 1FS-125 HR FTS at JPL using a temperaturecontrolled gas sample cell at various temperatures between $\sim 170$ and $250 \mathrm{~K}$. For these measurements, each FTS (McMath-Pierce and JPL) was configured with a $\mathrm{CaF}_{2}$ beamsplitter and InSb detectors. A quartz halogen lamp was the light source for the McMath-Piece FTS while a tungsten lamp was used for the Bruker IFS-125HR at JPL. The source aperture and filter band pass varied between the two arrangements. The instrumental setups and configuration details are given in Table 2, and the experimental conditions for the individual spectra are provided in Table 3.

Table 2 (FTS setups) appears here

For the Kitt Peak spectra, the absorption path lengths ranged between 2.46 and $121 \mathrm{~m}$ for 13 pure $\mathrm{CO}_{2}$ spectra and six air-broadened $\mathrm{CO}_{2}$ spectra. All spectra were recorded with a natural $\mathrm{CO}_{2}$ sample except 
for three obtained with a 99.99\% ${ }^{12} \mathrm{C}$-enriched $\mathrm{CO}_{2}$ sample. The 27 cold spectra from the JPL Bruker FTS include 11 pure $\mathrm{CO}_{2}$ spectra and 16 spectra of $\mathrm{CO}_{2}$ broadened by dry air (Ultra Zero grade from Airgas). All of the JPL spectra were taken with the multipass Herriott cell [37] which has a fixed path length of 20.941(6) m. The high-purity (99.99\% ${ }^{12} \mathrm{C}$-enriched) $\mathrm{CO}_{2}$ sample was used for all of the JPL spectra to simplify the retrievals by minimizing interferences due to absorption features arising from the rarer isotopologues (e.g. ${ }^{13} \mathrm{C}^{16} \mathrm{O}^{16} \mathrm{O},{ }^{12} \mathrm{C}^{16} \mathrm{O}^{18} \mathrm{O}$ ). In the Kitt Peak spectra, weak features of ${ }^{13} \mathrm{C}^{16} \mathrm{O}_{2}$ and ${ }^{12} \mathrm{C}^{16} \mathrm{O}^{18} \mathrm{O}$ isotopologues were observed mostly in longer absorption path length ( 25 and $49 \mathrm{~m}$ ) spectra using the high-purity natural sample of $\mathrm{CO}_{2}$. For these two species, the isotopologue abundances were determined individually and applied in each fitted spectrum. For all other rarer isotopologues, their natural abundances listed in the HITRAN database [38-40] were used.

For the 24 self-broadened spectra (13 from Kitt Peak and 11 from JPL), the sample pressures ranged between 11 Torr and 897 Torr; for the 22 air-broadened $\mathrm{CO}_{2}$ spectra the total sample pressures varied from 50 Torr to 924 Torr with the $\mathrm{CO}_{2}$ volume mixing ratios in the $0.03-0.40$ range. It should be noted that the lowest pressure pure sample spectrum with 11.04 Torr was included in the analysis to provide “zero-pressure” line positions. The $\mathrm{CO}_{2}$ spectra listed in Table 3 were taken over a wide temperature range from 170 to $297 \mathrm{~K}$, for which more than half the scans (11 pure sample and 16 air-broadened) were obtained at temperatures below $293 \mathrm{~K}$.

Additional care was taken to achieve consistency in the low-temperature data. For instance, at least 20 minutes were allowed for each new gas fill to reach temperature and pressure stabilization prior to starting their scanning. Sample pressures and temperatures were monitored continually during the entire scanning period using PRT temperature sensors and MKS Baratron transducers for pressure readings. The pressure gauges were calibrated regularly and the recommended calibration factors provided by the manufacturers were used for the temperature sensors. The interferograms were collected approximately every 10 minutes and then transformed individually before being included in the final averaged spectrum. Other details about characterization of instrumental line shape function for the Bruker FTS at JPL, the coolable Herriott cell system, and experimental precautions taken to minimize systematic errors have been provided in Refs. $[\mathbf{9 , 3 7 ]}$ and references therein.

Table 3 comes next (gas conditions by run) 
Calibrations for line positions from Kitt Peak $\mathrm{CO}_{2}$ spectra were performed with respect to two sets of secondary standards (the $2 \leftarrow 0$ band of $\mathrm{CO}$ [41] or the $v_{1}+v_{3}$ band of $\mathrm{C}_{2} \mathrm{H}_{2}$ [42]) whose spectra were obtained by inserting a second absorption cell in the beam's path [17-19]. For the Bruker spectra taken at JPL, a 10-cm cell containing low pressure of $\mathrm{HCl}$ was inserted in the optical path just before the detector, and the $2 \leftarrow 0$ line positions of $\mathrm{HCl}$ from HITRAN2008 [39] were used as the reference standard. The relative calibration factors of all the Bruker spectra were tied to that of a single Bruker spectrum (since $\mathrm{HCl}$ lines appear the same in all spectra they are independent of sample gas in absorption cell containing $\mathrm{CO}_{2}$ ); any differences between the calibration scales of spectra from the Kitt Peak McMath-Pierce FTS and the JPL Bruker FTS were removed by adjusting the calibration correction factor of that single Bruker spectrum to which all other Bruker FTS data were constrained, in order to obtain an internally consistent set of line positions from spectra recorded by the two different instruments. We estimate the overall absolute uncertainty in our retrieved line positions to be better than $\pm 0.0001 \mathrm{~cm}^{-1}$. Further details on line position comparisons are given in Section 4.1.

\section{Spectral retrievals and measurements}

The multispectrum fit in the present study was initiated using results from our previous study [18]. To reduce the redundancy in gas conditions we selected 19 spectra from the original set of 26 roomtemperature spectra in Ref. [18] and added the 27 new Bruker low-temperature spectra one at a time until all 46 spectra were included in the multispectrum fit.

\subsection{Line positions and intensities}

Line positions and intensities of the stronger individual bands were obtained by adjusting the rovibrational constants and band intensity parameters using well-known theoretical quantum mechanical expressions as part of the nonlinear least squares minimization. For individual line positions, $v_{i}$, and intensities, $S_{\mathrm{i}}$, three equations (1-3) were used to solve for the ro-vibrational (1) $G, B, D, H$ and transition moment constants (2) vibrational band strength $S_{\mathrm{v}}$, and (3) the Herman-Wallis type parameters $a_{1}, a_{2}, a_{3}$ and $a_{4}$ ). 


$$
\begin{aligned}
& v_{i}=G^{\prime}-G^{\prime \prime}+\left(B^{\prime} J^{\prime}\left[J^{\prime}+1\right]-D^{\prime}\left\{J^{\prime}\left[J^{\prime}+1\right]\right\}^{2}+H^{\prime}\left\{J^{\prime}\left[J^{\prime}+1\right]\right\}^{3}\right) \\
& -\left(B^{\prime \prime} J^{\prime \prime}\left[J^{\prime \prime}+1\right]-D^{\prime \prime}\left\{J^{\prime \prime}\left[J^{\prime \prime}+1\right]\right\}^{2}+H^{\prime \prime}\left\{J^{\prime \prime}\left[J^{\prime \prime}+1\right]\right\}^{3}\right) \\
& S_{i}=\frac{S_{v} v_{i} L_{i} F}{Q_{r} v_{0}} \exp \left(\frac{-C_{2} E^{\prime \prime}}{T_{0}}\right)\left[1-\exp \left(\frac{-C_{2} v_{i}}{T_{0}}\right)\right]
\end{aligned}
$$

where,

$$
F=\left(1+a_{1} m+a_{2} m^{2}+a_{3} m^{3}+a_{4} J(J+1)^{2}\right.
$$

and, $m=-J^{\prime \prime}$ for P-branch and $J^{\prime \prime}+1$ for R-branch lines. $v_{0}$ is the band center (equal to $G^{\prime}-G^{\prime \prime}$ ), $v_{\mathrm{i}}$ and $S_{\mathrm{i}}$ correspond, respectively, to the transition wavenumber $\left(\mathrm{cm}^{-1}\right)$ and the intensity in $\mathrm{cm} /(\mathrm{molecule}$ of the $i^{\text {th }}$ line, where prime and double prime refer to the upper and lower levels; $J$ is the rotational quantum number. The lower state ro-vibrational constants were constrained to be the values given by Miller and Brown [29] for ${ }^{12} \mathrm{C}^{16} \mathrm{O}_{2}$ and ${ }^{16} \mathrm{O}^{12} \mathrm{C}^{18} \mathrm{O}$ and by Miller et al. [30] for ${ }^{13} \mathrm{C}^{16} \mathrm{O}_{2}$. In Eq. (2), $E^{\prime \prime}$ is the lower state energy and $T_{0}$ is the reference temperature $(296 \mathrm{~K}) . L_{\mathrm{i}}$ are the Hönl-London factors, $\mathrm{S}_{\mathrm{v}}$ is the vibrational band strength and, $C_{2}$ is the second radiation constant. The values of the rotational quantum partition function, $Q_{\mathrm{r}}$, at $\mathrm{T}=296 \mathrm{~K}$ are 263.87063 for ${ }^{12} \mathrm{C}^{16} \mathrm{O}_{2}, 527.71608$ for ${ }^{13} \mathrm{C}^{16} \mathrm{O}_{2}$ and 559.30454 for ${ }^{12} \mathrm{C}^{16} \mathrm{O}^{18} \mathrm{O}[\mathbf{4 3}]$. We note that in our previous studies $[\mathbf{1 8 , 1 9}]$ a slightly different $Q_{\mathrm{r}}$ value (263.60) was used for ${ }^{12} \mathrm{C}^{16} \mathrm{O}_{2}$, contributing to a change in the vibrational band strength $S_{v}$ by $0.10 \%$ (Table 6) in the present study. The slight change in the vibrational band strength $\left(S_{v}\right)$ value $(0.16 \%)$ between PS and [18] is attributed due to small changes in the various retrieved spectral line parameters and the different sets of spectra used in the two analyses.

In practice, the multispectrum fitting computes the line positions and line intensities of the bands for which individual constraints are activated. The positions and intensities are calculated up to the highest rotational quantum numbers for which the constraints are applied. This technique is particularly important when absorption features are weak (e.g., high-J transitions), blended or overlapped with other neighboring features. Recall that these "calculated" line positions and intensities are actually determined from the ro-vibrational and intensity parameters obtained from present "measured” values applying the multispectrum fitting. These calculated values are useful to extrapolate the measurements to a few higher $J$ transitions beyond the experimentally measured lines using the constraints. The extrapolated position and intensity values beyond a reasonable $J$ outside of the measured transitions 
should be used with caution, especially when the band in question is perturbed by known or unknown local or non-local resonances. As will be shown later, for the Herman-Wallis factors, we found that the $a_{1}, a_{2}$ and $a_{3}$ terms were sufficient to describe the strongest $30013 \leftarrow 00001$ band while only $a_{1}$ and $a_{2}$

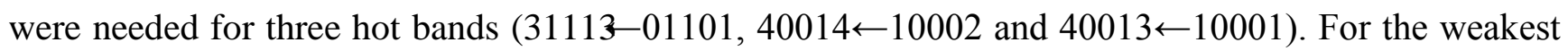
hot band $32213 \leftarrow 02201$, only the $a_{1}$ term could be determined. In practice, the $a_{4}$ term can be separated from the $a_{2}$ term only when a Q branch is present and measurable, and was retained in Eq. (3) for the sake of completeness.

\subsection{Pressure-broadened line shapes}

Similar to our previous analyses (e.g., $[\mathbf{1 8 , 1 9 ]})$, the air- and self-broadened Lorentz half-width and pressure-shift coefficients and their temperature dependences defined in (4)-(6), were measured on a line-by-line basis using the constrained multispectrum least squares fittings [33].

$$
\begin{aligned}
& b_{L}(p, T)=p\left[b_{L}^{0}(\text { air })\left(p_{0}, T_{0}\right)(1-\chi)\left[\frac{T_{0}}{T}\right]^{n 1}+b_{L}^{0}(\text { self })\left(p_{0}, T_{0}\right) \chi\left[\frac{T_{0}}{T}\right]^{n 2}\right] \\
& v=v_{0}+p\left[\delta^{0}(\text { air })(1-\chi)+\delta^{0}(\text { self }) \chi\right] \\
& \delta^{0}(T)=\delta^{0}\left(T_{0}\right)+\delta^{\prime}\left(T-T_{0}\right)
\end{aligned}
$$

In Eqs. (4) - (6), $b_{L}^{0}$ and $\delta^{0}$ represent pressure broadening and pressure-shift coefficients (in $\mathrm{cm}^{-1} \mathrm{~atm}^{-1}$ at $296 \mathrm{~K})$, respectively. $b_{L}(p, T)$ is the Lorentz half-width (in $\mathrm{cm}^{-1}$ ) of the spectral line at pressure $p$ and temperature $T$, and $b_{L}^{0}$ (Gas) $\left(p_{0}, T_{0}\right)$ is the Lorentz half-width coefficient of the line at the reference pressure $p_{0}(1 \mathrm{~atm})$ and temperature $T_{0}(296 \mathrm{~K})$ of the broadening gas (either air or $\left.\mathrm{CO}_{2}\right)$, and $\chi$ is the ratio of the partial pressure of $\mathrm{CO}_{2}$ to the total sample pressure in the cell. Temperature dependences of air- and self-broadened half-width coefficients, $b_{L}^{0}($ air $)\left(p_{0}, T_{0}\right)$ and $b_{L}^{0}($ self $)\left(p_{0}, T_{0}\right)$, and pressureinduced shift coefficients, $\delta^{\prime}$ (air) and $\delta^{\prime}$ (self) were determined separately for each transition from the same fit. As shown in Eq. (6) a linear model was used for the temperature dependence of pressure shift coefficients.

The final multispectrum fit of all 46 spectra at different optical densities and temperatures is shown in Fig. 1. The bottom panel Fig. 1(f) displays all 46 individual observed spectra that were fitted simultaneously. Since the emphasis for our new study is to determine temperature dependences of 
pressure-broadening, the residuals shown in the top five panels (a)-(e) are grouped by the different temperature ranges; these are the corresponding weighted fit residuals (observed minus calculated) for the air- and self-broadened spectra recorded with the two spectrometers. As in previous studies, a maximum weight of 1.0 was assigned to the spectrum with the highest $\mathrm{S} / \mathrm{N}$, while for each other spectrum the weight was set inversely proportional to the square of the ratio of the $\mathrm{S} / \mathrm{N}$ of that spectrum to the $\mathrm{S} / \mathrm{N}$ of the spectrum with the highest weight. No significant differences in the residuals from the various spectra are seen, thus confirming that proper weighting scheme has been applied. A shorter spectral interval (6220-6235 $\mathrm{cm}^{-1}$ ) covering the range of P8-R8 lines taken from Fig. 1 is re-plotted in Fig. 2 to show the details around the center of the strongest $30013 \leftarrow 00001$ band.

\section{Insert Figs. 1 and 2 here}

The multispectrum fits of all 46 spectra shown in Figs. 1 and 2 correspond to the retrieval for the entire $\mathrm{P}$ and $\mathrm{R}$ branches of $30013 \leftarrow 00001$ band as well as other weaker bands in the $6120-6280 \mathrm{~cm}^{-1}$. During the fittings, the Lorentz half-width and pressure-shift coefficients and their temperature dependences were slowly released, for a few lines at a time, then high pressure and low temperature spectra were added to the least squares solution. We note that in our analysis, the internal consistencies of the $\mathrm{CO}_{2}$ volume mixing ratios for each of the air-broadened spectra were closely inspected, and were carefully adjusted to minimize the fit residuals. The quantitative adjustments made to the volume mixing ratios of $\mathrm{CO}_{2}$ in air-broadened spectra should not be a huge concern because (1) line intensities were measured by simultaneously fitting a number of key pure $\mathrm{CO}_{2}$ spectra with known isotopologue abundances without changing pressures and temperatures which determined the calibration of the line intensities and, (2) we did not use premixed samples of $\mathrm{CO}_{2}$ and air; $\mathrm{CO}_{2}$-air mixtures were prepared by adding air to pre-measured amounts of $\mathrm{CO}_{2}$ already installed in the cell. Details about absolute uncertainties are discussed later in a separate section. Adding weak absorption features from the other seven bands appearing in this region alone did not remove the fit residuals completely until speed dependence and line mixing via relaxation matrix elements were also considered in the fit. The solid horizontal line at the bottom of Figs. 1(f) and 2(f) corresponds to 100\% absorption. The short vertical lines at the top of Figs. 1(f) and 2(f) indicate positions of absorption lines included in the fit. 
Table 4 (the count of types of retrieved parameters) comes here

The total numbers of measured parameters retrieved in this work are summarized in Table 4. For the positions and intensities, these include 74 transitions (P74-R72) for the $30013 \longleftarrow 00001$ band of ${ }^{12} \mathrm{C}^{16} \mathrm{O}_{2}$, 136 transitions (P59e-P3e, Q17e-Q1e, R3e -R59e; P60f-P2f, Q16f-Q2f, R2f-R60f) of the 31113Ł01101 ( $e$ and $f$ components) band of ${ }^{12} \mathrm{C}^{16} \mathrm{O}_{2}$, 41 lines (P40e-R39f) for the 32213 $\leftarrow 02201$ ( $e$ and $f$ components) band of ${ }^{12} \mathrm{C}^{16} \mathrm{O}_{2}$, 50 transitions (P48-R50) for the $40014 \longleftarrow 10002$ band of ${ }^{12} \mathrm{C}^{16} \mathrm{O}_{2}$, 47 lines (P46e-R46e) of the $40013 \leftarrow 10001$ band of ${ }^{12} \mathrm{C}^{16} \mathrm{O}_{2}$, 48 lines (P46-R48) for the $30013 \leftarrow 00001$ band of ${ }^{13} \mathrm{C}^{16} \mathrm{O}_{2}, 56$ transitions (P54-R54) for the 30012 $\leftarrow 00001$ band of ${ }^{13} \mathrm{C}^{16} \mathrm{O}_{2}$, and 45 transitions (P10-R41) for the $30013 \leftarrow 00001$ band of ${ }^{12} \mathrm{C}^{16} \mathrm{O}^{18} \mathrm{O}_{2}$. The remaining weak lines (fragmentary bands or without assignments) were added during the fitting process; those positions and intensities were also measured but not included in the Supplemental list. It may be recalled that, except for several spectra recorded at Kitt Peak using a natural $\mathrm{CO}_{2}$ sample, all the remaining spectra in Table 3 were obtained using either a 99.99\% ${ }^{12} \mathrm{C}$-enriched $\mathrm{CO}_{2}$ or $\mathrm{CO}_{2}$ samples mixed with air. Thus, the line intensities listed for ${ }^{13} \mathrm{C}^{16} \mathrm{O}_{2}$ and ${ }^{12} \mathrm{C}^{16} \mathrm{O}^{18} \mathrm{O}$ in the Supplemental file are thought to be a few percent less accurate, but nevertheless could be determined with sufficient precision to obtain the best overall multispectrum fit. For the natural $\mathrm{CO}_{2}$ sample, abundances for the various isotopologues listed in the HITRAN [38-40] database were used. For the ${ }^{12} \mathrm{C}$-enriched samples, the isotopologue abundances (minor species) were determined for each spectrum from least squares fittings to match the intensities in all spectra fit simultaneously. In the sections that follow, we compare our new measurements with our prior roomtemperature results and HITRAN. All individual measurements are given in the Supplemental file for four bands of ${ }^{12} \mathrm{C}^{16} \mathrm{O}_{2}$, two bands of ${ }^{13} \mathrm{C}^{16} \mathrm{O}_{2}$ and one band of ${ }^{12} \mathrm{C}^{16} \mathrm{O}^{18} \mathrm{O}$. We note that many entries contain only the positions and room temperature intensities of weaker lines, and those for the $30013 \longleftarrow 00001$ band of ${ }^{13} \mathrm{C}^{16} \mathrm{O}_{2}$ and the $40013 \leftarrow 10002$ band of ${ }^{12} \mathrm{C}^{16} \mathrm{O}_{2}$ are often extrapolated values calculated by our multispectrum fitting; these are included to indicate all of the lines incorporated in the fits in order to retrieve the target line shape parameters of main bands in this spectral region.

Table 5 sample (selected measures) comes here (landscape) 
A portion of the measured line parameters (P40 through R40) for the $30013 \leftarrow 00001$ band of ${ }^{12} \mathrm{C}^{16} \mathrm{O}_{2}$ are given in Table 5. The table lists the line identification in the first column followed by the calculated line position $\left(\mathrm{cm}^{-1}\right)$ and the calculated line intensity $(\mathrm{cm} /$ molecule) at $296 \mathrm{~K}$ (determined from the retrieved ro-vibrational and intensity parameters by the least squares fits). The two-row format for line shape parameters of each transition indicates air-broadening parameters in the upper row and selfbroadening values in the lower row; these are the measured broadening coefficient $\left(\mathrm{cm}^{-1} / \mathrm{atm}^{-1}\right)$ at 296 $\mathrm{K}$ for both air- and self-broadening, $b_{L}^{0}$ (air) and $b_{L}^{0}$ (self), the temperature dependence exponents $\left(n_{1}\right.$ and $n_{2}$ ) for air- and self-broadening, respectively (no units), air- and self- pressure-shift coefficient ( $\mathrm{cm}^{-}$ ${ }^{1} \mathrm{~atm}^{-1}$ at $296 \mathrm{~K}$ ), $\delta^{0}$ (air) and $\delta^{0}$ (self), and their temperature dependence coefficients (in $\mathrm{cm}^{-1} \mathrm{~atm}^{-1} \mathrm{~K}^{-}$

${ }^{1}$ ), $\delta^{\prime}$ (air) and $\delta^{\prime}$ (self), respectively. We note that only one speed dependence parameter (per transition) common to both broadening gases is reported, and it is assumed to be independent of the sample temperatures. The uncertainties in line positions, pressure-shift coefficients and their temperature dependences are listed in parentheses (in units of the last quoted digit) next to their values; $\%$ uncertainties are provided for line intensities, Lorentz half-width coefficients, the Lorentz half-width temperature dependence exponents and the speed dependence parameters; these are listed in the columns next to their values. The uncertainties listed in Table 5 and in the Supplemental file correspond to the one-sigma internal statistical uncertainties from the multispectrum fittings. However, these values are not considered to represent the absolute uncertainties because there may be systematic uncertainties arising from additional sources, such as the uncertainties in the experimental physical conditions of spectra, wavenumber calibration errors, and other spectrum parameters such as zero level, residual phase errors and field of view corrections.

\section{Discussion of results and comparison with databases}

The $\mathrm{CO}_{2}$ line parameters at $1.6 \mu \mathrm{m}$ were revised in the last three editions of the HITRAN database [3840]. For HITRAN2004 [38], existing entries from the Direct Numerical Diagonalization (DND) technique [44] were replaced by combining selected experimental results with calculated line positions and intensities from the 2003 version of the Carbon Dioxide Spectroscopic Databank, CDSD-1000 [45]. Subsequently, the Toth et al. compilation [17] further improved the positions and intensities for HITRAN2008 [39]. In HITRAN2012 [40], the database has been greatly expanded using an updated CDSD-296 databank [46] to include line parameters for $12 \mathrm{CO}_{2}$ isotopologues, providing information not only for positions and intensities but also for air- and self-broadened Lorentz half-width 
coefficients, temperature dependences of air-broadened half-width coefficients and air- pressureinduced shift coefficients. The CDSD-296 [46] line list includes $\mathrm{CO}_{2}$ transitions with intensities as low as $\sim 1 \times 10^{-30} \mathrm{~cm}^{-1} /\left(\right.$ molecule $\left.\mathrm{cm}^{-2}\right)$ at $296 \mathrm{~K}$. Comparisons of present line parameters with the CDSD296 [46] are shown in several graphs and are discussed in the section describing estimated total error budget. In addition to the CDSD-296 [46] databank, there are three other sources of spectroscopic information where line parameters are theoretically computed [47-49] with which present results are

compared. In the following subsections we detail how our new ${ }^{12} \mathrm{CO}_{2}$ measurements for the $30013 \leftarrow 00001$ band compare with HITRAN values, selected laboratory measurements [e.g., Refs. 13,27,50] and recent theoretical calculations [46-49].

\subsection{Line positions}

In Fig. 3, the mean differences in line positions from present work are compared to corresponding values from Toth et al. [13], seven R branch transitions reported by Long et al. [27] and three editions of the HITRAN database [38-40]; the position differenes are given in $\mathrm{cm}^{-1}$ vs. $m$. The Present Study (PS) and HITRAN values [38-40] extend from P74-R72, those from Toth et al. [13] cover the P60-R60 range, and from Long at al. [27] include 7 lines between R6 and R32. We recall that HITRAN2004 line parameters [38] were used as input to initiate our 2007 studies [18,19] and that the Toth et al. [13] values were included in the HITRAN2008 [39] update. We have also compared our present line positions with Majcherova et al. [51] who reported extensive measurements of the absorption spectrum of carbon dioxide in natural isotopologue abundance from spectra recorded with CW-cavity ring-down spectroscopy technique using several fibered DFB lasers in the 6132-6747 $\mathrm{cm}^{-1}$ interval. Spectroscopic parameters obtained from that study combined with selected experimental results from other measurements were used in updating the line positions for more than 29000 transitions for 364 bands using the effective Hamiltonian approach [45].

The systematic differences seen in PS-HITRAN2012 for transitions with $m>60$ arise from extrapolating available predictions beyond the measured range; the discontinuities at $m=62,64$ and 74 are likely due to differences in combining files from different sources for HITRAN (see Ref. [40] for details). Specifically, in HITRAN2012, line positions from Toth et al. [13] were used for P46-R48 and for P48-P80 and R50-R84, the positions were obtained from experimental energy levels. These 
experimental energy levels were in turn retrieved from measured line positions from several published studies using the RITZ computer code and applying Rayleigh-Ritz principle without any further modeling (for details see Ref. [46]). It may be that these procedures could be causing the $J$ dependence in HITRAN not following a smooth pattern. The mean position differences between the PS and the values from all other studies compared are shown in Fig. 3 and listed in the figure legend indicate very good agreement between the PS and all other studies. Fig. 3 indicates the best agreement with a mean position difference of 0.00006 (1) $\mathrm{cm}^{-1}$ between PS and Long et al. [27] whose measurements were referenced to a cesium atomic clock via an optical frequency comb. If the comparisons were limited only to P60-R60 with all other studies, the mean position differences between PS and other studies would be close to the difference PS-Toth et al., since HITRAN2008 and HITRAN2012 used Toth et al. [13] measurements as discussed above. Recall that line positions reported in this study are "calculated" from the ro-vibrational parameters that were determined from the present "measured line positions" in applying the multispectrum fits. Including the position constraints allowed us to determine (calculate) positions of lines that are otherwise overlapped or blended and could not have been determinable.

\section{Insert Fig. 3 here}

In Fig. 4 we have plotted two self-broadened spectra recorded with the longest optical path (49 m) and high pure $\mathrm{CO}_{2}$ pressures of 896.84 and 252.42 Torr at $\sim 294 \mathrm{~K}$ (see Table 3). In the top panel (a) the spectral interval from $6150-6270 \mathrm{~cm}^{-1}$ is plotted to show the overall strengths of all lines including the weak high $J$ lines for the $30013 \leftarrow 00001$ band. In the middle panel (b) the spectral interval 6150-6170 $\mathrm{cm}^{-1}$ to include the weak high $\mathrm{P}(J)$ transitions while in the bottom panel (c) several weak high-R(J) transitions in the $6250-6270 \mathrm{~cm}^{-1}$ are shown; including assignments for some of these high $-J$ lines. Higher $J$ lines of the $30013 \leftarrow 0001$ band (beyond that are marked in Fig. 4) are not easily recognizable in this figure due to their weakness and blends with transitions from other neighboring bands. This figure illustrates some of the weakest transitions that were measured in the present study. These high $J$ transitions are observable only at the high optical density spectra. By constraining the line positions and intensities using Eqs. (1)-(3), it was possible to measure those parameters for such weak and blended transitions that cannot otherwise be measured to the precisions achieved in this study. The plot indicates that by using longer absorption path, preferably CRDS spectra, it could be possible to 
measure the positions and intensities of these weak and even weaker (higher $J$ ) transitions with better precision and accuracy. Fig. 4 also confirms that the positions and intensities for transitions obtained by extrapolating the ro-vibrational and intensity parameters (Table 6) beyond the measured values of $J$ could be less precise and therefore should be used with caution. In any experimental studies, the accuracies in calculated (or observed) positions and intensities are largely depended upon the highest $J$ measured and hence on the $\mathrm{H}$ and $\mathrm{L}$ values determined for the ro-vibrational constants and, the F-factor parameters obtained from intensity measurements. These accuracies could in turn contribute to the level of deviations from zero difference for positions and unity for intensity ratios with other measurements/calculations.

\section{Insert Fig. 4 (showing the weakest lines)}

\subsection{Intensities}

Since the retrieved intensities for the various bands from the present study are nearly the same as those in our earlier room-temperature study [18], only the $30013 \longleftarrow 00001{ }^{12} \mathrm{C}^{16} \mathrm{O}_{2}$ intensities are discussed in Fig. 5. The measured line intensities vs. $m$ are plotted on both linear (Fig. 5a) and logarithmic (Fig. 5b) scales; since the error bars corresponding to the uncertainties are smaller than the size of the plot symbols in Fig. 5(a), the uncertainties are plotted separately in Fig. 5(b). For comparison, the HITRAN2012 [40] intensity values are also plotted as a solid curve in panels (a) and (b). Fig. 5(c) shows the ratios (including error bars when appropriate) between the present values and those of Refs. $[\mathbf{1 3}, \mathbf{3 9}, \mathbf{4 0}]$, and the mean values of those ratios are given in the legend. The very small intensity uncertainties achieved in the present study are $J$-dependent because their values have been constrained using the theoretical quantum mechanical expressions and the uncertainties also follow a specific formula. The very good agreement of the present results with HITRAN2012 [40], HITRAN2008 [39] and Toth et al. [13] can be seen in the mean ratios and their standard deviations (in parentheses) for line intensities: Present Study/Toth et al. [13] = 0.997(4) and Present Study/HITRAN2012 [40] = 1.005(13), while Present Study/HITRAN2008 [39] = 0.999 (8). Although Toth et al. [13] measured lines up to $m=60$ using a Voigt line shape and the unconstrained line-by-line and spectrum-by-spectrum fitting method, those intensities compare very well with the present study, as seen in Fig. 5(c). The agreement between the Present Study and HITRAN2008 [39] is excellent for $m \leq 72$. However, the comparison of our measured intensities with HITRAN2012 reveals larger differences beginning around $m=48$ and 
increases with higher $m$. Good agreement is seen between PS and HITRAN 2008 and PS and Toth et al., while a discontinuity in intensities beyond P46 and R48 is seen in the HITRAN2012 values. The line intensities for high $J$ transitions in HITRAN2012 are from the CDSD-296 databank [46], discussed in Section 4.1. Intensity comparisons with earlier measurements and with HITRAN2004 [38] were given in [18] and hence are not repeated here. Comparisons of intensities between PS with NIST [50], CDSD-296 [46], Huang [48] and Zak et al. [49] are also made but shown later in Fig. 15 (in the section discussing the estimated total error budget). Since the calculated intensities from Polyansky et al. [47] are virtually identical when extended to the same $J$ as Zak et al., we have not added a separate plot for PS/Polyansky et al.

Insert Fig. 5 (intensity comparisons) here

The ro-vibrational $\left(G, B, D\right.$, etc.), and transition moment constants (vibrational band strength $S_{\mathrm{v}}$, and three Herman-Wallis type parameters $a_{1}, a_{2}, a_{3}$ ) for five bands obtained in this study are reported in Table 6, along with the correlation coefficients between appropriate pairs of fitted parameters for the upper state constants needed to compute the uncertainties in line positions and intensities. The lower state rotational constants shown were constrained to values from Miller and Brown [29] and Miller et al. [30]. We remind the readers that extrapolating calculations beyond the range of measured $J$ can lead to systematic deviations, as seen in Figs. 3, 5 and 15. Because of the larger uncertainties associated with the corresponding constants determined for the ${ }^{13} \mathrm{C}^{16} \mathrm{O}_{2}$ and the ${ }^{12} \mathrm{C}^{16} \mathrm{O}^{18} \mathrm{O}$ bands, and also because better parameters have been determined for those isotopologues from spectra using enriched $\mathrm{CO}_{2}$ samples $[\mathbf{1 6 , 1 7}]$ those values are not included in Table 6.

As stated earlier in Section 4.1, Long et al. [27] reported absolute ${ }^{12} \mathrm{C}^{16} \mathrm{O}_{2}$ transition frequencies (with combined standard uncertainties as low as $6 \times 10^{-7} \mathrm{~cm}^{-1}$ ) measured at the National Institute of Standards and Technology [NIST] in Gaithersburg, Maryland using the frequency-stabilized cavity ring-down spectroscopy and the measured positions were listed for seven transitions between (R6-R32) for the $30013 \leftarrow 00001$ band of ${ }^{12} \mathrm{C}^{16} \mathrm{O}_{2}$. Spectroscopic constants $\left(G_{\mathrm{v}}, B_{\mathrm{v}}, D_{\mathrm{v}}\right.$, and $\left.H_{\mathrm{v}}\right)$ obtained by including these 7 measurements with a much larger dataset in a global fit listed in [27] are compared in Table 6. 
Good agreement is seen for the $G_{\mathrm{v}}, B_{\mathrm{v}}$, and $D_{\mathrm{v}}$ while their $H_{\mathrm{v}}$ value was considerably smaller compared to PS. However, it has been noted that CDSD-296 [46] calculations reproduce accurate measurements when values by Long et al. [27] were combined with other CRDS and FTS data, Lin et al. [52] and Burkart et al. [53] measurements. Lin et al. [52] using a cavity ring-down spectrometer system developed for near-infrared measurements were able to obtain spectra with signal-to-noise ratio of $1.5 \times 10^{6}: 1$. With spectra obtained with their apparatus, they made line shape parameters for airbroadened carbon dioxide transitions near $1.6 \mu \mathrm{m}$ region and modeled the line shapes using the partially correlated quadratic speed dependent Nelkin-Ghatak profile (pCqSDNGP). Burkart et al. [53] published line positions accurate to a few parts in $10^{11}$ for ten transitions in the $\mathrm{P}$ branch of the $30013 \leftarrow 00001$ and two transitions in the $\mathrm{R}$ branch of the $31113 \leftarrow 01101$ of ${ }^{12} \mathrm{C}^{16} \mathrm{O}_{2}$ in the $6189-6215 \mathrm{~cm}^{-1}$ by measuring Doppler free saturated absorption Lamp dips at sub-Pa pressures using optical feedback frequency stabilized cavity ring-down spectroscopy.

Table 6 (fit constants comes here)

In Table 7, we compare the vibrational band intensities, $S_{v}$, for the $30013 \leftarrow 00001$ and the $31113 \leftarrow 01101$ bands of ${ }^{12} \mathrm{C}^{16} \mathrm{O}_{2}$ measured in the present study (columns 2 and 4) with our previous measured values at room-temperature [18] and also to values obtained from line-by-line fitting using the Voigt line shape profile by Toth et al. [13] (columns 3 and 5). Although several other studies (e.g., Refs. [12,20] and references cited therein) reported the $30013 \leftarrow 00001$ band intensity, we have limited our comparisons to only Refs. [13,18] since Predoi-Cross et al. [20] have provided detailed comparisons of their measured $30013 \longleftarrow 00001$ line intensities with the results of $[\mathbf{1 2}, \mathbf{1 3}, \mathbf{1 8}]$ and other earlier studies.

\section{Table 7 (comparing band strengths comes here)}

For each parameter, the values on the top row under the columns labeled Present Study are from this study, while the values in the bottom row were retrieved in our previous study [18] using only roomtemperature data. The Herman-Wallis $a_{3}$ parameter for the $30013 \leftarrow 00001$ band was determinable only in the present study, and, as shown in Table 6, $a_{3}$ parameters were not determined for any other bands. The comparisons show good agreement of the Present Study with the room-temperature measurements 
by Devi et al. [18] and Toth et al. [13], providing confidence that the ${ }^{12} \mathrm{C}^{16} \mathrm{O}_{2}$ isotopologue abundances that we applied in all 46 spectra were properly accounted for. We emphasize that the band strengths/line intensities we have retrieved for the other two isotopologues $\left({ }^{13} \mathrm{C}^{16} \mathrm{O}_{2}\right.$ and the $\left.{ }^{12} \mathrm{C}^{16} \mathrm{O}^{18} \mathrm{O}\right)$ should only be considered as relative, since more accurate measurements for these bands using enriched samples of carbon dioxide were reported by Toth et al. [16,17].

We provide the following discussion relating to the sum of the line intensities, $S_{\text {band }}$, and vibrational band strength, $S_{v}$, determined from present measurements and values listed in Tables 6 and 7. As discussed in Section 3 (spectral retrievals and measurements), Eq. (1)-(3) were used connecting the line positions and line intensities to the ro-vibrational constants and the vibrational band intensity $\left(\mathrm{S}_{\mathrm{v}}\right)$ and Herman-Wallis parameters (e.g., $\left.a_{1}, a_{2}, a_{3}\right)$. The band strength, $\mathrm{S}_{\text {band, }}$ is defined as the sum of all the line intensities in a band. In this work $S_{\text {band }}$ for the $30013 \leftarrow 00001$ band of ${ }^{12} \mathrm{C}^{16} \mathrm{O}_{2}$ is $4.4959 \times 10^{-22}$ $\mathrm{cm} /$ molecule at $296 \mathrm{~K}$. Our present band strength ( $\mathrm{S}_{\text {band }}$ ) value shows excellent agreement with: (a) our previous 2007 measurements [18] of room temperature data $\left(4.501 \times 10^{-22}\right)$; (b) Toth et al. [13] = $4.4357 \times 10^{-22}$; (c) HITRAN2012 [40] $=4.5117 \times 10^{-22}$; (d) Zak et al. [49] $=4.5371 \times 10^{-22}$; CDSD-296 [46] $=4.5394 \times 10^{-22}$; and, (e) Huang [48] $=4.5399 \times 10^{-22}$ at $\mathrm{cm} / \mathrm{molecule}$ at $296 \mathrm{~K}$.

The vibrational band intensity, $S_{v}$, is defined starting from the general expression for the intensity of a line in terms of the total transition moment squared, which in general contains all interactions, for example see Eq. (38) of Ref. [54] or Eq. (17) of Ref. [55]. Assuming no interactions, the transition moment squared can be written as the product of a rotationless (vibrational) transition moment squared times the transition moment squared, for a rigid rotor (Hönl-London factors). Also assuming the product approximation for the total internal partition, i.e., $\mathrm{Q}_{\mathrm{tot}}=\mathrm{Q}_{\mathrm{vib}}{ }^{*} \mathrm{Q}_{\mathrm{rot}}$, the line intensity expression can be written as a vibrational part times a rotational part. $\mathrm{S}_{\mathrm{v}}$ is defined by the vibrational part;

$$
S_{v}=\frac{8 \pi^{3}}{3 h c} v_{\mathrm{v}^{\prime} \leftarrow \mathrm{v}^{\prime \prime}}\left(\frac{1-e^{-E_{\mathrm{v}^{\prime \prime}} / k T}}{Q_{\mathrm{v}}}\right)\left|R_{\mathrm{v}^{\prime} \leftarrow \mathrm{v}^{\prime \prime}}\right|^{2}
$$

where, $h$ is Planck's constant, $c$ is the speed of light, $\omega_{v^{\prime}} \leftarrow v^{\prime \prime}$ is the vibrational band center, $E_{v^{\prime}}$ is the lower state vibrational energy, $k$ is the Boltzmann constant $\left(\mathrm{cm}^{-1} / \mathrm{K}\right), \mathrm{T}$ the temperature in Kelvin, $\mathrm{Q}_{\mathrm{v}}$ is 
the vibrational partition sum, and $\left|\mathrm{R}_{\mathrm{v}^{\prime} \leftarrow \mathrm{v}^{\prime}}\right|^{2}$ is the vibrational transition moment squared. Furthermore, if the line intensity expression is summed over all lines of a band, a sum rule can be applied reducing the rotational part to 1 giving $S_{v}=S_{\text {band }}$. Note, this is only for the case of no vibration-rotation interactions. Interested readers can obtain more details in Ref. [55].

When there are vibration-rotation interactions, the line intensity formula is generally augmented with the Herman-Wallis factor, which defines the departure of line intensities from rigid-rotor behavior (see Eq. (2)). In such cases $S_{v}$ does not equal $S_{\text {band. }}$ The difference between the two can be used as a proxy to the strength of the vibration-rotation interactions. For most parallel bands the differences are only a few percent. In the present study, the ratio of the integrated band strength, $S_{\text {band, }}$, to the vibrational band intensity, $\mathrm{S}_{\mathrm{v}}$, is 1.02, indicating a small vibration-rotation interaction for this band. When the vibrationrotation interactions are strong, significant differences between $S_{\text {band }}$ and $S_{v}$ will be observed, for examples, see Rinsland et al. [56].

\subsection{Lorentz air- and self-broadening}

Although a multispectrum fitting method was applied to fit all the 46 spectra simultaneously, and line positions and line intensities were retrieved using constraints, the air- and self-broadened half-width coefficients, pressure-shift coefficients and their temperature dependences were adjusted individually for each measured transition. The speed dependence parameter was also measured for the strong and medium strength transitions (only for the $30013 \longleftarrow 00001$ band). The measured air- and self-broadened Lorentz half-width coefficients, pressure-shift coefficients, and their corresponding temperature dependences are listed in the Supplemental File. The majority of these were retrieved for the strong

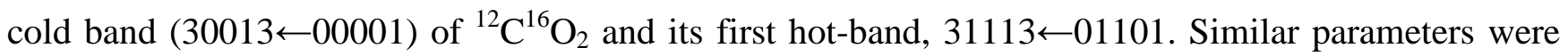
measured for a smaller number of transitions in the $40014 \leftarrow 10002$ band of ${ }^{12} \mathrm{C}^{16} \mathrm{O}_{2}$ and the $30013 \leftarrow 00001$ band of ${ }^{13} \mathrm{C}^{16} \mathrm{O}_{2}$, while only a very few self-width and self-shift coefficients were obtained for the $40013 \leftarrow 10001$ band of ${ }^{12} \mathrm{C}^{16} \mathrm{O}_{2}$ and the $30013 \leftarrow 00001$ band of ${ }^{12} \mathrm{C}^{16} \mathrm{O}^{18} \mathrm{O}$. Temperature dependences for half-width, pressure-shift and relaxation matrix element coefficients were determined only for the $30013 \leftarrow 00001$ band of ${ }^{12} \mathrm{C}^{16} \mathrm{O}_{2}$ (See the Supplemental File).

The measured air- and self-broadened half-width coefficients from present study for the $30013 \leftarrow 00001$ band are plotted as a function of $m\left(m=-J^{\prime \prime}\right.$ for P branch lines and $J^{\prime \prime}+1$ for R-branch lines) in Fig. 6. 
Unlike the line positions and intensities, the Lorentz half-width coefficients were not constrained in the fits to follow a smooth curve as a function of $\mathrm{m}$. Even so, the half-width coefficients for both broadening gases vary rather smoothly with $m$ for both self-broadening and air-broadening with a few exceptions at high- $J$ quantum numbers (see Fig. 6 and the Supplemental file).

Larcher et al. [32] published room-temperature self-broadened half-with coefficients for four transitions (P38, R10, R12, R20) in the $30013 \leftarrow 00001$ band of ${ }^{12} \mathrm{C}^{16} \mathrm{O}_{2}$ using various line shape models, including the Hartmann-Tran Profile (HTP). The line shape model in [32] included collision-induced velocity changes and speed dependence. Because of the differences in line shape models employed in [32] from present study, no direct comparison with those measurements are made here. Included in Fig. 6 are the predicted self- and air-broadened Lorentz half-width coefficients for the $30013 \leftarrow 00001$ band of ${ }^{12} \mathrm{C}^{16} \mathrm{O}_{2}$ published by Gamache and Lamouroux [57]. These values show excellent agreement with other measured and theoretical values.

\section{Insert Fig. 6 (widths here)}

In the top panel Fig. 6(a) the measured self- and air-broadened half-width coefficients from Toth et al. [14,15], HITRAN2012 [40], the predicted values by Gamache and Lamouroux [57] and the measured air-broadened half-width coefficients from Predoi-Cross et al. [24] are plotted as a function of $\mathrm{m}$. Ratios of half-width coefficients for each transition (present study/Toth et al. [14,15], present study/HITRAN2012 [40] and present study/Predoi-Cross et al. [24]) are plotted in Fig. 6(b). The means and the standard deviations of these ratios are given in the legend of panel 6(b). The largest differences between measurements are for self-width coefficients from the present study and Toth et al. [14]. These large differences are attributed to the different analysis techniques and the line shape models employed in the two studies. In Fig. 6(c) the ratios of self- to air-broadened half-width coefficients for each transition in the present study, Toth et al. [14] and HITRAN2012 [40] are plotted vs. $m$. These ratios vary significantly with $m$, ranging from $\sim 1.05$ to $\sim 1.35$. The form of each of the three ratio plots results from the rapid decrease of self-broadened half-width coefficients with increasing $|m|$ compared to the slower variations of air-broadened half-width coefficients over the same range of $|m|$ (see 6(a)). All three sets of ratios plotted in 6(c) agree to within their mutual statistical uncertainties; the means and 
standard deviations given in the legend of panel 6(c) indicate the level of agreement among the three data sets.

\subsection{Temperature-dependence exponents of Lorentz half-width coefficients $\left(n_{1}\right.$ and $\left.n_{2}\right)$}

For remote sensing applications, both temperature and pressure dependence of half-width coefficients are required on a line-by-line basis. In determining the temperature dependence exponents for the Lorentz air- and self-broadened half-width coefficients, $n_{1}$ and $n_{2}$, we have employed the power law relationship given in Eq. (4) by simultaneously fitting all the air-broadened and self-broadened spectra recorded at all sample temperatures and pressures [see Table 2]. The first measurements of the temperature dependence exponents of air- and self-broadening for the $30013 \leftarrow 00001$ (and the $30012 \longleftarrow 00001$ ) band of ${ }^{12} \mathrm{C}^{16} \mathrm{O}_{2}$ were reported by Predoi-Cross et al. [24,25], who analyzed a large number of high resolution FTS spectra using the multispectrum algorithm, but the sets of air-broadened and self-broadened $\mathrm{CO}_{2}$ spectra were analyzed separately. In those studies, the measured half-width coefficients and temperature dependence exponents were also modeled using semiclassical calculations based upon the Robert-Bonamy formalism. In the present study we have reinvestigated the $30013 \leftarrow 00001$ band by fitting a different set of experimental data obtained by two distinct FTS and combining both the self- and air-broadened spectra in a single global least squares fit, from which we retrieved both $n_{1}$ and $n_{2}$ simultaneously. Values obtained from the two studies are compared in Fig. 7.

\section{Insert Fig. 7 (widths temp dependence) here}

The measured values for $n_{1}$ and $n_{2}$ are plotted vs. $m$ in Fig. 7 . The values from present study are displayed in the upper panel (a), the corresponding values from Predoi-Cross et al. [24,25] in the middle panel (b) and, the predicted values [57] in the bottom panel (c). Although the range in $n_{1}$ and $n_{2}$ are generally close, there is less scatter in the results of the present study plotted in Fig. 7(a). The crossings of the $n_{1}$ and $n_{2}$ vs. $m$ graphs near $|m|=20$ are more obvious in 7(a) than in 7(b). Theoretical modeling by Gamache and Lamouroux [57] shows similar patterns in the $m$-dependences of the temperature dependence exponents for the $\mathrm{CO}_{2}$ and air broadening. The horizontal black dashed line in all three panels corresponds to $n=0.75$, which is close to the average value of the air-broadening temperature dependence exponents for $\mathrm{CO}_{2}$ transitions in recent editions of the HITRAN database [3840]. 


\subsection{Air- and self- pressure shift coefficients and their temperature dependences}

The measured air- and self- pressure-shift coefficients, $\delta^{0}$ (air) and $\delta^{0}$ (self), in units of $\mathrm{cm}^{-1} \mathrm{~atm}^{-1}$ at $296 \mathrm{~K}$ for the $30013 \leftarrow 00001$ band from the Present Study are plotted as a function of $m$ in Fig. 8, along with the shift values from other recent studies $[\mathbf{1 4}, \mathbf{1 5}, \mathbf{2 4}]$ and from HITRAN2012 [40]. The increased scatter observed in the Present Study results at higher $|m|$ values $(|m|>30)$, particularly for the airpressure-shift coefficients, is because at these high- $|m|$ (or $J$ ) values, the absorption lines are weaker especially when the sample temperatures are low. Also, due to the smaller optical path used for the low-temperature spectra and the low mixing ratios used for the air-broadened spectra (see Table 3) the number of transitions measurable in air-broadened spectra is less than for self-broadening. The general qualitative nature of variations of the pressure-shift coefficients vs. $m$ is similar for both broadening gases up to $|m|=\sim 20$ in the R-branch and $|m|=\sim 30$ in the P-branch. Beyond that the self-shift coefficients steadily increase in magnitude with $|m|$ while the air- pressure-shift coefficients show much smaller changes with $|m|$. The self-shift coefficients are systematically larger (more negative) than the corresponding air-shift coefficients for the same transitions. The same behavior has been observed in our previous room-temperature study of this band [18] and in the measurements from other studies whose results are shown in Refs. $[\mathbf{1 4}, \mathbf{1 5}, \mathbf{2 4}]$. Some differences among the measured shifts plotted in the figure for the same broadening gas are expected due to the inclusion (or not) of line mixing in the analysis. We note that the Present Study shift results shown in Fig. 8 are in excellent agreement with the results of our previous room temperature study [18], which included line mixing.

\section{Insert Fig. 8 pressure shifts here}

Applying the linear temperature dependence law in Eq. (6), the temperature dependence coefficients

$\delta^{\prime}$ (air) and $\delta^{\prime}$ (self) $\left(\mathrm{cm}^{-1} \mathrm{~atm}^{-1} \mathrm{~K}^{-1}\right)$ were retrieved directly from the multispectrum fit. The measured $\delta^{\prime}$ (air) and $\delta^{\prime}$ (self) plotted vs. $m$ are shown in Fig. 9.

\section{Insert Fig. 9 (temp-dependence of shifts here)}

The measured $\delta^{\prime}$, temperature dependences of pressure-shift coefficients $\left(\mathrm{cm}^{-1} \mathrm{~atm}^{-1}\right.$ at $\left.296 \mathrm{~K}\right)$ for the $30013 \leftarrow 00001$ band of ${ }^{12} \mathrm{C}^{16} \mathrm{O}_{2}$ from the present study are plotted vs. $m$ in Fig. 9(a) and the 
corresponding values measured by Predoi-Cross et al. [24,25] are similarly plotted in Fig. 9(b). It is puzzling to see that the range in magnitude and some signs of the temperature dependence coefficients are different in the two sets of measurements, although identical expressions (Eq. (6)) were used in both studies. The horizontal dashed lines in panels (a) and (b) represent zero value for the temperature dependence coefficients. It is also seen in (a) that for $\delta^{\prime}$ (self) in the Present Study, the values for $|m|$ near 50 to $\sim|m|=30$ are positive (up to $\sim+0.25 \times 10^{-4} \mathrm{~cm}^{-1} \mathrm{~atm}^{-1} \mathrm{~K}^{-1}$ ), and $\delta^{\prime}$ (self) gradually decreases with decreasing $|m|$ until its value reaches zero and continues to decrease (become more negative) until its value reaches $\sim-0.3 \times 10^{-4} \mathrm{~cm}^{-1} \mathrm{~atm}^{-1} \mathrm{~K}^{-1}$ near the band center. On the contrary, the temperature dependence coefficient for air-shifts, $\delta^{\prime}$ (air), stays positive (except for a couple of outliers near the high- $J \mathrm{P}$ and R lines) but slowly varies with $|\mathrm{m}|$, ranging in value between $+0.1 \times 10^{-4}$ and $+0.3 \times 10^{-4} \mathrm{~cm}^{-}$ ${ }^{1} \mathrm{~atm}^{-1} \mathrm{~K}^{-1}$. The overall range of our measured $\delta^{\prime}$ for both broadening gases is approximately $\pm 0.3 \times 10^{-4}$ $\mathrm{cm}^{-1} \mathrm{~atm}^{-1} \mathrm{~K}^{-1}$.

The results for $\delta^{\prime}$ (self) and $\delta^{\prime}$ (air) by Predoi-Cross et al. [24,25] shown in Fig. 9(b) are from two separate studies involving different sets of spectra. Although non-Voigt line shape profiles with speed dependence was applied in both analysis, the self-broadened spectra [25] were analyzed using a dispersion profile to account for line mixing compared to line mixing with the off-diagonal relaxation matrix elements applied for the air broadening [24]. In both of those studies $\delta^{\prime}$ showed wide variations from one $m$ to another (especially for self-shifts), and the values had a much larger range compared to present study. There were also differences in sign with respect to the present measurements; $\delta^{\prime}$ (self) in [25] were all positive and varied from zero to nearly $+2.0 \times 10^{-4} \mathrm{~cm}^{-1} \mathrm{~atm}^{-1} \mathrm{~K}^{-1}$ while $\delta^{\prime}$ (air) [24] were all negative with values ranging from zero to nearly $-8.0 \times 10^{-5} \mathrm{~cm}^{-1} \mathrm{~atm}^{-1} \mathrm{~K}^{-1}$. At this time we are not able to provide any explanations for the large observed differences between the two sets of temperaturedependence measurements of pressure-shift coefficients shown in Fig. 9 (a) and (b), especially since the corresponding pressure- shift coefficients from the Present Study and Refs. [24,25] are in agreement within their respective measurement uncertainties. However, the reason for these large differences could be that the analysis in [24] was performed using a different spectrum fitting software and fitting different spectra.

\subsection{Off-diagonal relaxation matrix element coefficients and speed dependence}


It is well-known that a conventional Voigt line shape is not adequate to fit high pressure $\mathrm{CO}_{2}$ spectra within the noise levels as seen in these spectra. In the present study, as higher pressure spectra were added to the fit, the fit residuals characteristic of line mixing were observed indicating that line mixing was required to fit the spectra to their noise levels. Line mixing via off-diagonal relaxation matrix element coefficients $\left(W_{\mathrm{ij}}\right)$ in $\mathrm{cm}^{-1} \mathrm{~atm}^{-1}$ at $296 \mathrm{~K}$ [35] between the nearest neighbor transition pairs were included systematically, for a few transition pairs at a time, in both the P and R branches, and for both $\mathrm{CO}_{2}$-air and $\mathrm{CO}_{2}-\mathrm{CO}_{2}$ mixing, until no significant fit residuals above the noise level were apparent. Temperature dependence exponents of the off-diagonal matrix element coefficients could be measured for transitions in the strongest parts of the $\mathrm{P}$ and $\mathrm{R}$ branches for the $30013 \leftarrow 00001$ band. The temperature dependence exponents for the remaining $\mathrm{CO}_{2}-\mathrm{CO}_{2}$ and $\mathrm{CO}_{2}$-air line-mixed pairs were fixed to a default value of 0.75 (a value comparable to the average temperature dependence exponents of the Lorentz half-width coefficients). We were not able to measure the temperature dependence exponents for the very low- $J$ and high- $J$ transitions in the P and R branches, and the reason for this is not clear. It may be associated with not having the optimum optical densities in the spectra used in the fittings, model deficiencies, insufficient range of gas mixture temperatures, or the combination of all of the above. The measured relaxation matrix element coefficients for $\mathrm{CO}_{2}-\mathrm{CO}_{2}$ and $\mathrm{CO}_{2}$-air mixing $\left(W_{\mathrm{ij}}\right)$ in $\mathrm{cm}^{-1} \mathrm{~atm}^{-1}$ at $296 \mathrm{~K}$, as well as their measured temperature dependence exponents, are listed in Table 8. Although we used a different approach to implement relaxation matrix element coefficients for $\mathrm{CO}_{2^{-}}$ $\mathrm{CO}_{2}$ and $\mathrm{CO}_{2}$-air in the present analysis considering only the nearest neighbor transition pairs, Lamouroux et al. ([58] and other references therein) have reported updated database including software for line-mixing in $\mathrm{CO}_{2}$ spectra and their test using laboratory spectra in the 1.5-2.3 $\mu \mathrm{m}$ region.

\section{Table 9 comes here}

The off-diagonal relaxation matrix element coefficients between the nearest neighbor pairs were measured from P2 \& P4 to P48 \& P50 and from R0 \& R2 to R46 \& R48 for $\mathrm{CO}_{2}-\mathrm{CO}_{2}$ and P2 \& P4 to P36 \& P38 and R0 \& R2 to R40 \& R42 for $\mathrm{CO}_{2}$-air. All other (nearest neighbor) relaxation matrix element coefficients were fixed to a default value of $0.004 \mathrm{~cm}^{-1} \mathrm{~atm}^{-1}$ at $296 \mathrm{~K}$ (for both broadening gases) and for a few additional pairs of transitions (up to $J^{\prime \prime}=60$ ) to be consistent with the $J_{\max }$ for which Lorentz half-width coefficients were measured. This procedure was adopted since it is not possible to obtain reliable values of the relaxation matrix element coefficients when the absorption at higher $J$ 
becomes weaker at low temperatures. A power-law expression similar to Eq. (4) for the temperature dependence exponents of the Lorentz half-width coefficients was also used for the temperature dependence exponents for the relaxation matrix element coefficients. As mentioned earlier, the temperature dependence exponents could be determined for only a few pairs of transitions between $|\mathrm{m}|$ $=6$ and 22. The values of these line mixing temperature dependence exponents ranged between 0.67 and 1.03 and showed no systematic variations with $|\mathrm{m}|$ or $J$, and hence all other unmeasured values were fixed to the default average value of 0.75 .

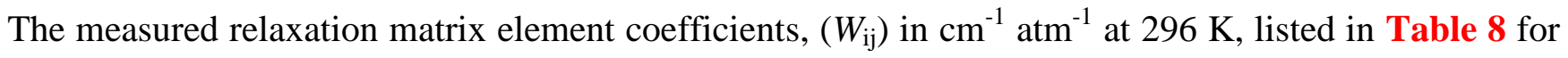
both $\mathrm{CO}_{2}-\mathrm{CO}_{2}$ and $\mathrm{CO}_{2}$-air are plotted in Fig. 10(a) as a function of the rotational quantum number index $m$. The measured relaxation matrix element coefficients range from $\sim 0.002$ to $0.023 \mathrm{~cm}^{-1} \mathrm{~atm}^{-1}$ at $296 \mathrm{~K}$ for $\mathrm{CO}_{2}$-air while for $\mathrm{CO}_{2}-\mathrm{CO}_{2}$ the values range between $\sim 0.005$ and $0.033 \mathrm{~cm}^{-1} \mathrm{~atm}^{-1}$ at $296 \mathrm{~K}$. For $\mathrm{CO}_{2}$-air the relaxation matrix element coefficients measured in the $\mathrm{P}$ and $\mathrm{R}$ branches are close (but not the same value) for transitions with similar $|m|$. In the case of $\mathrm{CO}_{2}-\mathrm{CO}_{2}$, the relaxation matrix element coefficients in the $\mathrm{R}$ branch are larger than those for corresponding $|m|$ in the $\mathrm{P}$ branch, and more measurements to higher $J$ are made in the R branch than in the P branch. For comparisons, we have also plotted the relaxation matrix element coefficients measured in our previous study of $30013 \leftarrow 00001$ band [18] from room-temperature spectra; the two sets of values agree well even though the present study included both room- and low-temperature spectra. Since the number of measured temperature dependence exponents of the relaxation matrix element coefficients was limited we did not plot their values, which are listed in Table 8.

The line shape profile in the present study assumes a quadratic speed dependence on molecular collision velocity. The speed dependence parameter was measured for the strong and medium strength transitions in the $30013 \leftarrow 00001$ band of ${ }^{12} \mathrm{C}^{16} \mathrm{O}_{2}$. The expression given in Eq. (8) to describe the Lorentz width as a function of velocity was used in several of our previous studies [e.g., 18, 19] and was applied to model the speed dependence for transitions with $J$ up to 46.

$$
b_{L}^{0}(v)=b_{L}^{0}\left(v_{m}\right)\left\{1+S\left[\left(\frac{v}{v_{p}}\right)^{2}-c\right]\right\}
$$


In the above expression, $v$ is the speed of the molecular collision, $v_{\mathrm{m}}$ is the mean speed of the molecular collision, $v_{\mathrm{p}}$ is the most probable speed of the collision, and $\mathrm{S}$ is the speed dependence parameter (SD) reported in this study. $\mathrm{c}$ is a constant and its value is taken to be 1.5 so that the Lorentz width will be the same when $S=0$ as that usually used in the Lorentz equation when speed dependence is neglected. When this expression is placed into the Voigt expression and integrated over all velocities of collision, the resulting real $\left(\mathrm{K}_{\mathrm{s}}\right)$ and imaginary $\left(\mathrm{L}_{\mathrm{s}}\right)$ expressions for the line shape becomes those of Eq. (9).

$$
\begin{aligned}
& K_{S}(x, y, S)=\frac{2}{\pi} \int_{-\infty}^{\infty} e^{-v^{2}} v \tan ^{-1}\left\{\left[\frac{v+x}{y\left(S\left\{v^{2}-c\right\}+1\right)}\right]^{2}\right\} d v \\
& L_{S}(x, y, S)=\frac{1}{\pi} \int_{-\infty}^{\infty} e^{-v^{2}} v \ln \left\{\left[\frac{v+x}{y\left(S\left\{v^{2}-c\right\}+1\right)}\right]^{2}+1\right\} d v
\end{aligned}
$$

For transitions for which speed dependence was not measured, that parameter's values were fixed to 0.1 for P42-P62 and 0.07 for R46-R58 (see the last two columns in the Supplemental file). The measured values are plotted in Fig. 10(b) along with those from our earlier study [18].

\section{Insert Fig. 10 (line-mixing \&speed-dep)}

It is clear that the results obtained in the present study are about 20-25\% smaller compared to [18] for all P-branch transitions and for R-branch transitions between $m=1$ and 21. This study included a large number of low temperature spectra, but our analysis assumed that the speed dependence is independent of the broadening gas ( $\mathrm{CO}_{2}$ and air in this case) and also independent of the gas sample temperatures. These assumptions could cause some of the large discrepancy between the present measurements and [18]. Lisak et al. [59] recently published theoretical prediction for the temperature dependence of the quadratic speed dependence parameter. Future analysis could include the model of Lisak et al. as an appropriate physical constraint on the speed-dependent parameter.

We note that because the present study included a number of low-temperature spectra, and temperature dependence exponents of the relaxation matrix element coefficients were retrieved for transitions with 
$J^{\prime \prime}=6$ to 24 while the previous study [18] included only room-temperature spectra and assumed a constant temperature dependence exponent of 0.75 for all line mixing coefficients.

\section{Uncertainties in some measured parameters}

\subsection{Lorentz half-width coefficients}

In simulating the spectrum of a gas/molecular band, it is not the uncertainties in the Lorentz half-width, pressure-shift or the relaxation matrix elements of the transitions that are important, but the uncertainties in those line parameters at the temperature at which the spectrum is to be simulated. As discussed in [24] when one uses a half-width coefficient at $\mathrm{T}=296 \mathrm{~K}$ and its temperature dependence exponent $(n)$ from a database such as the HITRAN, it is normally assumed that the half-width coefficients near $296 \mathrm{~K}$ are the best determined values, and the uncertainty in the temperature dependence exponent $(n)$ increases the uncertainty in half-width coefficient as the temperature gets farther from $296 \mathrm{~K}$. This is not always the case as shown in the following discussions.

As examples, in Fig. 11, we have plotted the formal (internal statistical) uncertainty in the measured Lorentz half-width coefficient $\left(\mathrm{cm}^{-1} \mathrm{~atm}^{-1}\right)$ vs. the gas sample temperatures (K) for a set of air- and selfbroadened transitions for the $30013 \leftarrow 00001$ band. We have chosen P4, P18, R18 and R42 to represent low $J$-, medium $J$ - and high $J$-transitions. Plots are shown for uncertainties in both air- and self-width coefficients vs. sample gas temperatures.

For the P(4) (air- and self-broadened widths) the minimum uncertainty occurs near $\sim 210 \mathrm{~K}$, for the $\mathrm{P}(18)$ air- and self-broadened half-width coefficients, the uncertainty minima are near $225 \mathrm{~K}$, and for the $\mathrm{R}(42)$ air-broadening the minimum uncertainty in half-width coefficients is near $240 \mathrm{~K}$. The uncertainties in half-width coefficients for the low $J$ lines are relatively constant over the range of the spectra in the fit (170 -296 K). For higher- $J$ lines, as the intensities of the transitions become weak at

\section{Insert Fig. 11 (unc-vs-temp) here}

low temperatures, the fit does not adequately determine the half-width coefficients at those temperatures, and the temperature region in which the half-width coefficients are best measured narrows to only the higher temperatures of the fitted spectra. The trend toward lower uncertainties at higher temperature for higher rotational quantum numbers is clear (curves labeled R42 in the figure) as 
is the trend toward lower uncertainties at low temperature in the strongest lines for the low-tointermediate $J$ values (curves labeled P4 in the figure).

\subsection{Uncertainties in pressure-shift coefficients}

The uncertainties of air- and self-broadened pressure-shift coefficients as a function of gas sample temperature for the same set of transitions (P4, P18, R18 and R42) in the $30013 \longleftarrow 00001$ band are

plotted in Fig. 12. Similar to the uncertainty vs. gas sample temperature for the Lorentz half-width coefficients, the uncertainties in the pressure-shift coefficients also tend to be smallest around the middle of the temperature range of the fitted spectra $(170 \mathrm{~K}-296 \mathrm{~K})$ and increase more towards the higher temperatures. For the high- $J$ transitions the deviations from the minima increase rapidly as the sample temperatures are beyond the measurement range (especially for air-broadening). The uncertainties derived from the multispectrum fits for both the Lorentz half-width and pressure shift coefficients are smaller than the real uncertainties because of the large number of spectra included in the least squares fittings that reduce small uncertainties from the noise levels in the spectra (because of the high $\mathrm{S} / \mathrm{N}$ ). The remaining systematic uncertainties dominating the actual uncertainties are due to unknown errors in wavenumber calibration uncertainty of the spectra, the knowledge of the physical conditions of the spectra, the spectral line shape used and other modeling of the spectral line parameters. Line mixing influences the pressure-shifts of the transitions in addition to affecting other line parameters such as intensities and speed dependence; each of which has some small role in the overall solution. The general shapes of the uncertainty curves with temperature plotted in both Figs. 11 and 12 are independent of the systematic effects, and the relative uncertainty from temperature to temperature is close to that plotted in Figs. 11 and 12.

\section{Insert Fig. 12 (unc temp-dep shift) here}

\subsection{Uncertainties in the measured relaxation matrix elements}

The uncertainty in the measured relaxation matrix element coefficients $\left(\mathrm{cm}^{-1} \mathrm{~atm}^{-1}\right)$ vs. gas sample temperature (K) is shown in Fig. 13 for two transitions pairs P12-P14 (self- and air-) and R12-R14 (self- and air-). The plots show that the uncertainties in the relaxation matrix element coefficients increase more rapidly towards lower temperatures ( below $190 \mathrm{~K}$ ) compared to the slow increase toward higher temperature. Similar to the P18 and R18 curves in the uncertainty plots for the half-width 
and pressure-shift coefficients (Figs. 11 and 12), the minimum uncertainty for the measured relaxation matrix element coefficients for $\mathrm{CO}_{2}$-air at medium $J^{\prime \prime}$ also occurs near the middle of the fitted temperature range (170 K-296 K) (though relaxation matrix element coefficients are reported at $296 \mathrm{~K}$ ), but for the $\mathrm{CO}_{2}-\mathrm{CO}_{2}$ mixing the minimum uncertainty is shifted to $280 \mathrm{~K}$, near room temperature.

\section{Insert Fig. 13 unc-line-mix-vs-temp here}

\section{Estimated total error budget}

Examples of the measured line parameters resulting from the present study are listed in Table 5 for selected $30013 \longleftarrow 00001$ transitions along with the one sigma internal statistical error associated with each measured line parameter. These uncertainties are solely based upon the formal uncertainties from the least squares fits and do not include errors arising from unknown sources. Because of the large range in pressures, volume mixing ratios and temperatures of both pure samples and air-broadened $\mathrm{CO}_{2}$ samples, and by fitting all the spectra simultaneously the random errors are greatly minimized. The absolute uncertainties in the retrieved parameters due to unknown sources are associated with experimental physical conditions of the data such as those related to the knowledge of the absorption path lengths, gas sample temperatures, pressures, and calibration uncertainties. The absolute accuracies in the listed parameters due to unknown sources of errors are estimated conservatively to be $\sim \pm 1.0 \%$ for line intensities, 2-3\% for Lorentz half-width coefficients, and 5-10\% for pressure-shift coefficients and the temperature dependences of half-width and pressure-shift coefficients. The absolute accuracies in the off-diagonal relaxation matrix element coefficients and their temperature dependence exponents and speed dependence parameters are more difficult to estimate and could range $\pm 10-20 \%$ of the measured values, depending upon the measurement quality of the transition involved.

To compute the absolute accuracies in our measured line intensities we have estimated the various contributions due to systematic error sources: (a) $0.3-0.4 \%$ in the knowledge of path lengths, (b) 0.1$0.2 \%$ in pressure readings, (c) $0.1-0.2 \%$ in temperature readings, and (d) $0.1-0.2 \%$ background polynomial fits, field of view corrections, residual phase errors, zero level determinations and, some undetermined contribution due to model deficiencies in our analysis. The global standard deviation of weighted observed minus calculated fit residuals are only $0.056 \%$, thus eliminating almost all random errors to within the noise levels of the fitted spectra. The maximum contribution due to sample pressure 
uncertainties corresponds to smallest gas pressure; the uncertainties in higher pressures are not very significant. In any experimental setup involving absorption cells, pressure and temperature gauges, outgassing/desorption/absorption of gas samples, determination of isotopologue abundances, systematic errors are difficult to eliminate. We have taken the best care possible in determining the various measured quantities and applied the best available tool to analyze the data.

Calculations of new line intensities (and positions) for $\mathrm{CO}_{2}$ including the $1.6 \mu \mathrm{m}$ region have been reported recently [46-49]. For a comprehensive understanding of the changes in the evolution of the $\mathrm{CO}_{2}$ line intensities (including the 30013-00001 band) listed in HITRAN database [ 38-40], and to compare our results with recent measurements [50] and the most recent calculations [46-49], we include two figures [Figs. 14 and 15]. In Fig. 14(a) comparison of line position differences between HITRAN2012 [40] and CDSD-296 [46] vs. $m$ and in 14(b) percent intensity differences between HITRAN2012 and CDSD-296 [46] vs. $m$ are shown. In both (a) and (b) the values corresponding to higher $m$ ( $=50$ and beyond shown by solid red circles) are predicted values from various sources (see Section 4). As seen in Fig. 14, the position differences between HITRAN2012 and CDSD-296 lie between +0.000027 and $+0.000046 \mathrm{~cm}^{-1}$ for P46-R48 and, beyond that the differences are within $\pm 0.003 \mathrm{~cm}^{-1}$. For the same range in $J$, the \% intensity differences between HITRAN2012 and CDSD296 are small and vary approximately from -0.8 to +0.4 and from -0.9 to -0.6 , respectively.

\section{Insert Fig. 14 here (Comparisons between HITRAN2012 vs. CDSD-296)}

Line intensities for 27 transitions (P32-P4 and R28-R50) in the 30013-00001 ${ }^{12} \mathrm{C}^{16} \mathrm{O}_{2}$ band were measured [50] at the National Institute of Standards and Technology (NIST) using the frequencystabilized cavity ring-down spectroscopy technique [FS-CRDS]. Those experimental measurements were reported in a joint experimental and theoretical $a b$ initio calculations published by Polyansky et al. [47]. The details of the experimental measurements from NIST are available in [47] where the measured line intensities (isotopologue abundance of 0.984599) are listed in Table 1 of the Supplementary file [47]. For comparisons shown in Fig. 15, the NIST intensities, given at an isotopologue abundance of 0.984599 , were scaled to the natural isotopologue abundance of 0.9842 . A few of those experimental details are repeated here in comparing the line intensities between NIST measurements and the present study to understand the reason for the intensity differences. The 27 line 
intensities in [50] were measured line-by-line using gas samples of known molar fraction of $\mathrm{CO}_{2}$ in air with values that were referenced to gravimetrically-prepared primary standard mixtures. To prevent exchange of $\mathrm{CO}_{2}$ with the surface of the absorption chamber, the sample was continuously introduced into the absorption chamber. The sample pressures were in the 50-150 Torr range, and each line was fit with the sum of a linear baseline and multiple quadratic speed-dependent Nelkin-Ghatak profile. Recently, Zak et al. [49] reported $a b$ initio calculated intensities for P92-R92 transitions for the $30013 \leftarrow 00001$ band. The comparisons of present line intensities to the new measurements [50] and $a b$ initio calculated values for P74-R72 [47-49] and calculated CDSD-296 line parameters [46] are shown in Fig. 15 (a-f).

In Fig. 15, the ratios of line intensities between PS and [47,49,50] vs. $m$ are plotted. The line intensities $[\mathbf{4 7 , 5 0}]$ plotted were scaled to match the natural isotopologue abundance of ${ }^{12} \mathrm{C}^{16} \mathrm{O}_{2}$ in HITRAN [3840]. The following mean ratios of line intensities with standard deviations are obtained: Polyansky et al. [47]/Zak et al. [49]=1.0012(2), PS/Zak et al. [49]=0.9960(79) and NIST/Zak et al. =1.0049(23). We find that line intensities from present study are about $-1.3 \%$ lower than the NIST measurements, but agree reasonably well considering the $\sim 1 \%$ absolute error estimated in this study. Note that the mean and standard deviation of the intensity ratios between the best laboratory measurements [NIST] and the latest $a b$ initio [49] calculated intensities for the 27 transitions in common are 1.0049(23); while a similar ratio between present measured intensities and the ab initio [49] calculated intensities for the P74-R72 transitions is 0.9960(79). Line mixing (off-diagonal relaxation matrix formalism) included in the PS could influence line intensities, although its magnitude is not quantified at this time. The very good agreement $(0.996 \pm 0.008)$ in line intensities between PS and the $a b$ initio calculated intensities [49] is very encouraging.

In addition to plotting the intensity ratios discussed above, we have shown several other comparisons in various panels (b)-(f) of Fig. 15. In (b) Line position differences PS-CDSD-296 are shown; in (c) ratios of line intensities between PS/CDSD-296, PS/Huang [48], CDSD-296/Huang; and Zak et al./CDSD296 are plotted. It is interesting to see that the curvature observed in the intensity ratios between PS/Zak et al. in panel (a) and between PS/CDSD-296 seen in panel (c) are also seen in the plots showing the intensity ratios between other $a b$ initio $[\mathbf{4 8 , 4 9 ]}$ and calculated [46] intensities, though to a lesser degree; (d) Ratios of Lorentz air- and self-broadened half-width coefficients between PS and CDSD-296; (e) 
temperature dependence exponents of Lorentz air-broadened half-width coefficients from PS and CDSD-296; and, (f) air- pressure-shift coefficients from PS and CDSD-296. In addition to the good agreement seen between present measurements and CDSD-296 for line positions, intensities and Lorentz half-width coefficients as shown in panels (b)-(d) for P56-R54 transitions, it is very encouraging to see also the excellent agreements in the temperature dependence exponents for airbroadened half-width coefficients and air- pressure-shift coefficients obtained from PS and the CDSD296.

\section{Insert Fig. 15 here (Comparisons of several parameters)}

As an additional check of our fitting results, we compared synthetic spectra computed from our final multispectrum fit against two air-broadened $\mathrm{CO}_{2}$ spectra not used in our analysis. They were recorded using a White cell whose path length was $32.54 \mathrm{~m}$. The gas sample temperatures were 295.3 and 293.2 $\mathrm{K}$, respectively. Their total sample pressures and $\mathrm{CO}_{2}$ volume mixing ratios were 742.08 Torr and 0.090341, 550.67 Torr and 0.090344, respectively (see Table 3). We found that all the retrieved parameters from the present work reproduced the two observed spectra with their fitting residuals within less than $0.2 \%$ when floating only the zero level, FTS residual phase errors and the background parameters. We note that our fit results represent a self-consistent set of parameters, and should be used as a complete set. For example, as a second test, we scaled our intensities by a factor of 1.0122 (a preliminary, but close estimate to the difference between PS and NIST) in our forward model described above and carried out forward model calculations for our measured 46 laboratory spectra included in our fit. It was found that fixing intensities to NIST values resulted in an unacceptable minimum with systematic residuals up to $0.7 \%$, thus indicating that the NIST intensities are not compatible with the line shape parameters determined in the present work. In the future, we will investigate if a different set of line shape parameters are retrieved when the intensities are fixed to the NIST values and other parameters are floated in the new multispectrum fits.

\section{Conclusions}

In the present study, we were able to fit all of the 46 experimental spectra to their noise levels with only temperature dependent nearest neighbor relaxation matrix element coefficients and other standard, lineby-line parameters. Including the off-diagonal relaxation matrix element coefficients and speed 
dependence parameters in the fits, we were able to determine the line shape parameters better than any previous studies so far for this band. It is important that for accurate simulation of the spectrum that a self-consistent set of line parameters be used. Our measured line parameters are based upon a set of 46 high resolution high S/N spectra covering a wide range of pressures, temperatures and widely varying absorption paths and were fitted simultaneously using a unique, well proven multispectrum fitting program. From our analysis we have provided a consistent set of spectral line parameters, such as positions, intensities, Lorentz air- and self-broadened half-width coefficients and their temperature dependence exponents, air- and self- pressure-shift coefficients and their temperature dependence coefficients, off-diagonal relaxation matrix element coefficients and their temperature dependence exponents, and the speed dependence parameters. All these parameters were measured for transitions in the $30013 \leftarrow 00001$ band. There are more than half a dozen bands in addition to the $30013 \leftarrow 00001$ band producing weak absorption features in the fitted region. Except for the first hot band $31113 \leftarrow 00001$, all other bands are weak. However, fits to the weaker bands were needed to determine accurate parameters for the $30013 \leftarrow 00001$ band. Only positions and intensities and in a few cases self-broadened halfwidths and pressure-shift coefficients were also measured in a few of these weaker bands. In principle, all bands exhibit non-Voigt line shapes provided sufficient optical densities are available, such as in atmospheric remote sensing or cavity ring down spectra.

It is important that a standard line shape model with line mixing be used to establish inter-laboratory comparisons of various spectral line parameters and spectral database standardization. The parameterization presented in this study should work well for retrievals of $\mathrm{CO}_{2}$ in the earth's atmospheric conditions. However, it is not clear whether this parameterization would work equally well for the Venusian atmosphere.

Although the present measurements included absorption features arising from several weaker bands, most of the temperature dependences of line shapes could only be determined for the strongest $30013 \leftarrow 00001$ band of ${ }^{12} \mathrm{C}^{16} \mathrm{O}_{2}$. Ideally, one should be able to retrieve all those parameters for all of the bands in the fitted region. For the future, similar studies could be pursued to include all the bands producing observable absorptions in the fitted interval. This could only be achieved by carefully selecting data by Cavity Ring Down and Photo-acoustic techniques and analyzed using a multispectrum fitting technique that includes new line shape models $[e . g ., 52,59,60]$. We recall that recently Lisak et 
al. [59] have published theoretical predictions for the temperature dependence of the quadratic speed dependent parameter.

Our new measurements of the temperature dependences for the air- and self-broadened Lorentz widths, pressure-shifts, and line mixing parameters via the off-diagonal relaxation matrix element coefficients along with speed dependence offer unprecedented precision for the $1.6 \mu \mathrm{m}$ region over the range of conditions encountered in Earth's atmosphere. Our database will be used to generate absorption coefficients for use within the OCO-2 retrieval algorithm. When simulating the spectrum of $\mathrm{CO}_{2}$, the best fits to laboratory data are achieved only when using the complete, consistent set of line parameters; the full accuracy would be reduced if our present line parameters were used employing another line shape/line mixing model or with a mixture of parameters from our study with other studies. We are analyzing a similar set of high-quality room- and low-temperature spectra for the $2-\mu \mathrm{m}$ region of $\mathrm{CO}_{2}$ using a similar analysis tool. 


\section{Acknowledgments}

Part of the material related to Kitt Peak measurements presented in this investigation was based upon our previous work supported by the National Science Foundation under Grant \# ATM-0338475 to the College of William and Mary. The recent study involving the low-temperature measurements was supported by contracts to the College of William and Mary for the OCO-2 mission through JPL. The research at the Jet Propulsion laboratory (JPL), California Institute of Technology, Connecticut College and NASA Langley Research Center was performed under contracts and cooperative agreements with the National Aeronautics and Space Administration. One of the authors, RRG, was supported by the National Science Foundation through Grant \# AGS-1156862. 


\section{Table titles}

1. Summary of recent line shape measurements ${ }^{\mathrm{a}}$ (number and quantum number range) for the $30013 \leftarrow 00001$ band of ${ }^{12} \mathrm{C}^{16} \mathrm{O}_{2}$.

2. Experimental setups and physical conditions of analyzed $\mathrm{CO}_{2}$ spectra.

3. Summary of experimental conditions of the $\mathrm{CO}_{2}$ spectra analyzed in this work.

4. Measured line parameters and number of $\mathrm{CO}_{2}$ measurements.

5. A sample of measured line parameters for the P40-R40 transitions in the $30013 \leftarrow 00001$ band of ${ }^{12} \mathrm{C}^{16} \mathrm{O}_{2}$.

6. Ro-vibrational, vibrational band intensity, Herman-Wallis parameters and correlation coefficients of measured ${ }^{12} \mathrm{C}^{16} \mathrm{O}_{2}$ bands: $6120-6280 \mathrm{~cm}^{-1}$.

7. Comparison of band intensity ${ }^{\mathrm{a}}$ parameters for the $30013 \leftarrow 00001$ and $31113 \leftarrow 01101$ bands of ${ }^{12} \mathrm{C}^{16} \mathrm{O}_{2}$.

8. Off-diagonal relaxation matrix element coefficients, $W_{i j}$, and their temperature dependence exponents for $\mathrm{CO}_{2}-\mathrm{CO}_{2}$ and $\mathrm{CO}_{2}$-air mixing in the $30013 \leftarrow 00001$ band of ${ }^{12} \mathrm{C}^{16} \mathrm{O}_{2}$. 


\section{Figure Captions}

Fig. 1. The multispectrum fit in the $1.6-\mu \mathrm{m}$ bands of $\mathrm{CO}_{2}$ covering the $6120-6280 \mathrm{~cm}^{-1}$ spectral region. All 46 observed spectra fitted simultaneously are overlaid in the bottom panel (f) with the weighted (observed minus calculated) fit residuals plotted in the top panels (a)-(e) corresponding to selected spectra grouped at different temperature ranges. Fit residuals plotted for each group are taken from the multispectrum fit of all 46 spectra, and the color of each group of residuals corresponds to their color in panel (f). The solid horizontal line at the bottom of (f) indicates the $100 \%$ absorption line. The black short vertical lines at the top of (f) correspond to positions of all absorption lines included in the multispectrum fit. (For interpretation of the reference to color in this figure legend, the reader is referred to the electronic version of this article).

Fig. 2. A short spectral interval (6220-6235 $\left.\mathrm{cm}^{-1}\right)$ from Fig. 1 re-plotted on an expanded wavenumber scale to show details near the band center. Colors and symbols have the same meanings as in Fig. 1. The minimal residuals seen overall indicate that the line shape model incorporating the line mixing (relaxation matrix elements) and speed dependence has well characterized the spectra. In this expanded plot, some small features under (P2-P6) and (R0-R2) are seen in the residuals of panels (b) and (c). Interestingly, those residual features are nearly absent for the higher and lowest temperature spectra. (For interpretation of the reference to color in this figure legend, the reader is referred to the electronic version of this article).

Fig. 3. Comparison of line position differences: Open black triangles: Present StudyHITRAN2012 [40]; Open inverted purple triangles: Present StudyHITRAN2004 [ 38]; Filled red stars: Present Study-HITRAN2008 [39]; and Open dark red circles: Present Study-Toth et al. [13]; Blue checker squares: Present Study-Long et al. [27]; Open inverted green down triangles: PS- Majcherova et al. [51]; Open purple diamonds: PS-CDSD-296 [46]. (For interpretation of the reference to color in this figure legend, the reader is referred to the electronic version of this article).

Fig. 4. Plots of two experimental spectra used in the present analysis to illustrate the strengths of the high $J$ lines measured in the present study. (a) Plots from $6150-6270 \mathrm{~cm}^{-1}$ (b) The interval 6150-6170 $\mathrm{cm}^{-1}$ showing the high $-J$ P lines and, (c) the 6250-6270 $\mathrm{cm}^{-1}$ interval showing the high- $J$ R transitions. (see the text for details). 
Fig. 5. (a) and (b). Line intensities in natural abundance determined in the Present Study (solid red triangles) for the $\mathrm{P}$ and $\mathrm{R}$ branches for the $30013 \leftarrow 00001$ band of ${ }^{12} \mathrm{C}^{16} \mathrm{O}_{2}$ plotted as a function of $m$ ( $m$ $=-J^{\prime \prime}$ for P-branch and $J^{\prime \prime}+1$ for R-branch lines), and compared to HITRAN2012 [40] line intensity values (solid black curve). A linear scale is used in (a), while a logarithmic scale is used in (b). In (b) both the measured line intensities (solid red triangles) and their uncertainties (open red triangles) are plotted. In (c) the ratios of line intensities are plotted with error bars. Solid black triangles: Present Study/HITRAN2012 [40]; Open green stars: Present Study/HITRAN2008 [39], and Open brown diamonds: Present Study/Toth et al. [13]. The larger error bars in (c) are dominated by the uncertainties in Toth et al. [13].

Fig. 6. (a) Measured Lorentz self- and air-broadened half-width coefficients ( $\mathrm{cm}^{-1} \mathrm{~atm}^{-1}$ at $\left.296 \mathrm{~K}\right)$ in the $30013 \leftarrow 00001$ band of ${ }^{12} \mathrm{C}^{16} \mathrm{O}_{2}$ plotted as a function of $m\left(m=-J^{\prime \prime}\right.$ for P-branch and $J^{\prime \prime}+1$ for Rbranch lines). The half-width coefficients are compared to those by Toth et al. [14,15], HITRAN2012 [40], Predoi-Cross et al. [24] and the predicted values by Gamache and Lamouroux [57]. (b) The ratios of Present Study (PS)/Other Study half-width coefficients for the data sets plotted in (a); the mean and standard deviation (in parentheses) of each ratio for the entire band is given in the legend. (c) The ratios of measured self- to air-broadened half-width coefficients for each transition are plotted separately for three data sets (PS, Toth et al. [14,15], and HITRAN2012 [40]). The means and standard deviations of these ratios are also given in the legend. In each panel, where error bars are not visible the uncertainties are smaller than the size of the symbols used.

Fig. 7. Measured temperature dependence exponents for the Lorentz air- and self-broadened half-width coefficients ( $n_{1}$ and $n_{2}$, respectively) in the $30013 \leftarrow 00001$ band of ${ }^{12} \mathrm{C}^{16} \mathrm{O}_{2}$ plotted as a function of $m(m$ $=-J^{\prime \prime}$ for P-branch and $J^{\prime \prime}+1$ for R-branch lines). Upper panel: (a) the measured $n_{2}$ (dark green solid circles) and $n_{1}$ (black solid diamonds) from the Present Study. Middle panel: (b) the measured $n_{2}$ (solid brown inverted triangles) and $n_{1}$ (solid blue stars) from Refs. [24,25]: Bottom panel (c) the predicted $n_{2}$ (solid pink triangles) and $n_{1}$ (solid green stars) from Ref. [57]. The black horizontal dashed lines in (a), (b) and (c) correspond to the temperature dependence exponent $n=0.75$. In all three panels, where the error bars are not visible, they are smaller than the symbol size. (For interpretation of the reference to color in this figure legend, the reader is referred to the electronic version of this article). 
Fig. 8. Measured self- and air- pressure-shift coefficients $\left(\mathrm{cm}^{-1} \mathrm{~atm}^{-1}\right.$ at $\left.296 \mathrm{~K}\right)$ in the $30013 \leftarrow 00001$ band of ${ }^{12} \mathrm{C}^{16} \mathrm{O}_{2}$ vs. $m$ ( $m=-J^{\prime \prime}$ for P-branch and $J^{\prime \prime}+1$ for R-branch lines) in the present study compared to other reported values. The symbols are Present study (self-broadened) $=$ solid red triangles; Present study (air-broadened) = solid black circles; Toth et al. [14] (self-broadened) = solid brown diamonds; Toth et al. [15] (air-broadened) = black inverted open triangle; HITRAN2012 [40] (air-broadened) = black crosses; Predoi-Cross et al. [24] (air-broadened) = solid blue stars. Where the error bars are not visible, they are smaller than the symbol size. (For interpretation of the reference to color in this figure legend, the reader is referred to the electronic version of this article).

Fig. 9. Measured $\delta^{\prime}$, temperature dependences of self- and air- pressure-shift coefficients $\left(\mathrm{cm}^{-1} \mathrm{~atm}^{-1}\right.$ $\mathrm{K}^{-1}$ ) in the $30013 \leftarrow 00001$ band of ${ }^{12} \mathrm{C}^{16} \mathrm{O}_{2}$ (defined by Eq. (6)) vs. $m$ ( $m=-J^{\prime \prime}$ for P-branch and $J^{\prime \prime}+1$ for R-branch lines). Symbols are: upper panel (a) $\delta^{\prime}$ (self) (Present study) = dark solid green circles; $\delta^{\prime}$ (air) (Present study) = solid black diamonds; lower panel (b) $\delta^{\prime}$ (self) (Predoi-Cross et al. [25]) = solid brown triangles; $\delta^{\prime}$ (air) (Predoi-Cross et al. [24]) = solid blue inverted triangles. The dashed horizontal line in (a) and (b) corresponds to $\delta^{\prime}=0$. In each panel, where error bars are not visible, they are smaller than the size of the symbol. (For interpretation of the reference to color in this figure legend, the reader is referred to the electronic version of this article).

Fig. 10. Upper panel (a): Measured off-diagonal relaxation matrix element coefficients, $W_{i j},\left(\mathrm{~cm}^{-1}\right.$ atm ${ }^{-1}$ ) at $296 \mathrm{~K}$ for $\mathrm{CO}_{2}-\mathrm{CO}_{2}$ and $\mathrm{CO}_{2}$-air line mixing plotted vs. $m\left(m=-J^{\prime \prime}\right.$ for P-branch and $J^{\prime \prime}+1$ for R-branch lines) for the $30013 \leftarrow 00001$ band of ${ }^{12} \mathrm{C}^{16} \mathrm{O}_{2}$. Solid dark blue diamonds: self-mixing, Present Study; Solid up red triangles: self-mixing, Ref. [18]; Solid purple circles: air-mixing, Present Study; Solid inverted black triangles: air-mixing, Ref. [18]. Lower panel (b): The measured speed dependence parameter in the $\mathrm{P}$ and $\mathrm{R}$ branches for the $30013 \leftarrow 00001$ band plotted against $m$. The speed dependence parameter is assumed to be independent of the broadening gas and sample temperature, and a single value is given for each transition. Solid dark blue circles: Present Study; Solid red stars: Ref. [18]. In both panels, where error bars are not visible, the uncertainties are smaller than the symbol.

Fig. 11. Uncertainty of self- and air-broadened Lorentz half-width coefficients $\left(\mathrm{cm}^{-1} \mathrm{~atm}^{-1}\right)$ plotted as a function of the gas sample temperature $(\mathrm{K})$ for the $30013 \leftarrow 00001$ band of ${ }^{12} \mathrm{C}^{16} \mathrm{O}_{2}$ illustrating that the minimum uncertainty does not always correspond to $\mathrm{T}=296 \mathrm{~K}$ (where half-width coefficients are 
reported). Plots are made for both self- and air-broadening for P4, P18, R18 and R42 transitions. Plots for middle $J$-transitions overlap and are not labeled individually. For the low- and mid- $J$ transitions, the uncertainties do not vary much with gas temperatures, but the minimum uncertainty is in the 220-230 K range. For the high- $J$ lines, the uncertainty increases rapidly below about $200 \mathrm{~K}$.

Fig. 12. Uncertainty of self- and air- pressure-shift coefficients $\left(\mathrm{cm}^{-1} \mathrm{~atm}^{-1}\right)$ plotted as a function of the gas sample temperature $(\mathrm{K})$ for $30013 \leftarrow 00001$ band of ${ }^{12} \mathrm{C}^{16} \mathrm{O}_{2}$ illustrating that the minimum uncertainty does not always correspond to $\mathrm{T}=296 \mathrm{~K}$ (where pressure shift coefficients are reported). The curves represent the uncertainties of both self- and air-shift coefficients for P4, P18, R18 and P42 transitions. Plots for middle $J$-transitions are close and are not labeled individually. The minimum uncertainty for R42 air-shifts is near $230 \mathrm{~K}$ while for R42 self-shifts, the minimum uncertainty occurs near $270 \mathrm{~K}$.

Fig. 13. Uncertainty in the measured relaxation matrix element coefficients $\left(\mathrm{cm}^{-1} \mathrm{~atm}^{-1}\right)$ plotted as a function of the gas sample temperature $(\mathrm{K})$ for the $30013 \leftarrow 00001$ band of ${ }^{12} \mathrm{C}^{16} \mathrm{O}_{2}$ for self $\left(\mathrm{CO}_{2}-\mathrm{CO}_{2}\right)$ and $\left(\mathrm{CO}_{2}\right.$-air) mixing. Plots are made for four line-mixed transition pairs, P12-P14 self- and air-mixing and R12-R14 self- and air-mixing (two each for $\mathrm{CO}_{2}-\mathrm{CO}_{2}$ and $\mathrm{CO}_{2}$-air). The minimum uncertainty for $\mathrm{CO}_{2}$-air mixing occurs at lower temperatures $(220 \mathrm{~K}, 240 \mathrm{~K})$ compared to $\mathrm{CO}_{2}-\mathrm{CO}_{2}$ mixing $(\sim 280 \mathrm{~K})$.

Fig. 14. (a) Comparison of line position differences between HITRAN2012 [40] and CDSD- 296 [46] vs. $m$. (b) Percent intensity differences between HITRAN2012 and CDSD-296 vs. $m$. In (a) and (b), the CDSD-296 data points for P46-P2 and R0-R48 (open black stars) were calculated using the experimental values from Toth et al. [17] and for the higher $m$ values (solid red circles) from Refs. $[\mathbf{4 5}, \mathbf{4 6}]$ (see the text for details). (For interpretation of the reference to color in this figure legend, the reader is referred to the electronic version of this article).

Fig. 15. (a) Ratios of line intensities: Red circles: Polyansky et al. [47]/Zak et al. [49]; Solid green stars: PS/Zak et al.; Dark brown triangles: NIST/Zak et al. For the same transitions measured in the NIST study [50] the mean ratio PS/Zak et al. = 0.992(2). (b) Line position differences PS-CDSD-296; (c) Ratios of line intensities between PS/CDSD-296, PS/Huang [48], CDSD-296/Huang; and Zak et al./CDSD-296; (d) Ratios of Lorentz air- and self-broadened half-width coefficients between PS and CDSD-296; (e) temperature dependence exponents of Lorentz air-broadened half-width coefficients from PS and CDSD-296; and, (f) air- pressure-shift coefficients from PS and CDSD-296. See the text 
for details. (For interpretation of the reference to color in this figure legend, the reader is referred to the electronic version of this article). 


\section{References}

1. Crisp D, Atlas RM, Breon PM, Brown LR, Burrows JP, Ciais P, et al. The Orbiting carbon Observatory (OCO) mission. Adv Space Res 2004;34:700-9.

2. Crisp D, Miller CE, DeCola PL. Orbiting carbon Observatory: measuring the column averaged carbon dioxide mole fraction from space. J Appl Rem Sens 2008: http://dx.doi.org/10.1117/1.2898457.

3. Boesch H, Baker D, Connor B, Crisp D, Miller CE. Global characterization of $\mathrm{CO}_{2}$ column retrievals from shortwave-infrared satellite observation of the Orbiting Carbon Observatory-2 mission. Remote Sens 2011;3:270-304.

4. Kuze A, Suto H, Nakajima M, Hamazaki T. Thermal and near infrared sensor for carbon observation Fourier transform spectrometer on the Greenhouse Gases Observing Satellite for greenhouse gases monitoring. Appl Opt 2009;48:6716-33, doi:10.1364/AO.48.006716 2009.

5. O’Dell CW, Connor B, Boesch H, O’Brien D, Frankenberg C, Castano R, et al. The ACOS $\mathrm{CO}_{2}$ retrieval algorithm - Part 1: Description and validation against synthetic observations. Atmos Meas Tech 2012;5: 99-121. doi:10.5194/amt-5-99-2012,2012.

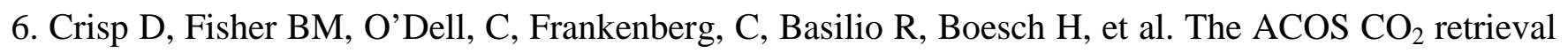
algorithm - Part II: Global XCO 2 characterization. Atmos Meas Tech 2012;5:687-707.

7. Connor BJ, Boesch H, Toon G, Sen B, Miller C, Crisp D. Orbiting Carbon Observatory: inverse method and prospective error analysis. J Geophys Res 2008;113,D05305, doi: 0.1029/2006JD008336, 2008.

8. Miller CE, Crisp D, Decola PL, Olsen SC, Randerson JT, Michalak AM, et al. Precision requirements for space-based $\mathrm{XCO}_{2}$ data. J Geophys Res 2007;112:D10314. http://dx.doi.org/10.1029/2006JD007659.

9. Miller CE, Brown LR, Toth RA, Benner DC, Devi VM. Spectroscopic challenges for high accuracy retrievals of atmospheric $\mathrm{CO}_{2}$ and the Orbiting Carbon Observatory (OCO) experiment. C R Phys 2005;6:876-87. 
10. Washenfelder RA, Toon GC, Blavier JFL, Yang Z, Allen NT, Wennberg PO, et al. Carbon dioxide column abundances at the Wisconsin Tall Tower site. J Geophys Res. 2006;111:D22305. http://dx.doi.org/10.1029/2006/D007154.

11. Thompson DR, Benner DC, Brown LR, Crisp D, Devi VM, Jiang Y, et al. Atmospheric validation of high accuracy $\mathrm{CO}_{2}$ absorption coefficients for the OCO-2 mission. J Quant Spectrosc Radiat Transf 2012;113:2265-76.

12. Regalia-Jarlot L, Zenninari V, Parvitte B, Grossel A, Thomas X, Heyden P von der, et al. A complete study of the line intensities of four bands of $\mathrm{CO}_{2}$ around 1.6 and $2.0 \mu \mathrm{m}$ : A comparison between Fourier transform and diode laser measurements. J Quant Spectrosc Radiat Transf 2006;101:325-38.

13. Toth RA, Brown LR, Miller CE, Devi VM, Benner DC. Line strengths of ${ }^{12} \mathrm{C}^{16} \mathrm{O}_{2}$ : $4550-7000 \mathrm{~cm}^{-1}$. J Mol Spectrosc. 2006;239:221-42.

14. Toth RA, Brown LR, Miller CE, Devi VM, Benner DC. Self-broadened widths and shifts of ${ }^{12} \mathrm{C}^{16} \mathrm{O}_{2}$ : 4750-7000 $\mathrm{cm}^{-1}$. J Mol Spectrosc 2006;239:243-71.

15. Toth RA, Miller CE, Devi VM, Benner DC, Brown LR. Air-broadened halfwidth and pressure shift coefficients of ${ }^{12} \mathrm{C}^{16} \mathrm{O}_{2}$ bands: 4750-7000 $\mathrm{cm}^{-1}$. J Mol Spectrosc 2007;246:133-57.

16. Toth RA, Miller CE, Brown LR, Devi VM, Benner DC. Line Positions and strengths of ${ }^{16} \mathrm{O}^{12} \mathrm{C}^{18} \mathrm{O}$, ${ }^{18} \mathrm{O}^{12} \mathrm{C}^{18} \mathrm{O}$ and ${ }^{17} \mathrm{O}^{12} \mathrm{C}^{18} \mathrm{O}$ between 2200 and $7000 \mathrm{~cm}^{-1}$. J Mol Spectrosc 2007;243:43-61.

17. Toth RA, Brown LR, Miller CE, Devi VM, Benner DC. Spectroscopic database of $\mathrm{CO}_{2}$ line

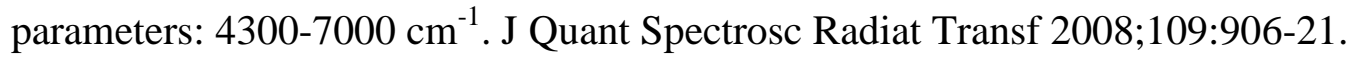

18. Devi VM, Benner DC, Brown LR, Miller CE, Toth RA. Line mixing and speed dependence in $\mathrm{CO}_{2}$ at $6227.9 \mathrm{~cm}^{-1}$ : constrained multispectrum analysis of intensities and line shapes in the 30013-00001 band. J Mol Spectrosc 2007;245:52-80.

19. Devi VM, Benner DC, Brown LR, Miller CE, Toth RA. Line mixing and speed dependence in $\mathrm{CO}_{2}$ at $6348 \mathrm{~cm}^{-1}$. Positions and intensities, and air- and self-broadening derived with constrained multispectrum analysis. J Mol Spectrosc 2007;242:90-117. 
20. Predoi-Cross A, Unni AV, Liu W, Schofield I, Holladay C, McKeller ARW, Hurtmans D. Line shape parameters measurement and computations for self-broadened carbon dioxide transitions in the 30012-00001 and 30013-00001 bands, line mixing and speed dependence. J Mol Spectrosc 2007;245:34-51.

21. Predoi-Cross A, Liu W, Holladay C, Unni AV, Schofield I, McKellar ARW, et al. Line profile study of transitions in the 30012-00001 and 30013-0001 bands of carbon dioxide perturbed by air. J Mol Spectrosc 2007;246:98-112.

22. Hartmann JM, Tran H, Toon GC. Influence of line mixing on the retrievals of atmospheric $\mathrm{CO}_{2}$ from space in the 1.6 and $2.1 \mu \mathrm{m}$ regions. Atmos Chem Phys 2008;9:7303-12. http://dx.doi.org/10.5194/acp-9-7303-2009.

23. Povey C, Predoi-Cross A. Computations of temperature dependences for line shape parameters in the 30012-00001 and 30013-00001 bands of pure $\mathrm{CO}_{2}$. J Mol Spectrosc 2009;257:187-99.

24. Predoi-Cross A, McKellar ARW, Benner DC, Devi VM, Gamache RR, Miller CE, et al. Temperature dependences of air-broadened Lorentz half-width and pressure shift coefficients in the $30013 \leftarrow 00001$ and $30012 \leftarrow 00001$ bands of $\mathrm{CO}_{2}$ near $1600 \mathrm{~nm}$. Can J Phys 2009;87:517-35.

25. Predoi-Cross A, Liu W, Murphy R, Povey C, Gamache RR, Laraia AL, et al. Measurements and computations for temperature dependences of self-broadened carbon dioxide transitions in the 30012-00001 and 30013-00001 bands. J Quant Spectrosc Radiat Transf 2010;111:1065-79.

26. Hartmann JM, Tran H, Ngo NH, Landsheere X, Chelin P, Lu Y, et al. Ab initio calculations of the spectral shapes of $\mathrm{CO}_{2}$ isolated lines including non-Voigt effects and comparisons with experiments. Phys Rev A. 2013;87:013403.

27. Long DA, Truong C.-W, Hodges JT, Miller CE. Absolute ${ }^{12} \mathrm{C}^{16} \mathrm{O}_{2}$ transition frequencies at the $\mathrm{kHz}$ level from 1.6 to $7.8 \mu \mathrm{m}$. J Quant Spectrosc Radiat Transf 2013;130:112-15.

28. Lamouroux J, Gamache RR, Laraia AL. Semiclassical calculations of half-widths and line shifts for transitions in the 30012-00001 and 30013-00001 bands of $\mathrm{CO}_{2}$. III. Self collisions. J Quant Spectrosc Radiat Transf 2012;113:1536-46. 
29. Miller CE, Brown LR. Near infrared spectroscopy of carbon dioxide. I. ${ }^{16} \mathrm{O}^{12} \mathrm{C}^{16} \mathrm{O}$ line positions. J Mol Spectrosc 2004;228:329-54.

30. Miller CE, Montgomery MA, Onorato RM, Johnstone C, McNicholas TP, Kovaric B, et al. Near infrared spectroscopy of carbon dioxide. II: ${ }^{16} \mathrm{O}^{13} \mathrm{C}^{16} \mathrm{O}$ and ${ }^{16} \mathrm{O}^{13} \mathrm{C}^{18} \mathrm{O}$ line positions. J Mol Spectrosc 2004;228:355-74.

31. Larcher G, Tran H, Schwell M, Chelin P, Landsheere X, Hartmann J-M, Hu S-M. $\mathrm{CO}_{2}$ isolated line shapes by classical molecular dynamics simulations: Influence of the intermolecular potential and comparison with new measurements. J Chem Phys 2014;140:084308.

32. Larcher G, Landsheere X, Schwell M, Tran H. Spectral shape parameters of pure $\mathrm{CO}_{2}$ transitions near1.6 $\mu \mathrm{m}$ by tunable diode laser spectroscopy. J Quant Spectrosc Radiat Transf 2015;164:82-88.

33. Benner DC, Rinsland CP, Devi VM, Smith MAH, Atkins D. A multispectrum nonlinear leastsquares fitting technique. J Quant Spectrosc Radiat Transf 1995;53:705-21.

34. Letchworth KL, Benner DC. Rapid and accurate calculation of the Voigt functions. J Quant Spectrosc Radiat Transf 2007;107:173-92.

35. Levy A, Lacome N, Chackerian Jr. C. Collisional line mixing In: Rao K Narahari, Weber Alfons, editors. Spectroscopy of the earth's atmosphere and interstellar medium. San Diego, CA. Academic Press, Inc. 1992 (Chapter 4).

36. Vitcu A. Line shape studies in the 0310-0110 Q branch of $\mathrm{N}_{2} \mathrm{O}$ using a mid-infrared difference frequency spectrometer. Dissertation, University of Toronto, 2003.

37. Mantz AW, Sung K, Crawford TJ, Brown LR, Smith MAH, Devi VM, et al. A cryogenic Herriott cell vacuum coupled to a FT-IR JPL Bruker IFS-125 HR. J Mol Spectrosc 2014;304:12-24.

38. Rothman LS, Jacquemart D, Barbe J, Benner DC, Birk M, Brown LR, et al. The HITRAN2004 molecular spectroscopic database. J Quant Spectrosc Radiat Transf 2005;96:139-204.

39. Rothman LS, Gordon IE, Barbe A, Benner DC, Bernath PF, Birk M, et al. The HITRAN2008 molecular spectroscopic database. J Quant Spectrosc Radiat Transf 2009;110:533-72. 
40. Rothman LS, Gordon IE, Babikov Y, Barbe A, Benner DC, Bernath PF, et al. The HITRAN2012 molecular spectroscopic database. J Quant Spectrosc Radiat Transf 2013;130:4-50.

41. Pollock CR, Petersen PR, Jennings DA, Wells JS, Maki AG. Absolute frequency measurements of the 2-0 band of $\mathrm{CO}$ at $2.3 \mu \mathrm{m}$; calibration standard frequencies from high resolution color center laser spectroscopy. J Mol Spectrosc 1983;99:357-68.

42. Swann WC, Gilbert SL. Pressure induced shift and broadening of 1510-1540-nm acetylene wavelength calibration lines. J Opt Soc Am B 2000;17:1263-70.

43. Gamache RR [unpublished results, 2015].

44. Wattson RB, Rothman LS. Direct numerical diagonalization: wave of the future. J Quant Spectrosc Radiat Transf 1992;48:763-80.

45. Tashkun SA, Perevalov VI, Teffo J-L, Bykov AD, Lavrentieva. CDSD-1000, the high-temperature carbon dioxide spectroscopic databank. J Quant Spectrosc Radiat Transf 2003;82:165-96.

46. Tashkun SA, Perevalov VI, Gamache RR, Lamouroux J. CDSD-296, high resolution carbon dioxide spectroscopic databank: Versions for atmospheric applications. J Quant Spectrosc Radiat Transf 2015;152:45-73.

47. Polyansky OL, Bielska K, Ghysels M, Lodi L, Zobov NF, Hodges JT, Tennyson J. High-accuracy $\mathrm{CO}_{2}$ line intensities determined from theory and experiment. Phys Rev Lett 2015;114:243001-5.

48. Huang X. [Private communication, Dec. 2015].

49. Zak E, Tennyson J, Polyansky OL, Lodi L, Zobov NF, Tashkun SA, Perevalov VI. A room temperature $\mathrm{CO}_{2}$ linelist with accurate intensities. J Quant Spectrosc Radiat Transf (accepted) 2015.

50. Hodges JT. National Institute of Standards and Technology, Private communication (2015).

51. Majcherova Z, Macko P, Romanini D, Perevalov VI, Tashkun SA, Teffo J-L, Campargue A. Highsensitivity CW-cavity ringdown spectroscopy of ${ }^{12} \mathrm{CO}_{2}$ near $1.5 \mu \mathrm{m}$. J Mol Spectrosc 2005;230:1-21.

52. Lin H, Reed ZD, Sironneau VT, Hodges JT. Cavity ring-down spectrometer for high-fidelity molecular absorption measurements. J Quant Spectrosc Radiat Transf 2015;161:11-20. 
53. Burkart J, Saia T, Romanini D, Marangoni M, Campargue A, Kassi S. Communication: Saturated $\mathrm{CO}_{2}$ absorption near $1.6 \mu \mathrm{m}$ for kilohertz-accuracy transition frequencies. J Chem Phys 2015;141:191103.

54. Gamache RR, Rothman LS. Extension of the HITRAN Database to Non-LTE Applications. J Quant Spectrosc Radiat Transf 1992;48:519-25.

55. Gamache RR, Goldman A. Einstein A coefficient, integrated band intensity, and population factors: Application to the a ${ }^{1} \Delta_{g}-X^{3} \Sigma_{g}^{-}(0,0) \mathrm{O}_{2}$ band. J Quant Spectrosc Radiat Transf 2001;69:389-401.

56. Rinsland CP, Benner DC, Devi VM. Absolute line intensities in $\mathrm{CO}_{2}$ bands near $4.8 \mu \mathrm{m}$. Appl Opt 1986;25:1204-14.

57. Gamache RR, Lamouroex J. Predicting accurate line shape parameters for $\mathrm{CO}_{2}$ transitions. J Quant Spectrosc Radiat Transf 2013;130:158-71, doi: 10.10.1016/j.jqsrt.2013.05.021.

58. Lamouroux J, Tran H, Laraia AL, Gamache RR, Rothman LS, Gorgon IE, Hartman J-M. Updated database plus software for line-mixing in $\mathrm{CO}_{2}$ infrared spectra and their test using laboratory spectra in the 1.5-2.3 $\mu \mathrm{m}$ region. J Quant Spectrosc Radiat Transf 2010;111:2321-2331.

59. Lisak D, Cygan A, Wcislo P, Ciurylo R. Quadratic speed dependence of collisional broadening and shifting for atmospheric applications. J Quant Spectrosc Radiat Transf 2015;151:43-8.

60. Tran H, Ngo NH, Hartmann JM. Efficient computation of some speed-dependent isolated line shapes. J Quant Spectrosc Radiat Transf 2013;129:199-203. 

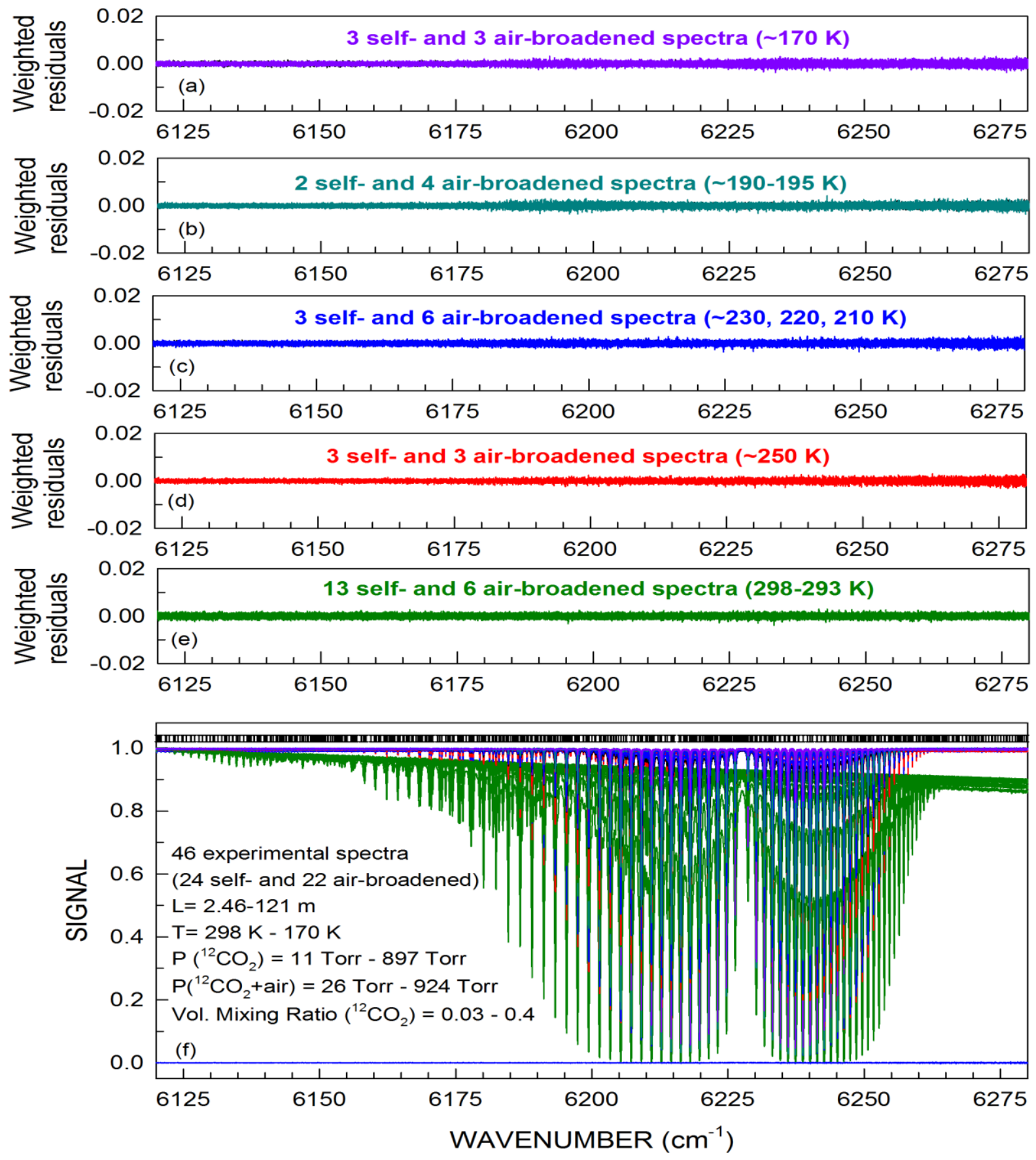

Fig. 1 

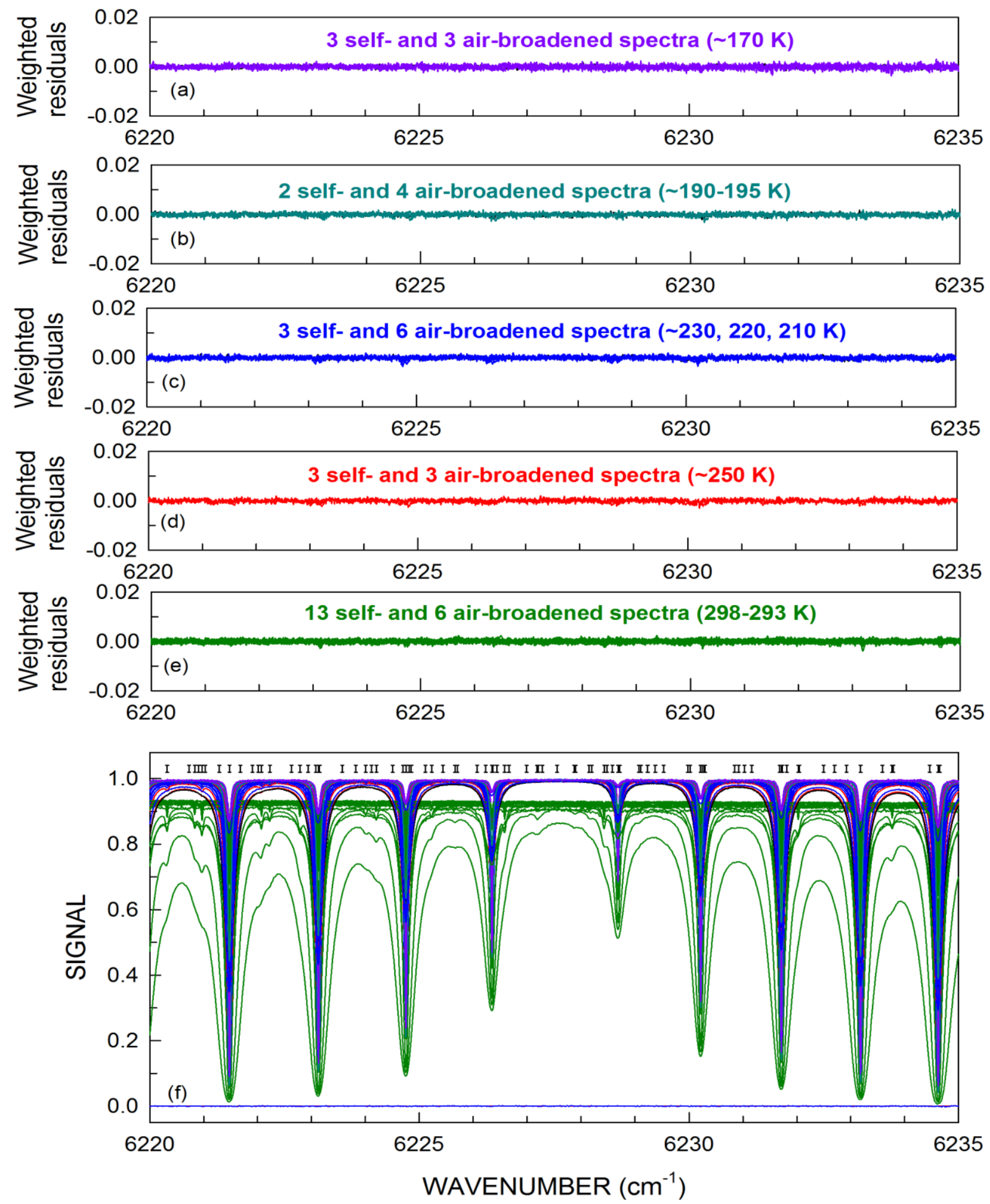

Fig. 2 


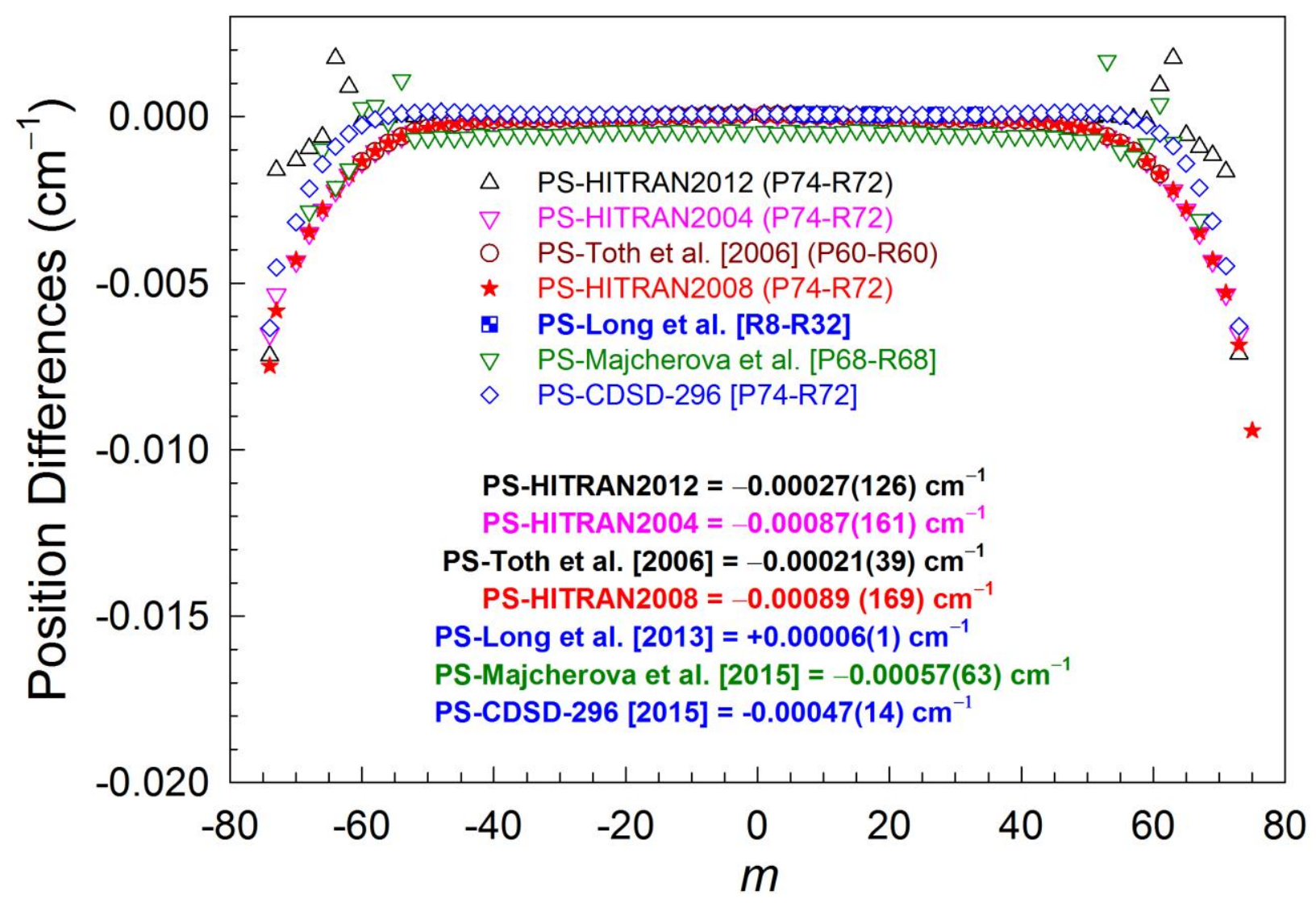

Fig. 3 
(a)
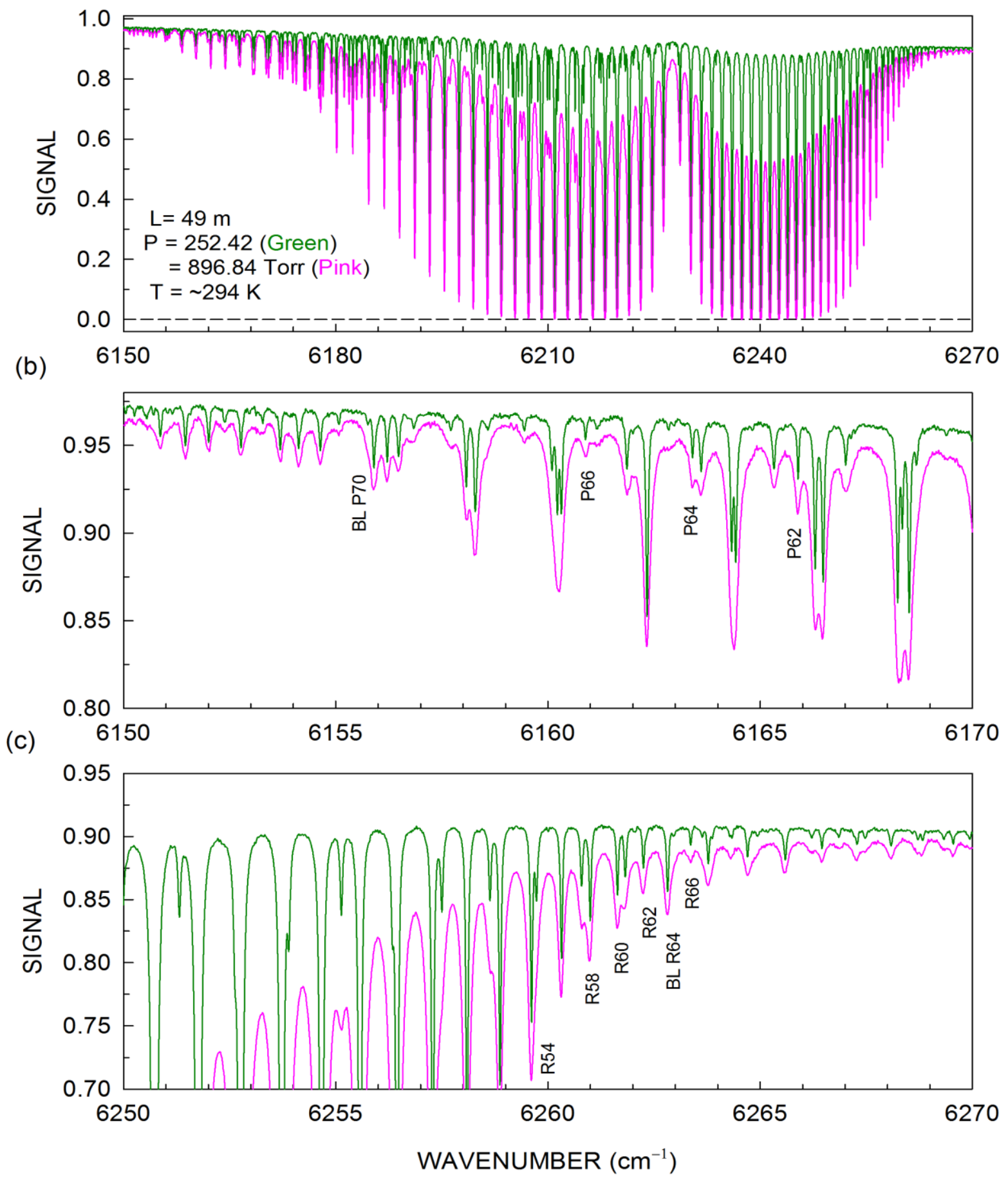

Fig. 4 

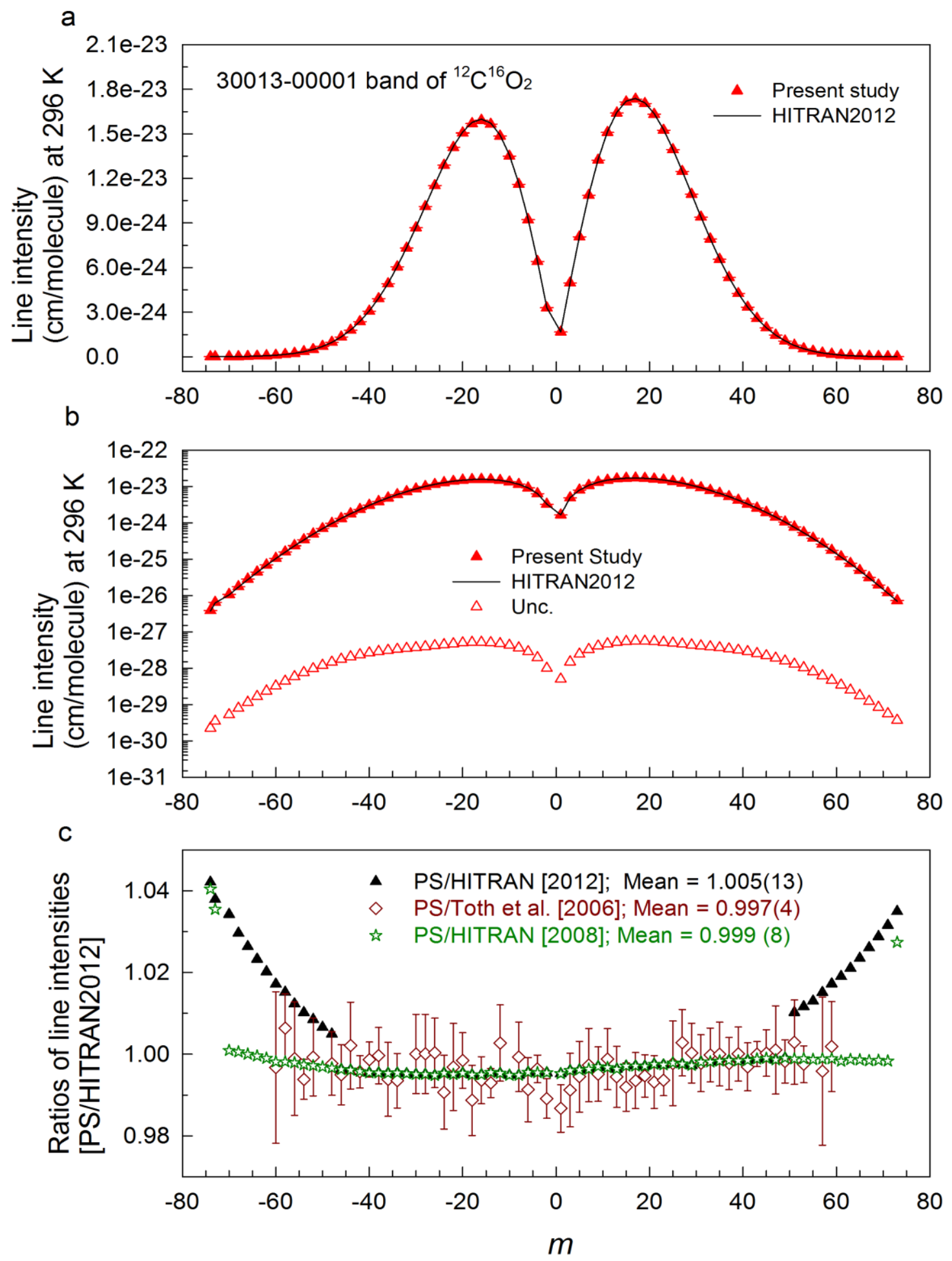

Fig. 5 
a
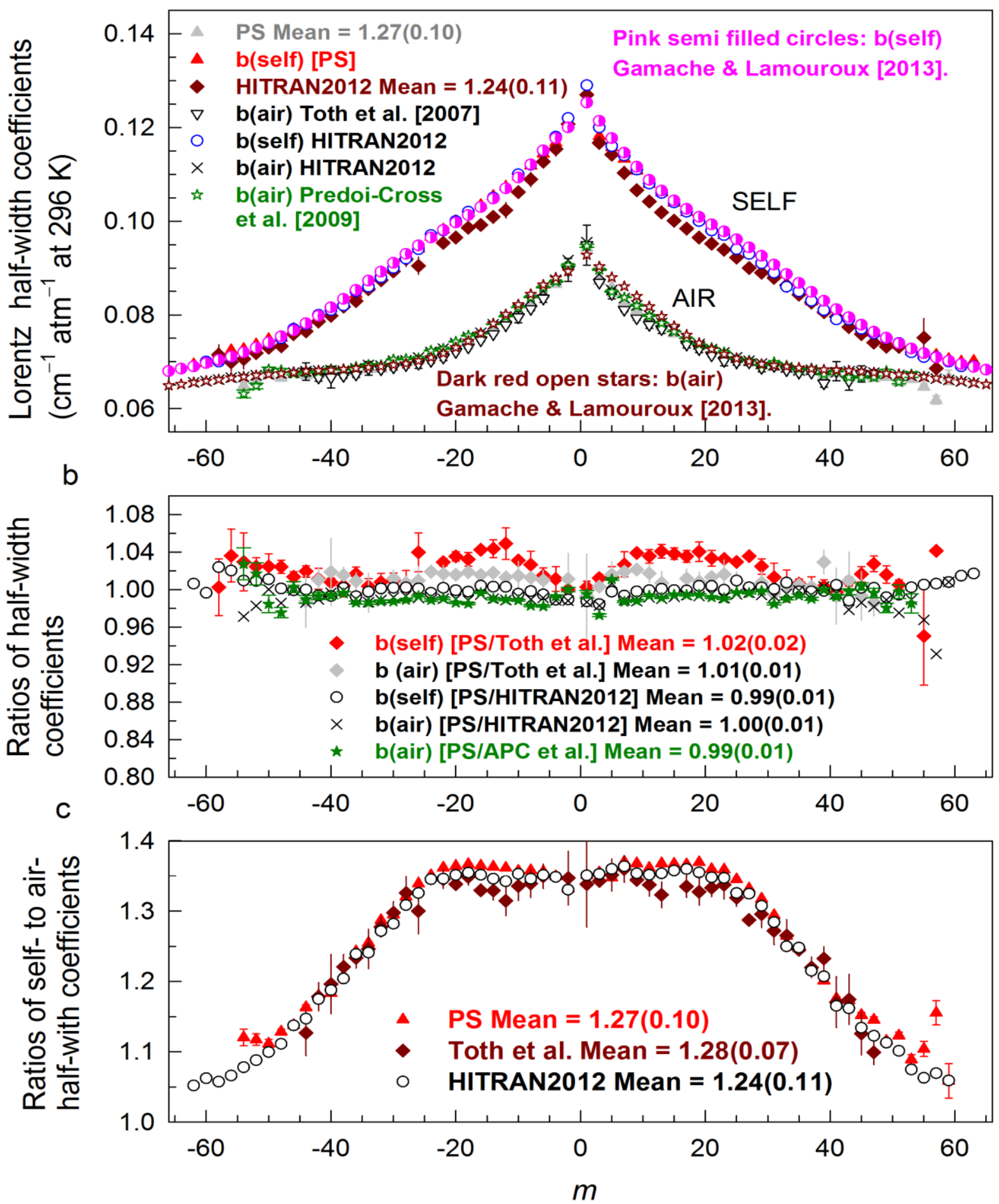

Fig. 6 
a)
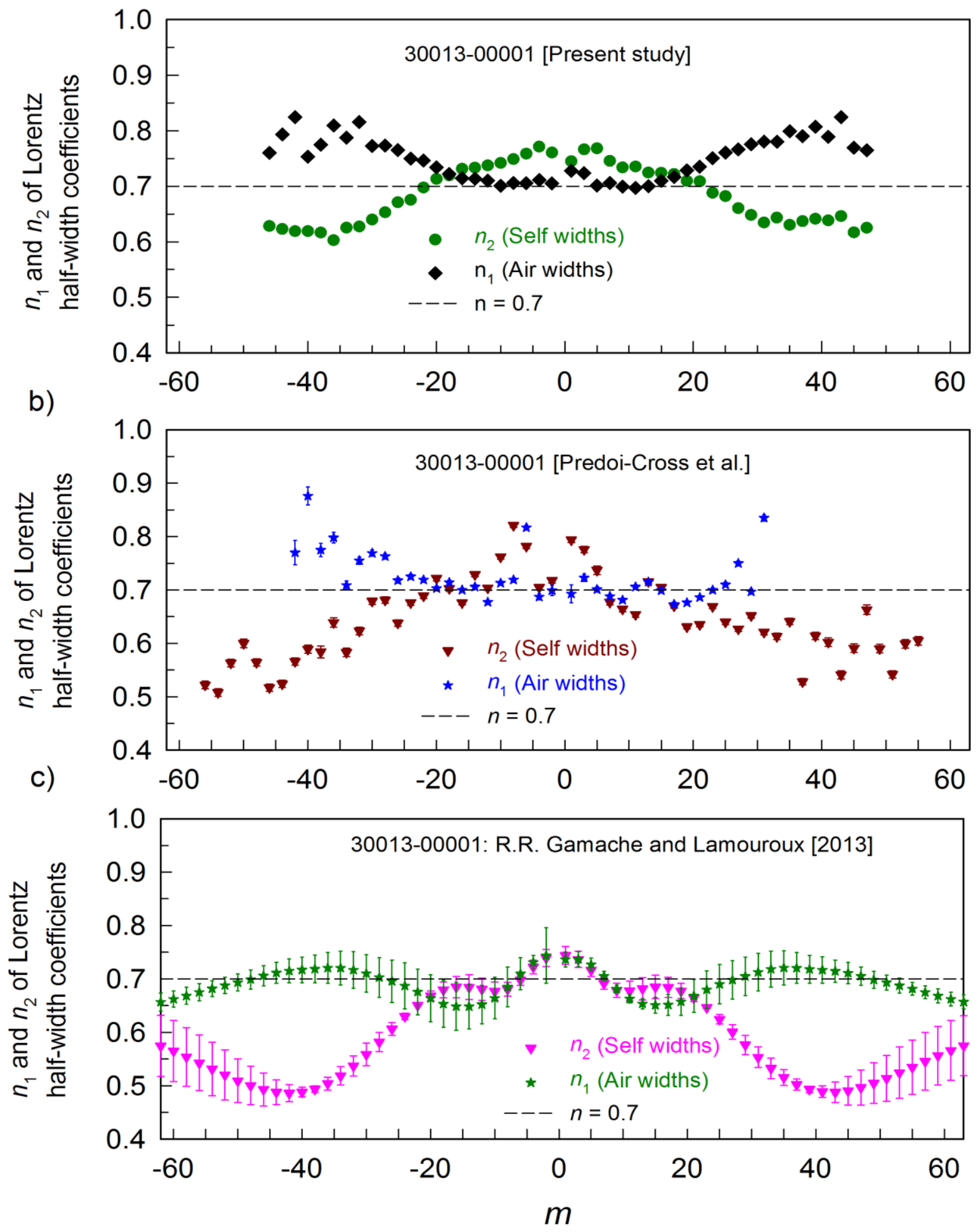

Fig. 7 


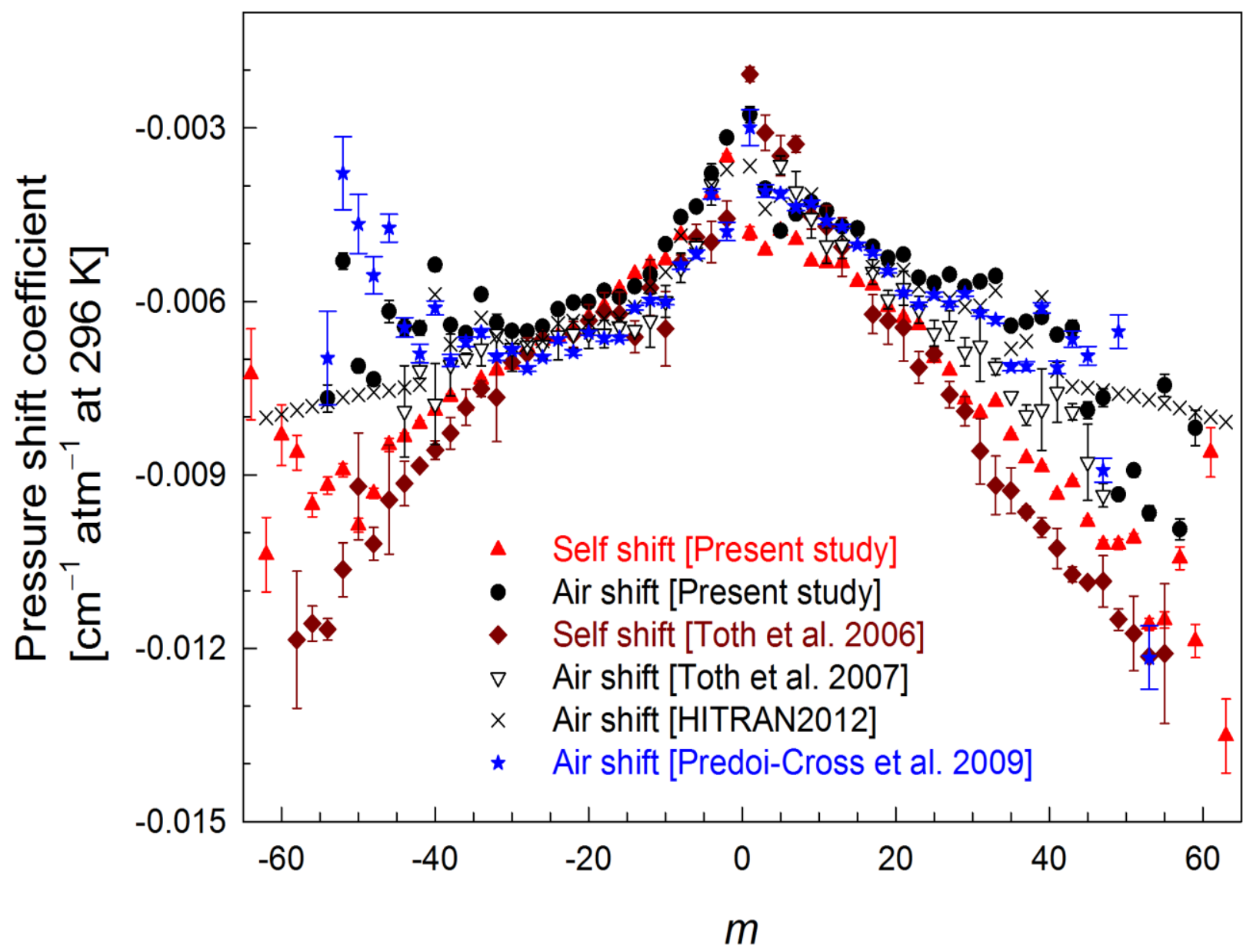

Fig. 8 
a)

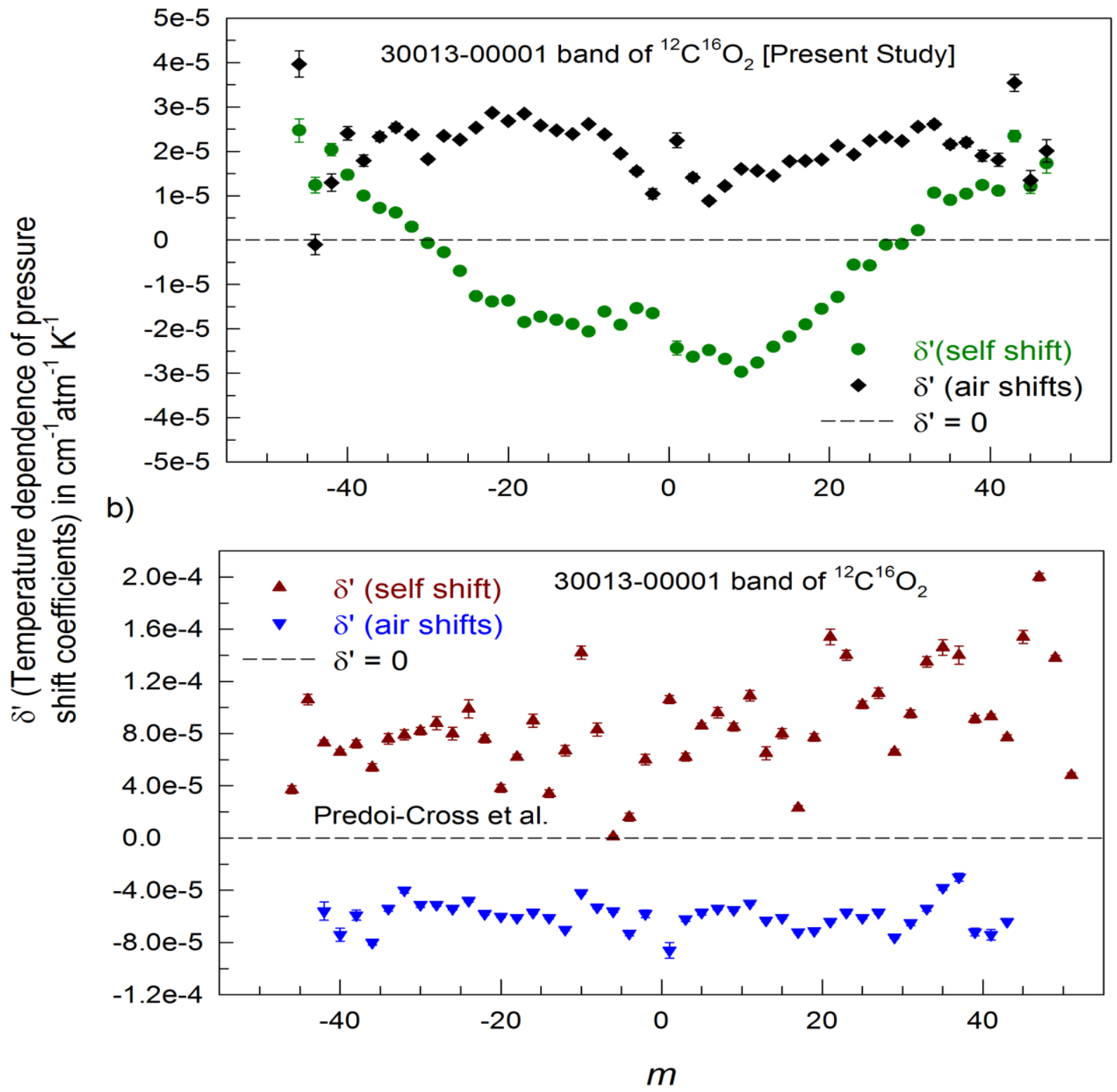

Fig. 9 
a

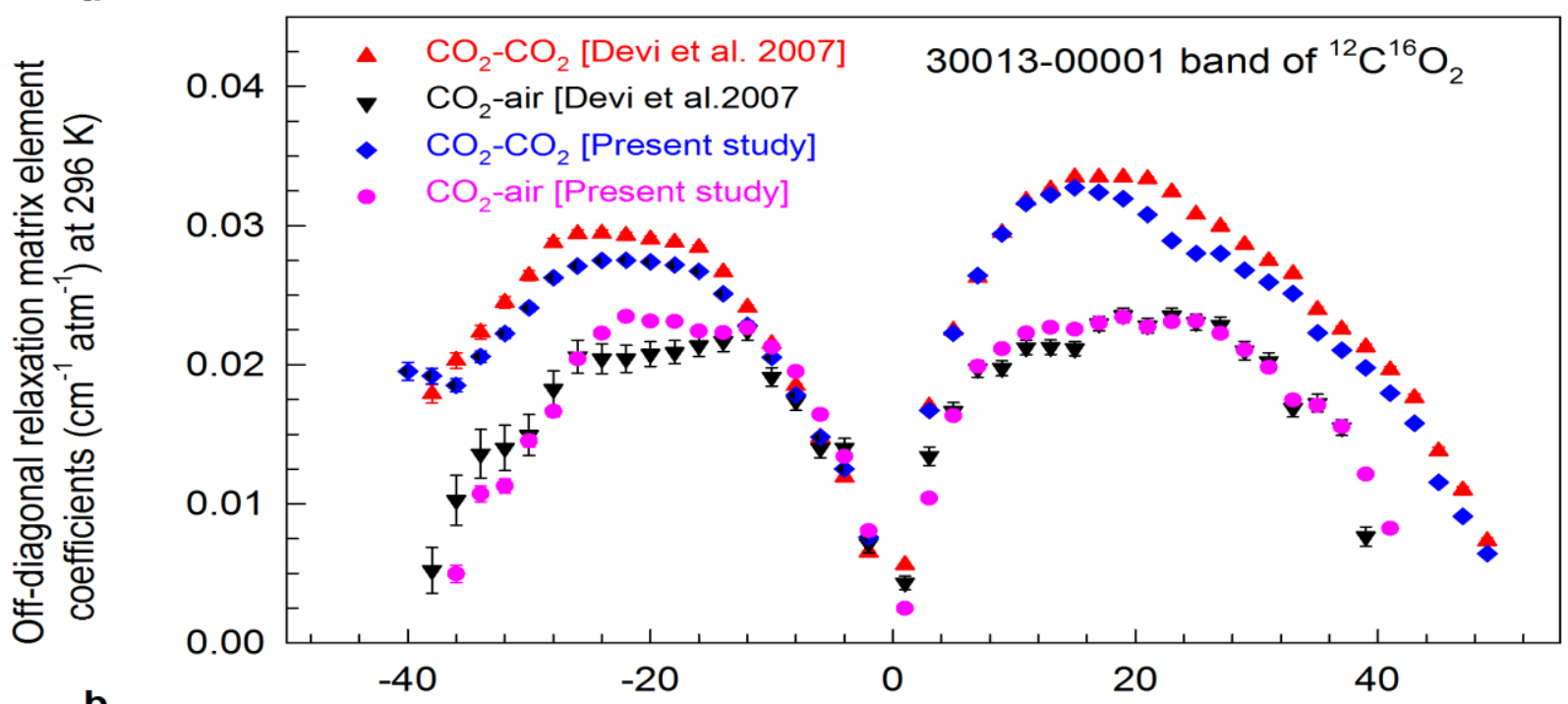

b

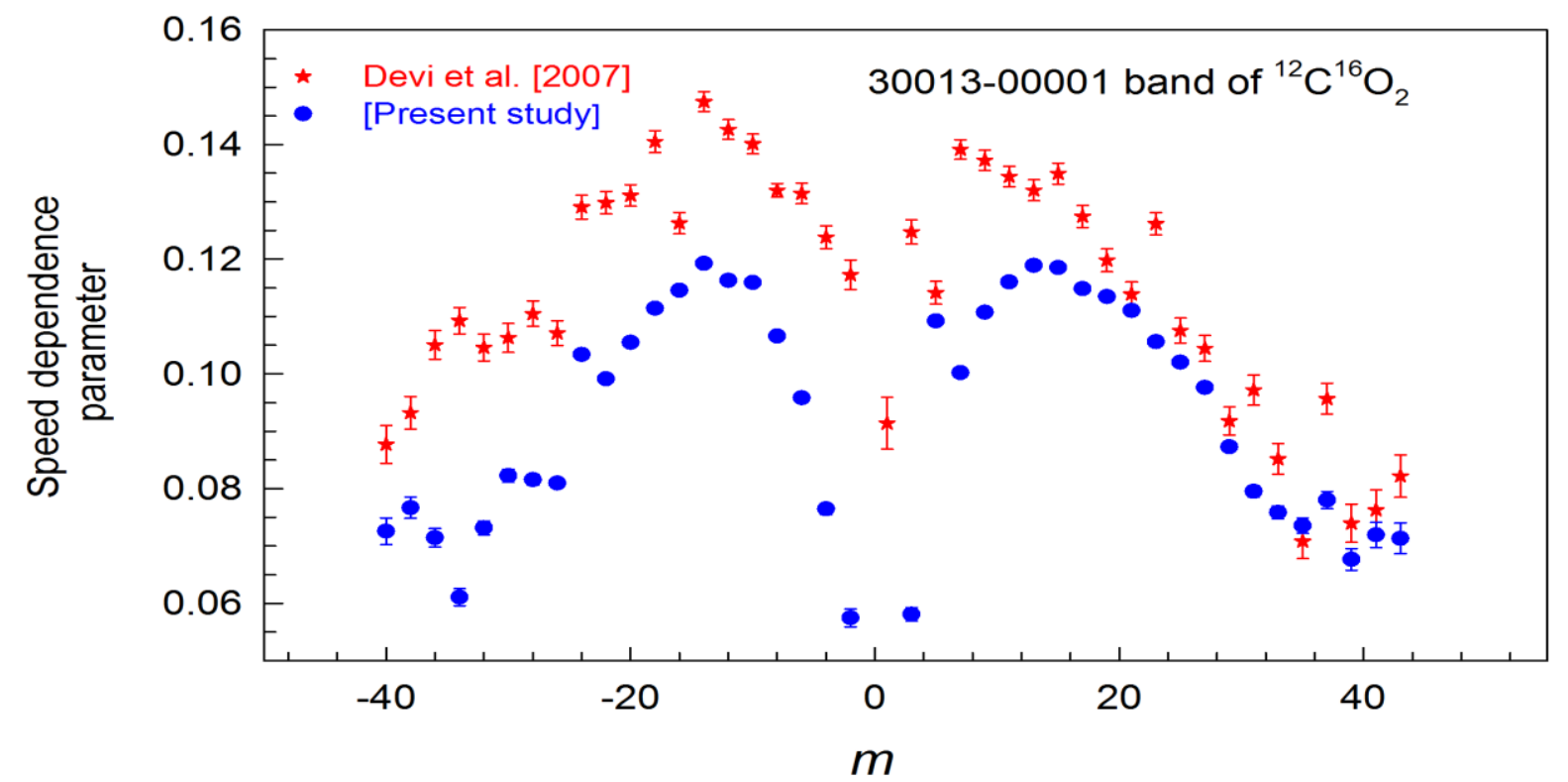

Fig. 10 


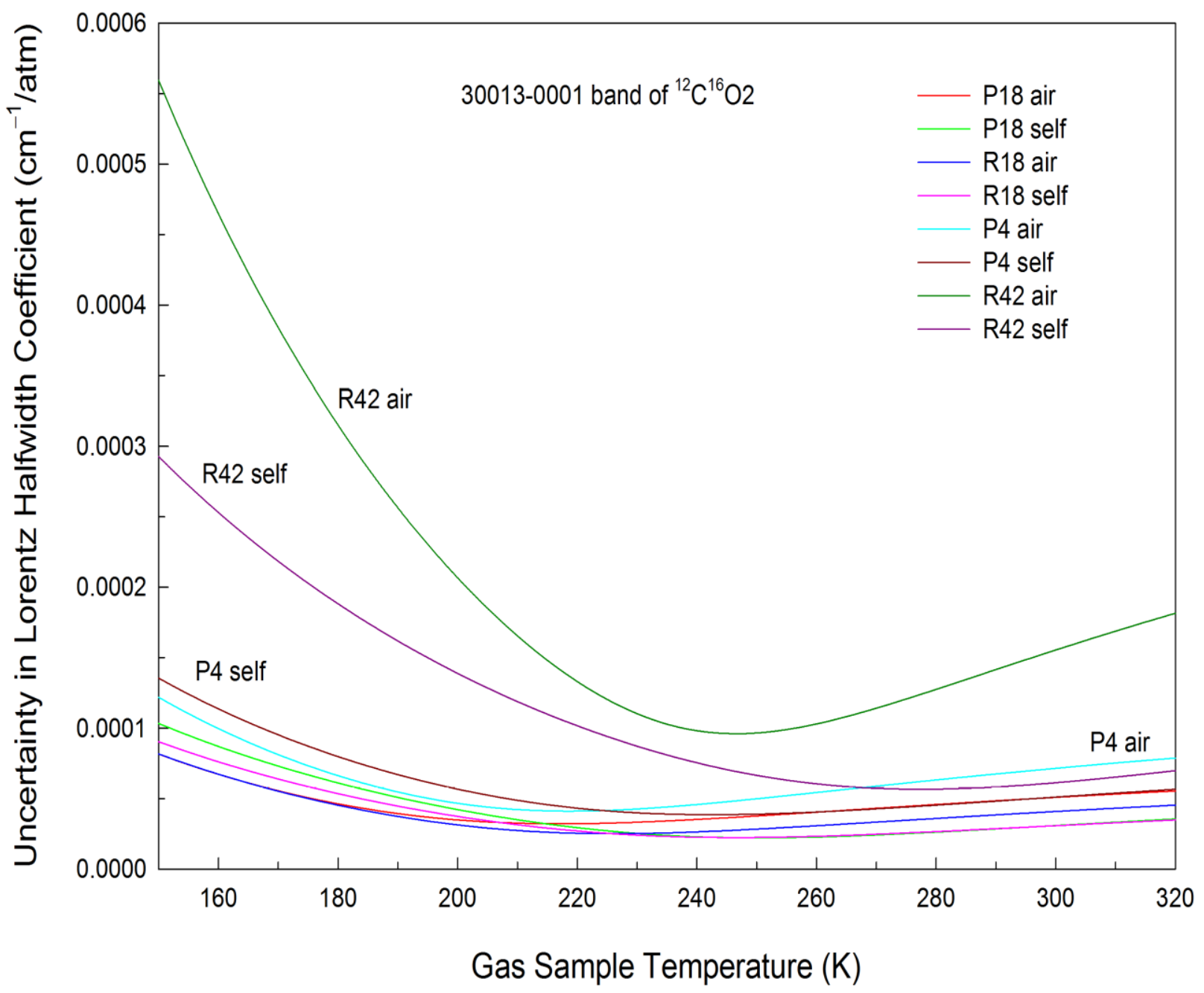

Fig. 11 


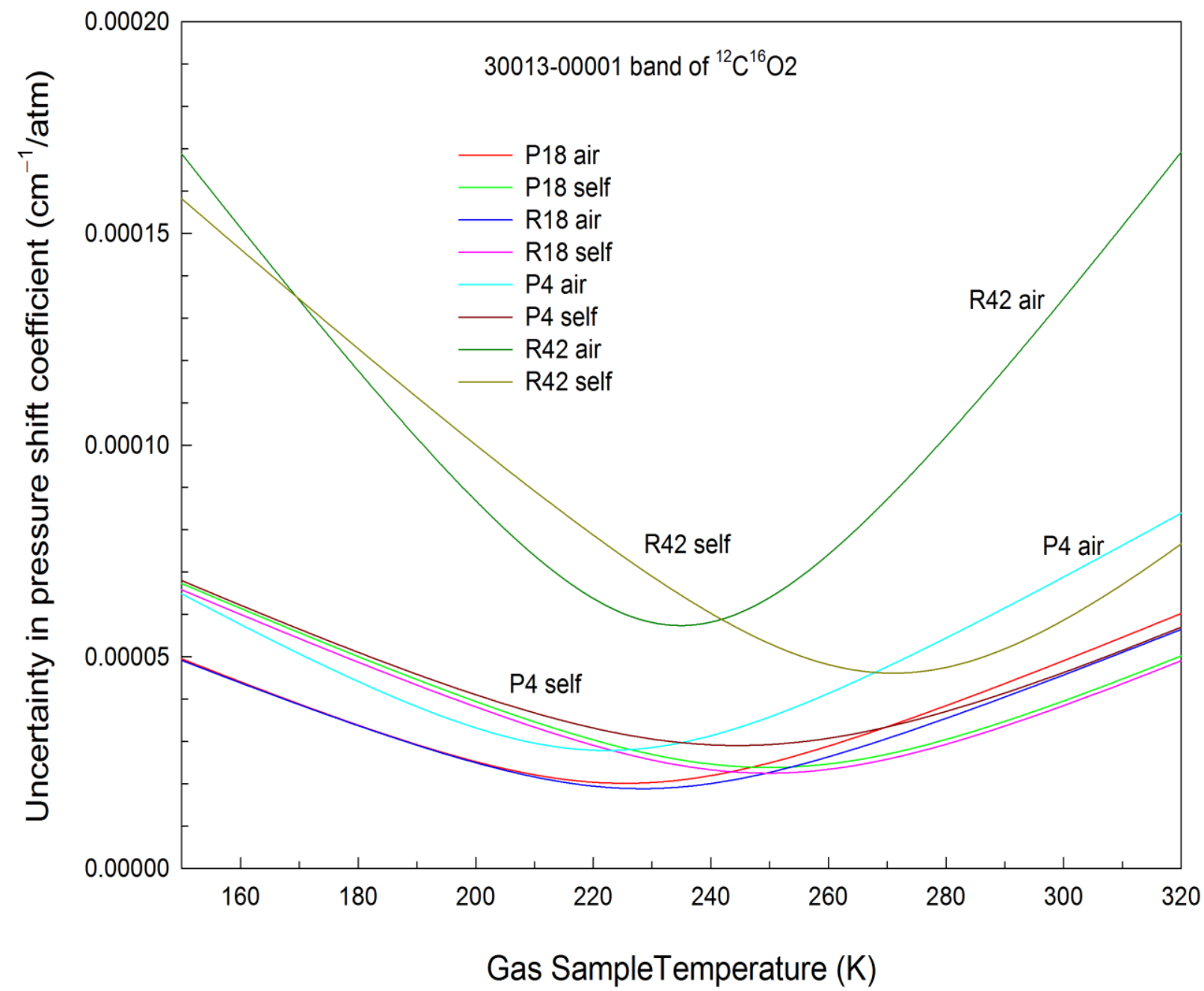

Fig. 12 


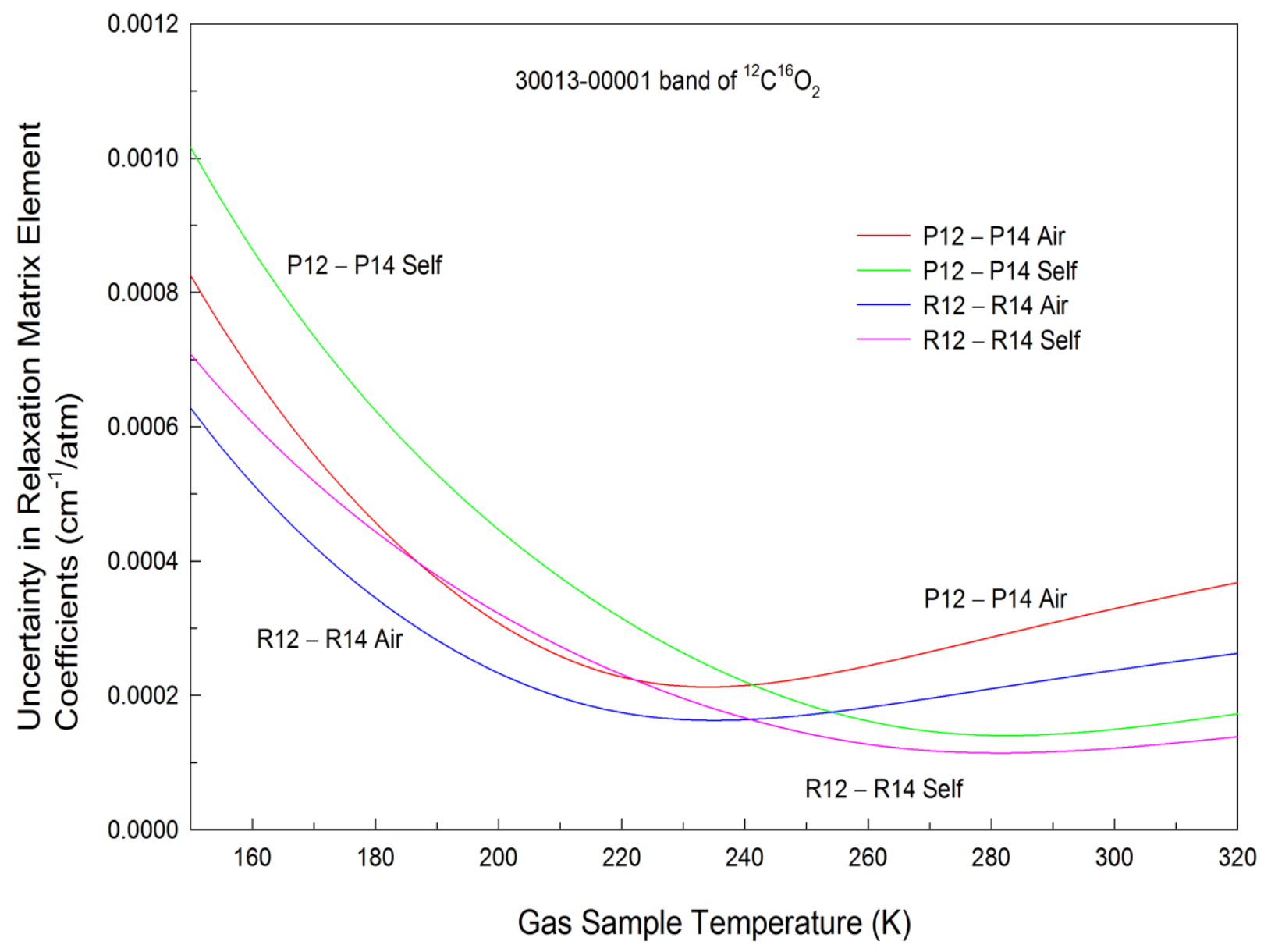

Fig. 13 
(a)

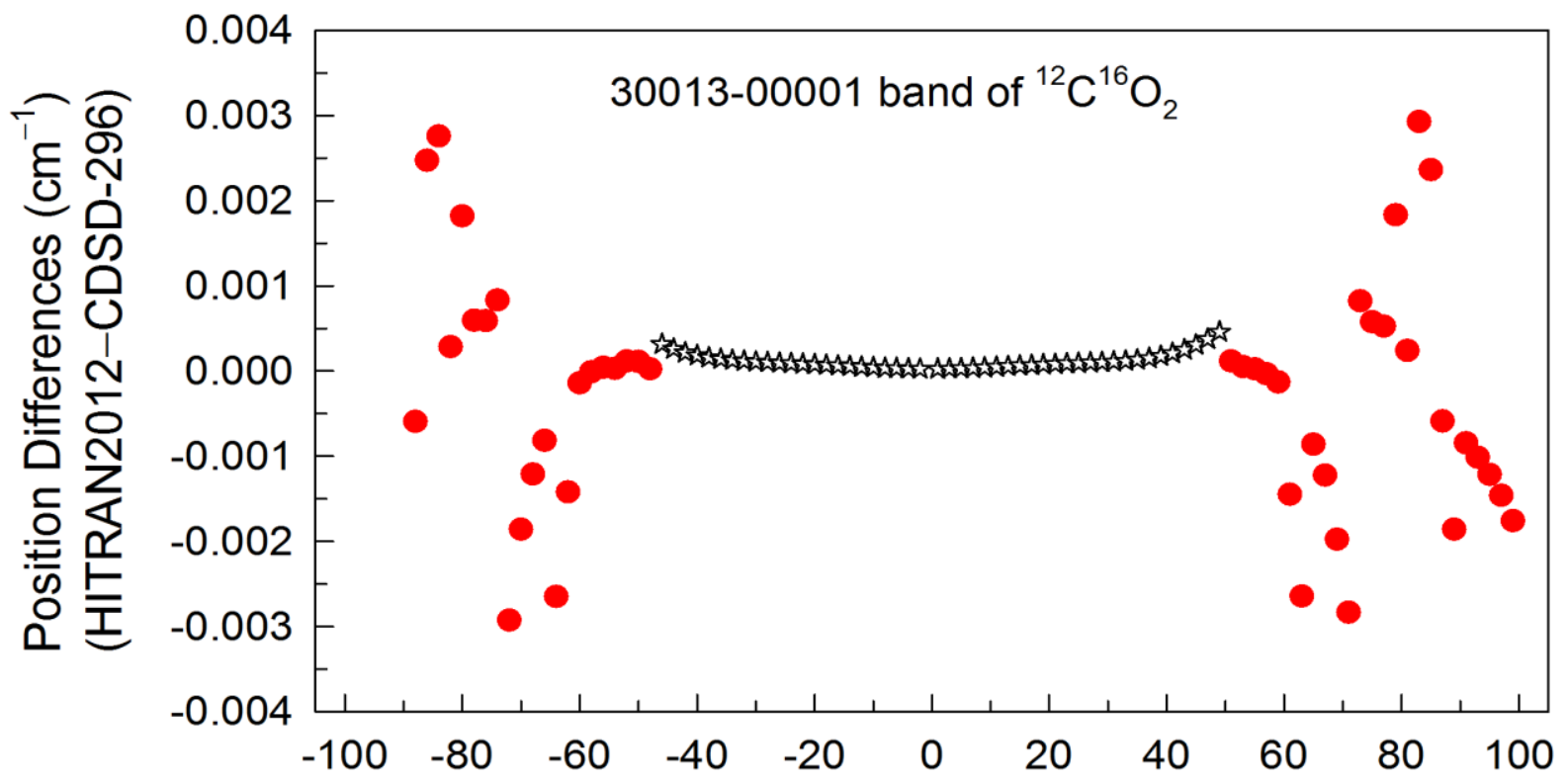

(b)

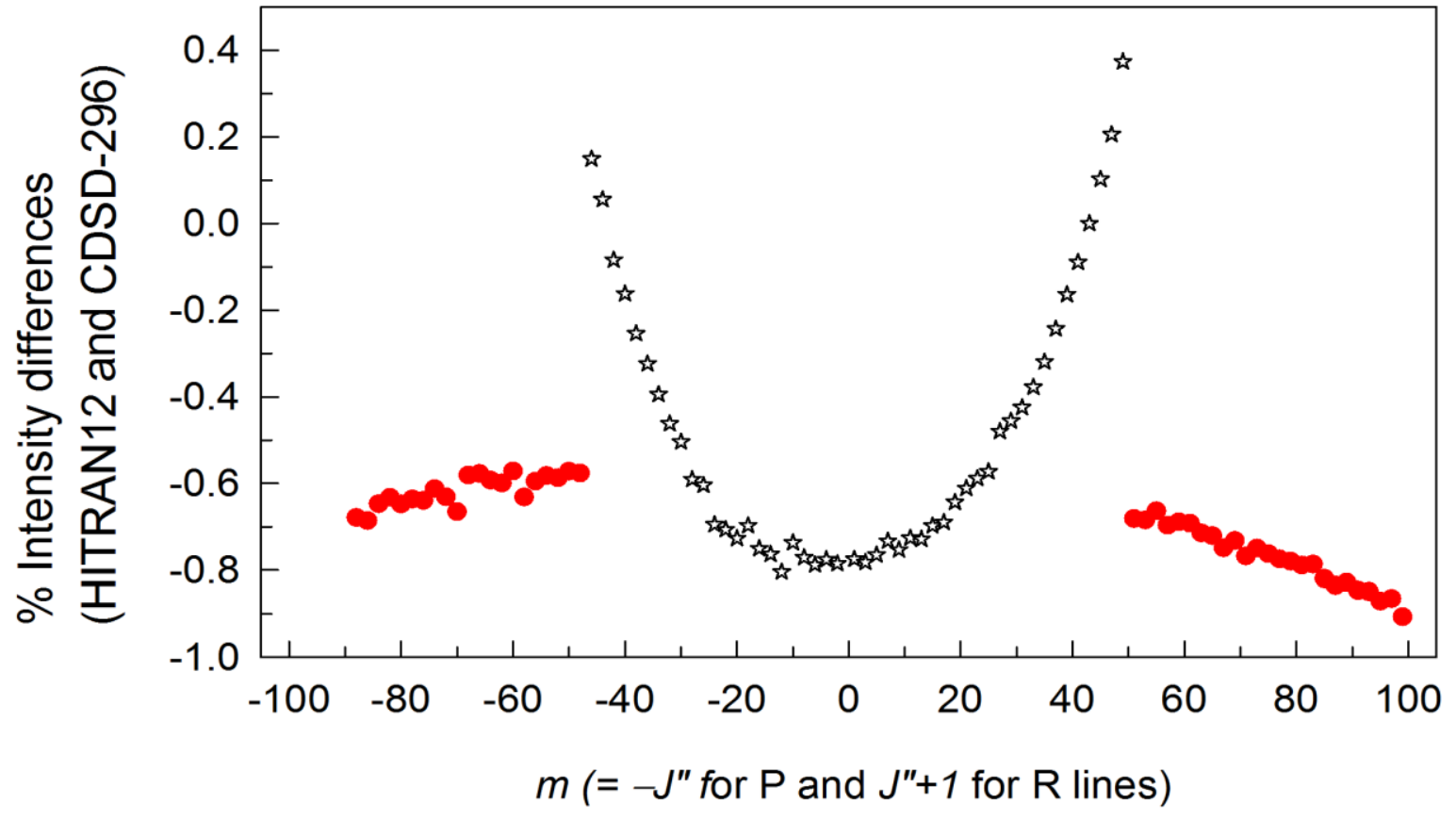

Fig. 14 
(a)

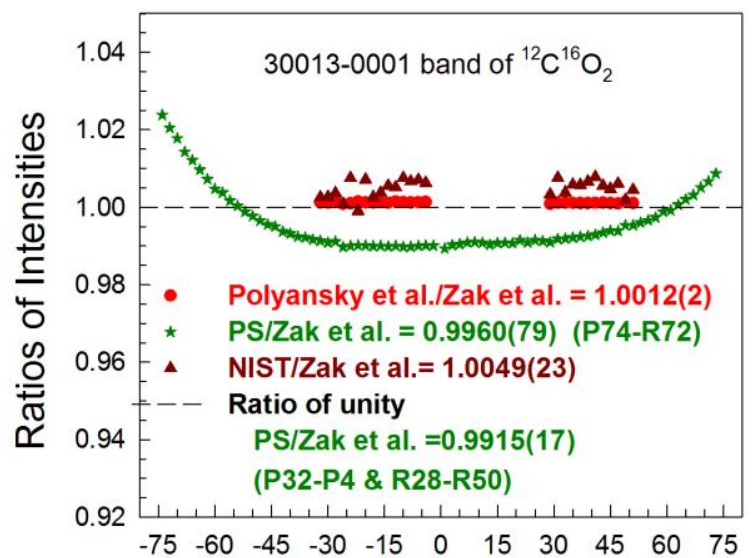

(c)

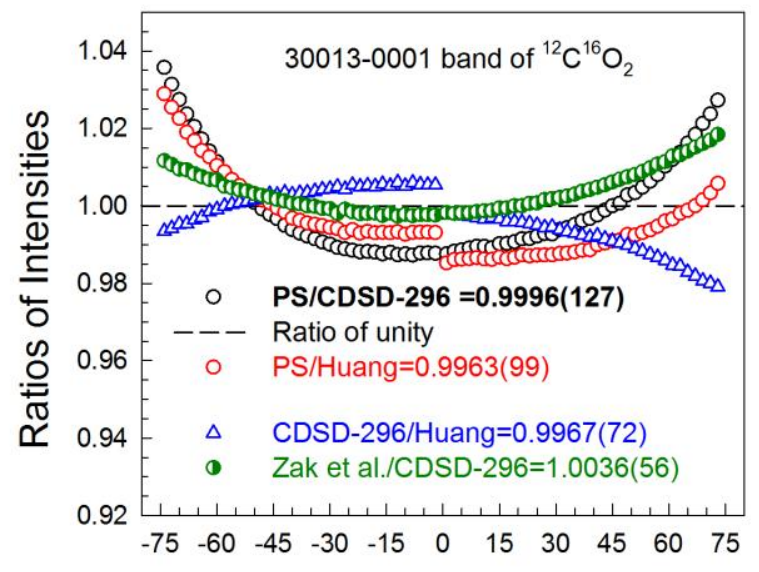

(e)

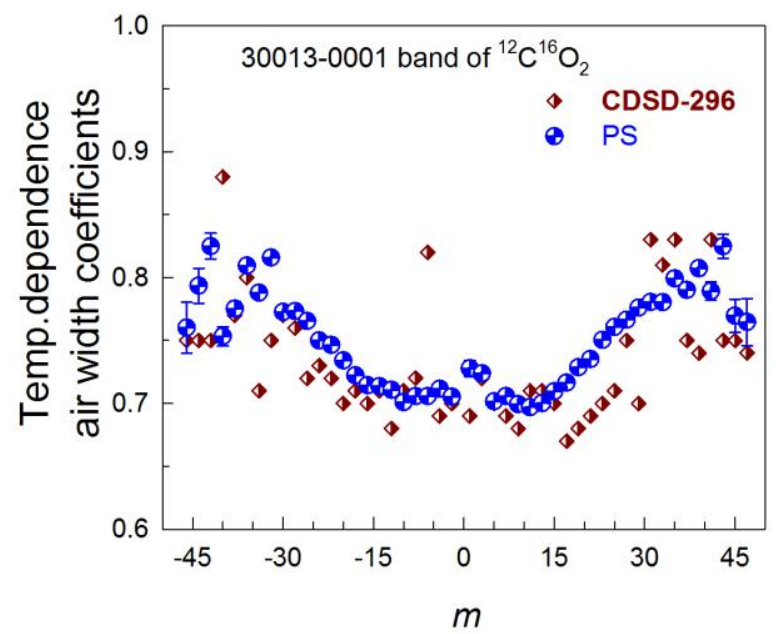

(b)

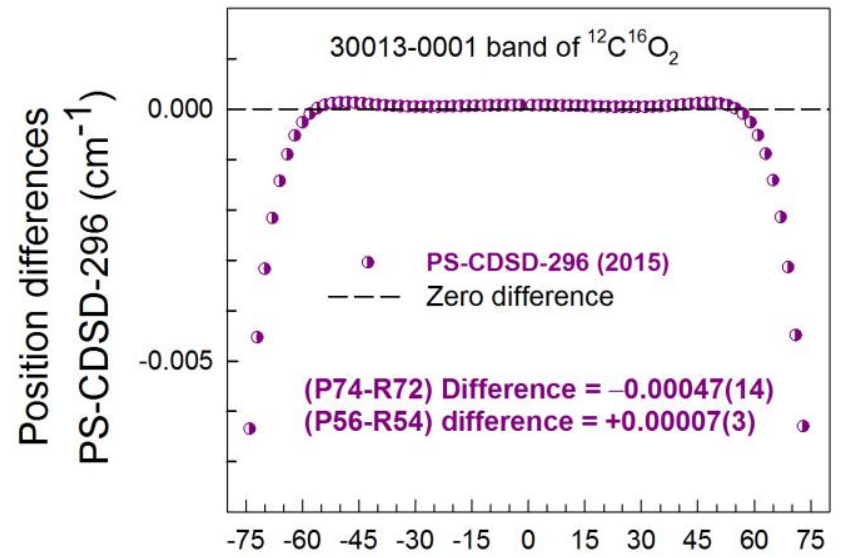

(d)
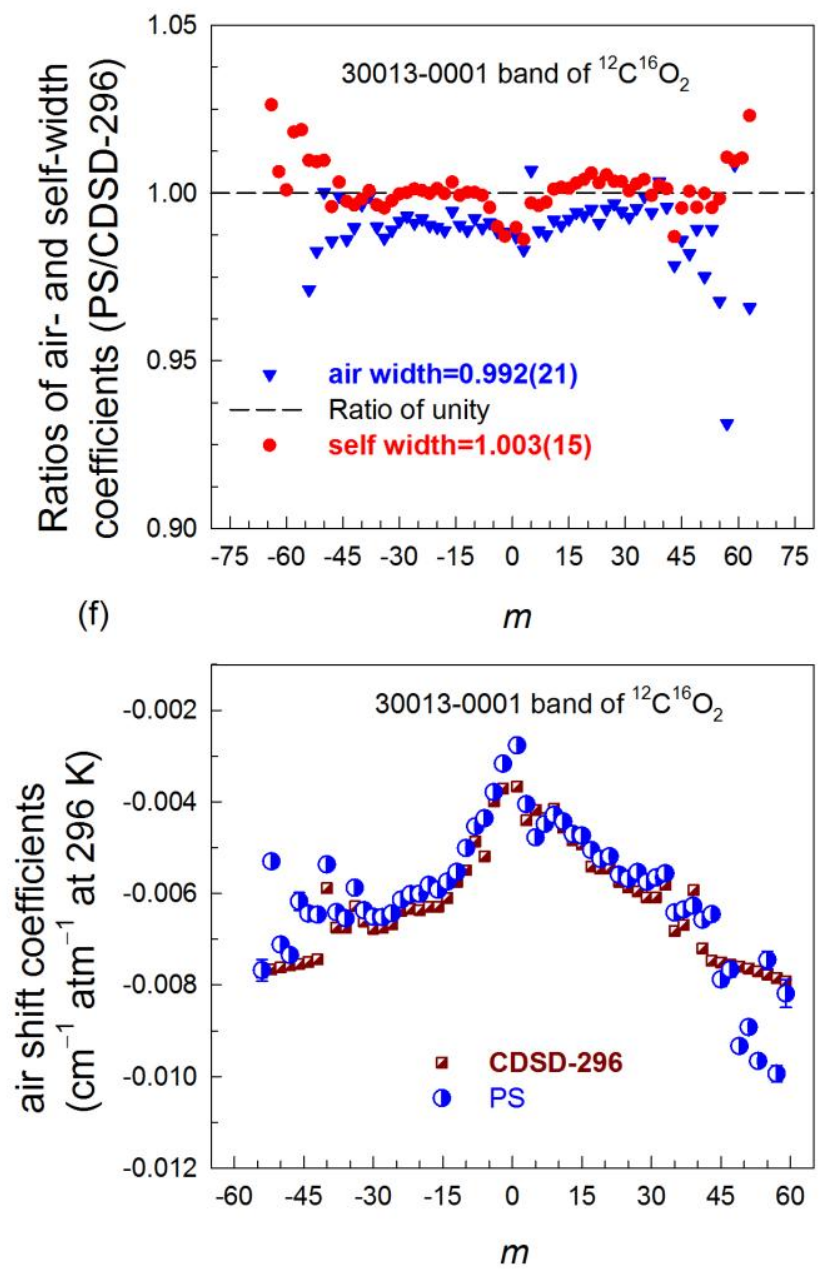

Fig. 15 


\section{Table 1}

Summary of recent line shape measurements ${ }^{\mathrm{a}}$ (number and quantum number range) for the $30013 \leftarrow 00001$ band of ${ }^{12} \mathrm{C}^{16} \mathrm{O}_{2}$.

\begin{tabular}{|c|c|c|c|c|c|c|c|c|c|}
\hline Reference & Line shape & $\begin{array}{c}\text { self- } \\
\text { width }^{\mathrm{b}}\end{array}$ & $\begin{array}{c}n_{2} \text { (self } \\
\text { width) }\end{array}$ & $\begin{array}{l}\text { self- } \\
\text { shift }^{b}\end{array}$ & 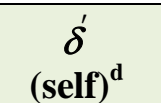 & $\begin{array}{c}\text { air- } \\
\text { width }^{b}\end{array}$ & $\begin{array}{c}n_{1}(\text { air } \\
\text { width) }\end{array}$ & $\begin{array}{l}\text { air- } \\
\text { shift }^{b}\end{array}$ & $\begin{array}{c}\delta^{\prime} \\
\text { (air) }^{d}\end{array}$ \\
\hline Present study & $\begin{array}{l}\text { Speed dependent Voigt, } \\
\text { Line mixing }\end{array}$ & $\begin{array}{c}65 \\
\text { P66-R62 }\end{array}$ & $\begin{array}{c}47 \\
\text { P46-R46 }\end{array}$ & $\begin{array}{c}64 \\
\text { P64-R62 }\end{array}$ & $\begin{array}{c}47 \\
\text { P46-R46 }\end{array}$ & $\begin{array}{c}59 \\
\text { P54-R62 }\end{array}$ & $\begin{array}{c}47 \\
\text { P46-R46 }\end{array}$ & $\begin{array}{c}57 \\
\text { P54-P58 }\end{array}$ & $\begin{array}{c}47 \\
\text { P46-R46 }\end{array}$ \\
\hline $\begin{array}{l}\text { Devi et al. } 2007 \\
{[\mathbf{1 8}}\end{array}$ & $\begin{array}{l}\text { Speed dependent Voigt, } \\
\text { Line mixing }\end{array}$ & $\begin{array}{c}63 \\
\text { P62-R62 }\end{array}$ & None & $\begin{array}{c}63 \\
\text { P62-R6 }\end{array}$ & & $\begin{array}{c}53 \\
\text { P52-R52 }\end{array}$ & & $\begin{array}{c}53 \\
\text { P52-R52 }\end{array}$ & \\
\hline $\begin{array}{l}\text { Toth et al. } \\
2006[\mathbf{1 4}]\end{array}$ & Voigt & $\begin{array}{c}57 \\
\text { P58-R56 }\end{array}$ & & $\begin{array}{c}54 \\
\text { P58-R54 }\end{array}$ & & & & & \\
\hline $\begin{array}{l}\text { Toth et al. } \\
2007[\mathbf{1 5}]\end{array}$ & Voigt & & & & & $\begin{array}{c}44 \\
\text { P44-R46 }\end{array}$ & & $\begin{array}{c}46 \\
\text { P46-R46 }\end{array}$ & \\
\hline $\begin{array}{l}\text { Predoi-Cross et } \\
\text { al. (2007) [20] }\end{array}$ & $\begin{array}{l}\text { Speed dependent Voigt, } \\
\text { Line mixing }\end{array}$ & $\begin{array}{c}57 \\
\text { P56-R56 }\end{array}$ & & $\begin{array}{c}57 \\
\text { P56-R56 }\end{array}$ & & & & & \\
\hline $\begin{array}{l}\text { Predoi-Cross et } \\
\text { al. (2010) [25] }\end{array}$ & $\begin{array}{c}\text { Voigt, line mixing, } \\
\text { Speed-dependent-Voigt }\end{array}$ & & $\begin{array}{c}56 \\
\text { P56-R54 }\end{array}$ & & $\begin{array}{c}49 \\
\text { P46-R50 }\end{array}$ & & & & \\
\hline $\begin{array}{l}\text { Predoi-Cross et } \\
\text { al. (2007) [21] }\end{array}$ & $\begin{array}{c}\text { Voigt, line mixing , } \\
\text { Speed-dependent Voigt }\end{array}$ & & & & & $\begin{array}{c}57 \\
\text { P56-R56 }\end{array}$ & & $\begin{array}{c}57 \\
\text { P56-R57 }\end{array}$ & \\
\hline $\begin{array}{l}\text { Predoi-Cross et } \\
\text { al.[2009] [24] }\end{array}$ & $\begin{array}{l}\text { Voigt, line mixing, } \\
\text { Speed-dependent-Voigt }\end{array}$ & & & & & $\begin{array}{c}54 \\
\text { P54-R52 }\end{array}$ & $\begin{array}{c}43 \\
\text { P42-R42 }\end{array}$ & $\begin{array}{c}54 \\
\text { P54-R52 }\end{array}$ & $\begin{array}{c}43 \\
\text { P42-R42 }\end{array}$ \\
\hline
\end{tabular}

${ }^{\text {a }}$ All line shape studies published up to 2007 were discussed and compared in Predoi-Cross et al. [21]. However earlier results by Toth et al. [14,15] and Devi et al. [18], and measurements by Predoi-Cross et al. [20, 21, 24, 25] are included in this Table. The reader may refer to the original articles for details.

${ }^{\mathrm{b}}$ Lorentz half-width coefficients and pressure-shift coefficients are in $\mathrm{cm}^{-1} \mathrm{~atm}^{-1}$ at $296 \mathrm{~K}$.

${ }^{\mathrm{c}}$ Temperature dependence exponents of air- and self-broadened half-width coefficients $\left(n_{1}\right.$ and $\left.n_{2}\right)$ have no units.

${ }^{\mathrm{d}}$ Temperature dependences of air- and self-shift coefficients, $\delta^{\prime}$ (air) and $\delta$ (self), are in $\mathrm{cm}^{-1} \mathrm{~atm}^{-1} \mathrm{~K}^{-1}$.

${ }^{\mathrm{e}}$ Line mixing using the off-diagonal relaxation matrix element coefficients. The temperature dependence exponents of the line mixing coefficients were also determined in the present study. 


\section{Table 2}

Experimental setups and physical conditions of analyzed $\mathrm{CO}_{2}$ spectra.

\begin{tabular}{|c|c|c|}
\hline Parameters & Kitt Peak FTS & JPL 125HR FTS: \\
\hline Light Source & Quartz halogen Lamp & Tungsten Lamp \\
\hline Bean Splitter & $\mathrm{CaF}_{2}$ & $\mathrm{CaF}_{2}$ \\
\hline Detector & Two matched InSb & InSb \\
\hline $\begin{array}{l}\text { Focal length of the collimating } \\
\text { lens (mm) }\end{array}$ & 2260 & 418 \\
\hline Source aperture diameter (mm) & 8 & 1.3 \\
\hline Filter band pass $\left(\mathrm{cm}^{-1}\right)$ & $\sim 3000-9000$ & $\sim 4200-6400$ \\
\hline Resolution $\left(\mathrm{cm}^{-1}\right)$ Unapodized & $\begin{array}{l}\sim 01 \\
\sim 0.01\end{array}$ & $0.004-0.011$ \\
\hline Max. Optical Path Difference (cm) & 50 & $45-113$ \\
\hline Pure Sample Pressure (Torr) & $11-897$ & $28-249$ \\
\hline Total pressures of $\mathrm{CO}_{2}+$ air (Torr) & $26-924$ & $200-712$ \\
\hline Volume mixing ratio & $0.05-1.0$ & $\sim 0.03-1.0$ \\
\hline Temperature (K) & $\sim 293-297$ & $\sim 170-250$ \\
\hline Cell path length (m) & $\begin{array}{c}2.46,24.94,49.0 \\
121.18\end{array}$ & 20.941 \\
\hline Scanning time (h) & $\sim 1.5$ & $\sim 5-8$ \\
\hline Signal-to-noise & $800-1000$ & $>2000$ \\
\hline Gas Samples & ${ }^{12} \mathrm{CO}_{2}^{\mathrm{b}, \mathrm{c}}$ & ${ }^{12} \mathrm{C}$-enriched $\mathrm{CO}_{2}{ }^{\mathrm{c}}$ \\
\hline Calibration standards $^{\mathrm{a}}$ & $\mathrm{CO}, \mathrm{C}_{2} \mathrm{H}_{2}$ & $\mathrm{HCl}$ \\
\hline
\end{tabular}

${ }^{\mathrm{a}}$ Calibration of wavelength scales of spectra was achieved using $\mathrm{CO} / \mathrm{C}_{2} \mathrm{H}_{2} / \mathrm{HCl}$ as appropriate (see the text for details).

${ }^{\mathrm{b}} \mathrm{CO}_{2}$ sample with natural isotopic abundances.

${ }^{\text {c } 99.99 \%}{ }^{12} \mathrm{C}$-enhanced $\mathrm{CO}_{2}$ sample. 
Table 3

Summary of experimental conditions of the $\mathrm{CO}_{2}$ spectra analyzed in this work.

\begin{tabular}{|c|c|c|c|c|c|c|}
\hline \multicolumn{3}{|c|}{ Pure CO $_{2}$} & \multicolumn{4}{c|}{$\mathbf{C O}_{2}$ in air } \\
\hline $\begin{array}{c}\text { Temp } \\
(\mathrm{K})\end{array}$ & $\begin{array}{c}\text { Pressure } \\
\left(^{\text {Torr })^{\mathrm{b}}}\right.\end{array}$ & $\begin{array}{c}\text { Path length } \\
(\mathrm{m})\end{array}$ & $\begin{array}{c}\text { Temp } \\
(\mathrm{K})\end{array}$ & $\begin{array}{c}\text { Pressure } \\
(\text { Torr })^{\mathrm{a}}\end{array}$ & $\begin{array}{c}\mathrm{CO}_{2} \text { Volume } \\
\text { mixing ratio }\end{array}$ & $\begin{array}{c}\text { Path length } \\
(\mathrm{m})\end{array}$ \\
\hline 293.99 & $896.84^{\mathrm{b}}$ & 49.00 & 292.92 & $923.52^{\mathrm{b}}$ & 0.0593 & 121.18 \\
\hline 293.49 & $556.56^{\mathrm{b}}$ & 49.00 & 293.07 & $250.38^{\mathrm{b}}$ & 0.0595 & 121.18 \\
\hline 293.49 & $252.42^{\mathrm{b}}$ & 49.00 & 293.09 & $100.86^{\mathrm{b}}$ & 0.0605 & 121.18 \\
\hline 294.40 & $80.00^{\mathrm{b}}$ & 49.00 & 293.05 & $549.545^{\mathrm{b}}$ & 0.0499 & 49.00 \\
\hline 293.09 & $52.14^{\mathrm{b}}$ & 49.00 & 293.17 & $50.07^{\mathrm{b}}$ & 0.0749 & 49.00 \\
\hline 293.70 & $450.93^{\mathrm{b}}$ & 24.94 & 292.63 & $26.05^{\mathrm{b}}$ & 0.0679 & 49.00 \\
\hline 293.70 & $101.95^{\mathrm{b}}$ & 24.94 & 249.90 & 711.68 & 0.04436 & 20.941 \\
\hline 293.94 & $26.10^{\mathrm{b}}$ & 24.94 & 249.90 & 627.53 & 0.3960 & 20.941 \\
\hline 294.05 & $11.04^{\mathrm{b}}$ & 24.94 & 249.90 & 499.90 & 0.04436 & 20.941 \\
\hline 294.37 & 94.65 & 2.46 & 230.10 & 709.48 & 0.2801 & 20.941 \\
\hline 293.58 & $75.27^{\mathrm{b}}$ & 2.46 & 230.10 & 350.26 & 0.2823 & 20.941 \\
\hline 294.09 & 50.70 & 2.46 & 220.20 & 649.73 & 0.05085 & 20.941 \\
\hline 293.57 & 25.61 & 2.46 & 220.20 & 502.02 & 0.05110 & 20.941 \\
\hline & & & 210.20 & 499.94 & 0.3120 & 20.941 \\
\hline 249.90 & 249.05 & 20.941 & 210.20 & 248.23 & 0.3132 & 20.941 \\
\hline 249.90 & 101.90 & 20.941 & 195.00 & 496.96 & 0.03067 & 20.941 \\
\hline 249.90 & 49.85 & 20.941 & 195.00 & 301.25 & 0.03066 & 20.941 \\
\hline 230.00 & 199.45 & 20.941 & 190.30 & 422.85 & 0.2133 & 20.941 \\
\hline 220.20 & 88.85 & 20.941 & 190.30 & 201.36 & 0.2146 & 20.941 \\
\hline 210.30 & 155.15 & 20.941 & 170.30 & 181.73 & 0.2133 & 20.941 \\
\hline 195.10 & 102.21 & 20.941 & 170.10 & 400.43 & 0.02985 & 20.941 \\
\hline 195.00 & 47.74 & 20.941 & 170.10 & 200.41 & 0.02999 & 20.941 \\
\hline 170.35 & 40.01 & 20.941 & & Spectra used only to check final results \\
\hline 170.30 & 29.70 & 20.941 & 295.30 & 742.08 & 0.090341 & 32.54 \\
\hline 170.00 & 33.78 & 20.941 & 293.20 & 550.67 & 0.090344 & 32.54 \\
\hline & & & & & & \\
\hline
\end{tabular}


a 760 Torr $=1 \mathrm{~atm}=101.3 \mathrm{kPa}$.

${ }^{\mathrm{b}}$ Natural $\mathrm{CO}_{2}$ sample (Volume Mixing Ratio $=1$ with $0.9842{ }^{16} \mathrm{O}^{12} \mathrm{C}^{16} \mathrm{O}$ ). The rest of the spectra were obtained using a $99.99 \%{ }^{12} \mathrm{C}$-enriched $\mathrm{CO}_{2}$ sample. Abundances of other isotopologues in the ${ }^{12} \mathrm{C}$ - enhanced sample were determined spectroscopically during the fitting in each spectrum. 


\section{Table 4}

Measured line parameters and number of $\mathrm{CO}_{2}$ measurements.

\begin{tabular}{|c|c|c|c|}
\hline Parameters & $\begin{array}{l}\text { Number of } \\
\text { measurements }\end{array}$ & Parameters & $\begin{array}{c}\text { Number of } \\
\text { measurements }\end{array}$ \\
\hline Position $(v)^{\mathrm{a}}$ & $\begin{array}{l}(585 \text { total })^{\mathrm{a}} \\
522\end{array}$ & Intensity $(S)^{b}$ & $\begin{array}{l}(585 \text { total })^{\mathrm{a}} \\
522\end{array}$ \\
\hline $\begin{array}{l}\text { Air-broadened width } \\
\text { coefficient (air-width) }^{\mathrm{c}}\end{array}$ & 110 & $\begin{array}{l}\text { Self-broadened width } \\
\text { coefficient (self-width) }^{\mathrm{c}}\end{array}$ & 178 \\
\hline $\begin{array}{l}\text { Temperature dependence of } \\
\text { air-broadened width } \\
\text { coefficient }^{\mathrm{d}}\left(n_{1}\right)\end{array}$ & 47 & $\begin{array}{l}\text { Temperature dependence of } \\
\text { self-broadened width } \\
\text { coefficient }^{\mathrm{d}}\left(n_{2}\right)\end{array}$ & 47 \\
\hline $\begin{array}{c}\text { Air- pressure-shift } \\
\text { Coefficient }\left(\delta^{0} \text { air }\right)^{\mathrm{c}}\end{array}$ & 98 & $\begin{array}{l}\text { Self- pressure-shift coefficient } \\
\left(\delta^{0} \text { self }\right)^{\mathrm{c}}\end{array}$ & 164 \\
\hline $\begin{array}{l}\text { Temperature dependence of air- } \\
\text { pressure-shift coefficient }^{\mathrm{e}}\left(\delta^{\prime}\right)\end{array}$ & 47 & $\begin{array}{c}\text { Temperature dependence of } \\
\text { self- pressure-shift coefficient } \\
\left(\delta^{\prime}\right) \\
\end{array}$ & 47 \\
\hline $\begin{array}{l}\text { Off-diagonal relaxation matrix } \\
\text { element coefficients for } \\
\mathrm{CO}_{2} \text {-air mixing }\left(W_{\mathrm{ij}}\right)^{\mathrm{c}}\end{array}$ & 40 & $\begin{array}{l}\text { Off-diagonal relaxation matrix } \\
\text { element coefficients for } \\
\mathrm{CO}_{2}-\mathrm{CO}_{2} \text { mixing }\left(W_{\mathrm{ij}}\right)^{\mathrm{c}}\end{array}$ & 48 \\
\hline $\begin{array}{l}\text { Temperature dependence of off- } \\
\text { diagonal relaxation matrix } \\
\text { element coefficients for } \\
\mathrm{CO}_{2} \text {-air mixing }\end{array}$ & 16 & $\begin{array}{l}\text { Temperature dependence of off- } \\
\text { diagonal relaxation matrix } \\
\text { element coefficients for } \\
\mathrm{CO}_{2}-\mathrm{CO}_{2} \text { mixing }\end{array}$ & 16 \\
\hline Speed dependence $^{\mathrm{d}}$ & 46 & Auxiliary $^{\mathrm{f}}$ & 45 \\
\hline
\end{tabular}

${ }^{a}$ Total numbers of measured positions and intensities. The positions and intensities determined using constraints are given in parentheses at the top of the row. The numbers given outside the parentheses correspond to those within the fitted region. The few lines outside of the fitted region correspond to constrained positions and intensities computed using the constants determined for the 300180001 band of ${ }^{13} \mathrm{C}^{16} \mathrm{O}_{2}$ (below $6120 \mathrm{~cm}^{-1}$ ) and the $40013 \leftarrow 10001$ band of ${ }^{12} \mathrm{C}^{16} \mathrm{O}_{2}$ (beyond $6280 \mathrm{~cm}^{-1}$ ). (See the Supplemental file for further details). Positions are in $\mathrm{cm}^{-1}$.

${ }^{\mathrm{b}}$ Line intensity in $\mathrm{cm}^{-1} /\left(\right.$ molecule $\left.\mathrm{cm}^{-2}\right)$ at $296 \mathrm{~K}$.

${ }^{\mathrm{c}}$ Lorentz half-width and pressure-shift coefficients and the off-diagonal relaxation matrix element coefficients in cm ${ }^{-1} \mathrm{~atm}^{-1}$ at $296 \mathrm{~K}$.

${ }^{d}$ Temperature dependence exponents of half-width coefficients, the off-diagonal relaxation matrix element coefficients and speed dependence have no units. 
e Temperature dependences of pressure-shift coefficients are in units of $\mathrm{cm}^{-1} \mathrm{~atm}^{-1} \mathrm{~K}^{-1}$.

${ }^{\mathrm{f}}$ Examples of auxiliary parameters used in this study include position differences and intensity ratios (see the text for details). 
Table 5

A sample of measured line parameters for the P40-R40 transitions in the $30013 \leftarrow 00001$ band of ${ }^{12} \mathrm{C}^{16} \mathrm{O}_{2}$.

\begin{tabular}{|c|c|c|c|c|c|c|c|c|c|c|c|}
\hline Line & $\begin{array}{l}\text { Line position } \\
\quad \text { (unc.) }^{\text {a }}\end{array}$ & $\begin{array}{l}\text { Inten }^{\mathrm{b}} \\
\times 10^{-24}\end{array}$ & $\begin{array}{c}\% \\
\text { Inten } \\
\text { (unc) }\end{array}$ & $\begin{array}{c}\text { half-width } \\
\text { coeffs }^{c}\end{array}$ & $\begin{array}{c}\% \\
\text { unc. }\end{array}$ & $\underset{n_{2}}{n_{1} \text { or }}$ & $\begin{array}{c}\% \\
\text { unc. }\end{array}$ & $\begin{array}{c}\text { Pressure shift } \\
\delta^{0} \text { (unc.) }^{\mathrm{c}}\end{array}$ & $\begin{array}{c}\text { T-dep. shift } \\
\delta^{\prime}\left(\text { unc.) }{ }^{\mathrm{e}}\right.\end{array}$ & $\begin{array}{l}\text { Speed } \\
\text { depend. }\end{array}$ & $\begin{array}{c}\% \\
\text { unc. }\end{array}$ \\
\hline \multirow{2}{*}{ P40 } & \multirow{2}{*}{ 6191.171809(3) } & \multirow{2}{*}{3.072} & \multirow{2}{*}{0.009} & 0.06797 & 0.19 & 0.7532 & 1.01 & $-0.005366(11)$ & $+0.241(15)$ & \multirow{2}{*}{0.0726} & \multirow{2}{*}{3.2} \\
\hline & & & & 0.08045 & 0.07 & 0.6192 & 0.53 & $-0.007887(50)$ & $+0.147(11)$ & & \\
\hline \multirow{2}{*}{ P38 } & \multirow{2}{*}{$6193.284448(2)$} & \multirow{2}{*}{3.920} & \multirow{2}{*}{0.007} & 0.06804 & 0.15 & 0.7751 & 0.75 & $-0.006409(93)$ & $+0.180(13)$ & \multirow{2}{*}{0.0767} & \multirow{2}{*}{2.4} \\
\hline & & & & 0.08216 & 0.06 & 0.6166 & 0.44 & $-0.007643(42)$ & $+0.100(9)$ & & \\
\hline \multirow{2}{*}{ P36 } & \multirow{2}{*}{ 6195.367172(2) } & \multirow{2}{*}{4.915} & \multirow{2}{*}{0.006} & 0.06791 & 0.12 & 0.8094 & 0.57 & $-0.006548(74)$ & $+0.233(10)$ & \multirow{2}{*}{0.0714} & \multirow{2}{*}{2.3} \\
\hline & & & & 0.08440 & 0.06 & 0.6028 & 0.38 & $-0.007803(39)$ & $+0.072(8)$ & & \\
\hline \multirow{2}{*}{ P34 } & \multirow{2}{*}{ 6197.420175(2) } & \multirow{2}{*}{6.053} & \multirow{2}{*}{0.006} & 0.06837 & 0.10 & 0.7877 & 0.47 & $-0.005879(69)$ & $+0.254(10)$ & \multirow{2}{*}{0.0611} & \multirow{2}{*}{2.4} \\
\hline & & & & 0.08581 & 0.05 & 0.6254 & 0.32 & $-0.007345(35)$ & $+0.062(7)$ & & \\
\hline \multirow{2}{*}{ P32 } & \multirow{2}{*}{ 6199.443645(2) } & \multirow{2}{*}{7.319} & \multirow{2}{*}{0.005} & 0.06844 & 0.09 & 0.8157 & 0.37 & $-0.006370(59)$ & $+0.238(8)$ & \multirow{2}{*}{0.0732} & \\
\hline & & & & 0.08810 & 0.05 & 0.6274 & 0.29 & $-0.007187(35)$ & $+0.030(6)$ & & 1.6 \\
\hline & & & & 0.06962 & 0.09 & 0.7725 & 0.35 & $-0.006511(57)$ & $+0.183(7)$ & & \\
\hline P30 & $6201.43 / 761(2)$ & 8.685 & 0.004 & 0.09017 & 0.04 & 0.6399 & 0.27 & $-0.007087(36)$ & $-0.007(6)$ & 0.0823 & 1.4 \\
\hline D) 8 & & & & 0.06982 & 0.07 & 0.7732 & 0.30 & $-0.006522(48)$ & $+0.235(6)$ & & \\
\hline P28 & $6203.402694(2)$ & 10.11 & 0.004 & 0.09221 & 0.03 & 0.6531 & 0.23 & $-0.006789(34)$ & $-0.027(6)$ & 0.0816 & 1.1 \\
\hline & & & & 0.07027 & 0.07 & 0.7653 & 0.26 & $-0.006437(45)$ & $+0.227(6)$ & & \\
\hline P26 & $6205.338606(2)$ & 11.5 & 0.004 & 0.09411 & 0.03 & 0.6710 & 0.21 & $-0.006672(33)$ & $-0.069(5)$ & 0.0010 & 1.0 \\
\hline P24 & $45(1)$ & 289 & 0003 & 0.07155 & 0.08 & 0.7499 & 0.28 & $-0.006136(49)$ & $+0.254(6)$ & 01034 & 08 \\
\hline 124 & $5040(1)$ & 2.05 & .003 & 0.09667 & 0.04 & 0.6754 & 0.21 & $-0.006599(36)$ & $-0.126(6)$ & 034 & 0.0 \\
\hline P?2 & 6209 & 400 & 0003 & 0.07210 & 0.06 & 0.7464 & 0.24 & $-0.006020(48)$ & $+0.287(6)$ & & 07 \\
\hline $\mathrm{P} Z 2$ & 620 & 09 & 003 & 0.09819 & 0.03 & 0.6975 & 0.19 & $-0.006490(35)$ & $-0.138(6)$ & & 0.1 \\
\hline & & & & 0.07325 & 0.05 & 0.7340 & 0.23 & $-0.006011(46)$ & $+0.268(6)$ & & \\
\hline $\mathrm{P} 20$ & 6210 & 15.06 & 0.003 & 0.09993 & 0.03 & 0.7130 & 0.17 & $-0.006268(35)$ & $-0.136(6)$ & 055 & 0.6 \\
\hline P18 & & 569 & 0.003 & 0.07446 & 0.07 & 0.7221 & 0.24 & $-0.005816(47)$ & $+0.285(6)$ & & 0.6 \\
\hline P18 & $6212.7948 / 4(1)$ & 5.69 & 0.003 & 0.10178 & 0.03 & 0.7194 & 0.17 & $-0.006083(38)$ & $-0.185(6)$ & .1114 & 0.6 \\
\hline & & & & 0.07579 & 0.05 & 0.7143 & 0.22 & $-0.005922(45)$ & $+0.259(6)$ & & \\
\hline P16 & 6214.587707(1) & 5.91 & 0.003 & 0.10343 & 0.03 & 0.7312 & 0.15 & $-0.005782(35)$ & $-0.173(6)$ & 0.1146 & 0.5 \\
\hline P14 & 6216.352248(1) & 15.6 & 0.003 & 0.07726 & 0.05 & 0.7135 & 0.22 & $-0.005740(46)$ & $+0.247(6)$ & 0.1193 & 0 \\
\hline $\mathrm{P} 14$ & $0210.352240(1)$ & 10.0 & 0.003 & 0.10532 & 0.03 & 0.7334 & 0.15 & $-0.005521(38)$ & $-0.180(6)$ & 1193 & 0.5 \\
\hline
\end{tabular}




\begin{tabular}{|c|c|c|c|c|c|c|c|c|c|c|c|}
\hline $\mathrm{P} 12$ & 6218.088573(1) & 14.85 & 0.003 & $\begin{array}{l}0.07882 \\
0.10732\end{array}$ & $\begin{array}{l}0.05 \\
0.03\end{array}$ & $\begin{array}{l}0.7106 \\
0.7374\end{array}$ & $\begin{array}{l}0.23 \\
0.15\end{array}$ & $\begin{array}{l}-0.005530(46) \\
-0.005346(36)\end{array}$ & $\begin{array}{r}+0.239(6) \\
-0.189(6)\end{array}$ & 0.1163 & 0.5 \\
\hline $\mathrm{P} 10$ & 6219.796748(2) & 13.50 & 0.003 & $\begin{array}{l}0.08069 \\
0.10952\end{array}$ & $\begin{array}{l}0.06 \\
0.04\end{array}$ & $\begin{array}{l}0.7009 \\
0.7419\end{array}$ & $\begin{array}{l}0.23 \\
0.15\end{array}$ & $\begin{array}{l}-0.005012(49) \\
-0.005285(37)\end{array}$ & $\begin{array}{l}+0.262(6) \\
-0.206(6)\end{array}$ & 0.1159 & 0.5 \\
\hline P8 & $6221.476922(2)$ & 11.61 & 0.003 & $\begin{array}{l}0.08234 \\
0.11182\end{array}$ & $\begin{array}{l}0.06 \\
0.04\end{array}$ & $\begin{array}{l}0.7057 \\
0.7488\end{array}$ & $\begin{array}{l}0.24 \\
0.16\end{array}$ & $\begin{array}{l}-0.004542(53) \\
-0.004848(37)\end{array}$ & $\begin{array}{l}+0.239(7) \\
-0.161(6)\end{array}$ & 0.1066 & 0.6 \\
\hline P6 & 6223.128831(2) & 9.223 & 0.003 & $\begin{array}{l}0.08435 \\
0.11440 \\
\end{array}$ & $\begin{array}{l}0.06 \\
0.04 \\
\end{array}$ & $\begin{array}{l}0.7057 \\
0.7585 \\
\end{array}$ & $\begin{array}{l}0.26 \\
0.17 \\
\end{array}$ & $\begin{array}{l}-0.004361(60) \\
-0.004924(40)\end{array}$ & $\begin{array}{l}+0.195(8) \\
-0.191(7) \\
\end{array}$ & 0.0958 & 0.7 \\
\hline P4 & $6224.752797(2)$ & 6.415 & 0.003 & $\begin{array}{l}0.08650 \\
0.11672 \\
\end{array}$ & $\begin{array}{l}0.08 \\
0.04 \\
\end{array}$ & $\begin{array}{l}0.7114 \\
0.7712 \\
\end{array}$ & $\begin{array}{l}0.31 \\
0.18 \\
\end{array}$ & $\begin{array}{l}-0.003787(66) \\
-0.004121(44) \\
\end{array}$ & $\begin{array}{l}+0.156(8) \\
-0.153(7)\end{array}$ & 0.0765 & 1.2 \\
\hline $\mathrm{P} 2$ & $6226.348728(2)$ & 3.297 & 0.003 & $\begin{array}{l}0.09063 \\
0.12072\end{array}$ & $\begin{array}{l}0.12 \\
0.05\end{array}$ & $\begin{array}{l}0.7052 \\
0.7605\end{array}$ & $\begin{array}{l}0.50 \\
0.24\end{array}$ & $\begin{array}{l}-0.003166(94) \\
-0.003504(65)\end{array}$ & $\begin{array}{l}+0.104(12) \\
-0.165(9)\end{array}$ & 0.0575 & 2.7 \\
\hline R0 & $6228.690037(2)$ & 1.670 & 0.003 & $\begin{array}{l}0.09426 \\
0.12737\end{array}$ & $\begin{array}{l}0.21 \\
0.07\end{array}$ & $\begin{array}{l}0.7277 \\
0.7448\end{array}$ & $\begin{array}{l}0.88 \\
0.34\end{array}$ & $\begin{array}{l}-0.002768(14) \\
-0.004821(11)\end{array}$ & $\begin{array}{l}+0.225(17) \\
-0.243(15)\end{array}$ & 0.0500 & --- \\
\hline R2 & $6230.215814(2)$ & 4.965 & 0.003 & $\begin{array}{l}0.08720 \\
0.11814\end{array}$ & $\begin{array}{l}0.09 \\
0.03\end{array}$ & $\begin{array}{l}0.7237 \\
0.7664\end{array}$ & $\begin{array}{l}0.36 \\
0.13\end{array}$ & $\begin{array}{l}-0.004050(76) \\
-0.005110(48)\end{array}$ & $\begin{array}{l}+0.141(9) \\
-0.263(7)\end{array}$ & 0.0581 & 2.0 \\
\hline $\mathrm{R} 4$ & 6231.713466(2) & 8.076 & 0.003 & $\begin{array}{l}0.08588 \\
0.11575\end{array}$ & $\begin{array}{l}0.07 \\
0.04\end{array}$ & $\begin{array}{l}0.7016 \\
0.7683\end{array}$ & $\begin{array}{l}0.29 \\
0.18\end{array}$ & $\begin{array}{l}-0.004780(55) \\
-0.004777(40)\end{array}$ & $\begin{array}{l}+0.089(7) \\
-0.248(6)\end{array}$ & 0.1092 & 0.6 \\
\hline R6 & 6233.182934(2) & 10.87 & 0.003 & $\begin{array}{l}0.08266 \\
0.11327 \\
\end{array}$ & $\begin{array}{l}0.06 \\
0.04 \\
\end{array}$ & $\begin{array}{l}0.7057 \\
0.7455 \\
\end{array}$ & $\begin{array}{l}0.24 \\
0.16 \\
\end{array}$ & $\begin{array}{l}-0.004483(56) \\
-0.004933(38) \\
\end{array}$ & $\begin{array}{l}+0.122(7) \\
-0.268(7)\end{array}$ & 0.1002 & 0.6 \\
\hline R8 & $6234.624145(2)$ & 13.24 & 0.003 & $\begin{array}{l}0.08099 \\
0.11079 \\
\end{array}$ & $\begin{array}{l}0.06 \\
0.04 \\
\end{array}$ & $\begin{array}{l}0.6993 \\
0.7337 \\
\end{array}$ & $\begin{array}{l}0.23 \\
0.15 \\
\end{array}$ & $\begin{array}{l}-0.004284(50) \\
-0.005307(38)\end{array}$ & $\begin{array}{l}+0.161(6) \\
-0.297(6)\end{array}$ & 0.1108 & 0.5 \\
\hline R10 & 6236.037013(1) & 15.10 & 0.003 & $\begin{array}{l}0.07926 \\
0.10792\end{array}$ & $\begin{array}{l}0.05 \\
0.03\end{array}$ & $\begin{array}{l}0.6969 \\
0.7355\end{array}$ & $\begin{array}{l}0.23 \\
0.15\end{array}$ & $\begin{array}{l}-0.004431(47) \\
-0.005337(37)\end{array}$ & $\begin{array}{l}+0.156(6) \\
-0.276(6)\end{array}$ & 0.1160 & 0.5 \\
\hline $\mathrm{R} 12$ & 6237.421435(1) & 16.40 & 0.003 & $\begin{array}{l}0.07755 \\
0.10608\end{array}$ & $\begin{array}{l}0.05 \\
0.03\end{array}$ & $\begin{array}{l}0.7001 \\
0.7246\end{array}$ & $\begin{array}{l}0.23 \\
0.15\end{array}$ & $\begin{array}{l}-0.004703(45) \\
-0.005330(37)\end{array}$ & $\begin{array}{l}+0.145(6) \\
-0.240(6)\end{array}$ & 0.1189 & 0.5 \\
\hline $\mathrm{R} 14$ & 6238.777296(1) & 17.15 & 0.003 & $\begin{array}{l}0.07601 \\
0.10394\end{array}$ & $\begin{array}{l}0.05 \\
0.03\end{array}$ & $\begin{array}{l}0.7096 \\
0.7242\end{array}$ & $\begin{array}{l}0.23 \\
0.15\end{array}$ & $\begin{array}{l}-0.004739(44) \\
-0.005658(37)\end{array}$ & $\begin{array}{l}+0.178(6) \\
-0.217(6)\end{array}$ & 0.1185 & 0.5 \\
\hline $\mathrm{R} 16$ & $6240.104467(1)$ & 17.34 & 0.003 & $\begin{array}{l}0.07457 \\
0.10190 \\
\end{array}$ & $\begin{array}{l}0.05 \\
0.03 \\
\end{array}$ & $\begin{array}{l}0.7164 \\
0.7219 \\
\end{array}$ & $\begin{array}{l}0.22 \\
0.15 \\
\end{array}$ & $\begin{array}{l}-0.005054(43) \\
-0.005721(37)\end{array}$ & $\begin{array}{l}+0.179(6) \\
-0.190(6)\end{array}$ & 0.1148 & 0.5 \\
\hline R18 & 6241.402807(1) & 17.04 & 0.003 & $\begin{array}{l}0.07331 \\
0.10040\end{array}$ & $\begin{array}{l}0.05 \\
0.03\end{array}$ & $\begin{array}{l}0.7286 \\
0.7096\end{array}$ & $\begin{array}{l}0.22 \\
0.16\end{array}$ & $\begin{array}{l}-0.005248(44) \\
-0.006090(37)\end{array}$ & $\begin{array}{l}+0.182(6) \\
-0.155(6)\end{array}$ & 0.1135 & 0.5 \\
\hline R20 & $6242.672160(1)$ & 16.32 & 0.003 & $\begin{array}{l}0.07235 \\
0.09838 \\
\end{array}$ & $\begin{array}{l}0.06 \\
0.03\end{array}$ & $\begin{array}{l}0.7351 \\
0.7089 \\
\end{array}$ & $\begin{array}{l}0.23 \\
0.17\end{array}$ & $\begin{array}{l}-0.005189(44) \\
-0.006277(36)\end{array}$ & $\begin{array}{l}+0.213(6) \\
-0.128(6)\end{array}$ & 0.1110 & 0.5 \\
\hline R22 & 6243.912358(1) & 15.25 & 0.003 & $\begin{array}{l}0.07136 \\
0.09699\end{array}$ & $\begin{array}{l}0.06 \\
0.03\end{array}$ & $\begin{array}{l}0.7504 \\
0.6881\end{array}$ & $\begin{array}{l}0.23 \\
0.19\end{array}$ & $\begin{array}{l}-0.005590(45) \\
-0.006405(36)\end{array}$ & $\begin{array}{l}+0.193(6) \\
-0.055(6)\end{array}$ & 0.1056 & 0.6 \\
\hline
\end{tabular}




\begin{tabular}{|c|c|c|c|c|c|c|c|c|c|c|c|}
\hline R24 & $6245.123224(2)$ & 13.94 & 0.004 & $\begin{array}{l}0.07056 \\
0.09491\end{array}$ & $\begin{array}{l}0.06 \\
0.03\end{array}$ & $\begin{array}{l}0.7605 \\
0.6821\end{array}$ & $\begin{array}{l}0.24 \\
0.19\end{array}$ & $\begin{array}{l}-0.005683(41) \\
-0.006979(35)\end{array}$ & $\begin{array}{l}+0.225(5) \\
-0.057(5)\end{array}$ & 0.1020 & 0.7 \\
\hline R26 & $6246.304565(2)$ & 12.47 & 0.004 & $\begin{array}{l}0.06998 \\
0.09322\end{array}$ & $\begin{array}{l}0.07 \\
0.03\end{array}$ & $\begin{array}{l}0.7663 \\
0.6604\end{array}$ & $\begin{array}{l}0.26 \\
0.21\end{array}$ & $\begin{array}{l}-0.005536(43) \\
-0.007197(35)\end{array}$ & $\begin{array}{l}+0.232(6) \\
-0.011(5)\end{array}$ & 0.0976 & 0.8 \\
\hline R28 & $6247.456179(2)$ & 10.93 & 0.004 & $\begin{array}{l}0.06922 \\
0.09121\end{array}$ & $\begin{array}{l}0.07 \\
0.03\end{array}$ & $\begin{array}{l}0.7759 \\
0.6482\end{array}$ & $\begin{array}{l}0.28 \\
0.23\end{array}$ & $\begin{array}{l}-0.005749(46) \\
-0.007694(35)\end{array}$ & $\begin{array}{l}+0.224(6) \\
-0.009(6)\end{array}$ & 0.0873 & 1.0 \\
\hline R30 & $6248.577855(2)$ & 9.398 & 0.004 & $\begin{array}{l}0.06881 \\
0.08906 \\
\end{array}$ & $\begin{array}{l}0.07 \\
0.04 \\
\end{array}$ & $\begin{array}{l}0.7804 \\
0.6345 \\
\end{array}$ & $\begin{array}{l}0.32 \\
0.27\end{array}$ & $\begin{array}{l}-0.005655(51) \\
-0.007930(36) \\
\end{array}$ & $\begin{array}{l}+0.256(7) \\
-0.022(6) \\
\end{array}$ & 0.0795 & 1.2 \\
\hline R32 & 6249.669372(2) & 7.925 & 0.005 & $\begin{array}{l}0.06849 \\
0.08664 \\
\end{array}$ & $\begin{array}{l}0.09 \\
0.04 \\
\end{array}$ & $\begin{array}{l}0.7803 \\
0.6433 \\
\end{array}$ & $\begin{array}{l}0.37 \\
0.28 \\
\end{array}$ & $\begin{array}{l}-0.005560(58) \\
-0.007930(36) \\
\end{array}$ & $\begin{array}{l}+0.262(8) \\
+0.107(6) \\
\end{array}$ & 0.0759 & 1.5 \\
\hline R34 & $6250.730499(2)$ & 6.561 & 0.006 & $\begin{array}{l}0.06804 \\
0.08484 \\
\end{array}$ & $\begin{array}{l}0.10 \\
0.05 \\
\end{array}$ & $\begin{array}{l}0.7992 \\
0.6304\end{array}$ & $\begin{array}{l}0.44 \\
0.33\end{array}$ & $\begin{array}{l}-0.006420(64) \\
-0.008312(38) \\
\end{array}$ & $\begin{array}{l}+0.216(9) \\
+0.090(7) \\
\end{array}$ & 0.0736 & 1.8 \\
\hline R36 & 6251.760996(2) & 5.334 & 0.006 & $\begin{array}{l}0.06790 \\
0.08284\end{array}$ & $\begin{array}{l}0.12 \\
0.05\end{array}$ & $\begin{array}{l}0.7900 \\
0.6370\end{array}$ & $\begin{array}{l}0.56 \\
0.38\end{array}$ & $\begin{array}{l}-0.006353(74) \\
-0.008711(40)\end{array}$ & $\begin{array}{l}+0.220(10) \\
+0.105(7)\end{array}$ & 0.0780 & 1.9 \\
\hline R38 & 6252.760618(3) & 4.259 & 0.007 & $\begin{array}{l}0.06733 \\
0.08089 \\
\end{array}$ & $\begin{array}{l}0.15 \\
0.06\end{array}$ & $\begin{array}{l}0.8073 \\
0.6412\end{array}$ & $\begin{array}{l}0.68 \\
0.44\end{array}$ & $\begin{array}{l}-0.006267(89) \\
-0.008863(44)\end{array}$ & $\begin{array}{l}+0.191(13) \\
+0.124(8)\end{array}$ & 0.0677 & 2.8 \\
\hline R40 & 6253.729113(3) & 3.342 & 0.009 & $\begin{array}{l}0.06752 \\
0.07940\end{array}$ & $\begin{array}{l}0.18 \\
0.08\end{array}$ & $\begin{array}{l}0.7890 \\
0.6386\end{array}$ & $\begin{array}{l}0.91 \\
0.50\end{array}$ & $\begin{array}{l}-0.006577(10) \\
-0.009339(49)\end{array}$ & $\begin{array}{l}+0.181(15) \\
+0.111(10)\end{array}$ & 0.0719 & 3.1 \\
\hline
\end{tabular}

The uncertainties listed under the various columns correspond to one sigma internal statistical errors obtained from least-squares fits and do not include systematic errors (see the text for details). Uncertainties for line positions, pressure shift coefficients and their temperature dependences are given in parentheses in units of the last digit quoted. For all other parameters the uncertainty is given in percent in the column immediately to the right of that parameter value.

${ }^{\text {a }}$ Positions and their uncertainties are in $\mathrm{cm}^{-1}$.

${ }^{\mathrm{b}}$ Line intensities (S) are in cm/molecule at $296 \mathrm{~K}$ and scaled by $10^{-24}$.

${ }^{\mathrm{c}}$ Lorentz half-width coefficients $\left(b_{L}^{0}\right)$ and pressure shift coefficients $\left(\delta^{0}\right)$ are in units of $\mathrm{cm}^{-1} \mathrm{~atm}^{-1}$ at $296 \mathrm{~K}$.

The numbers in each transition entry correspond to air-broadening in the upper row and self-broadening in the lower row.

${ }^{\mathrm{d}} n_{1}$ and $n_{2}$ are the corresponding temperature dependence exponents of air- and self-width coefficients and have no units.

e Temperature dependences of pressure shift coefficients, $\delta^{\prime}$ (air) and $\delta^{\prime}$ (self), are in units of $\mathrm{cm}^{-1} \mathrm{~atm}^{-1} \mathrm{~K}^{-1}$.

${ }^{\mathrm{f}}$ Speed dependence parameter has no units and is assumed to be independent of gas sample temperature and same for both self- and air-broadening. 
Table 6

Ro-vibrational, vibrational band intensity, Herman-Wallis parameters and correlation coefficients of measured ${ }^{12} \mathrm{C}^{16} \mathrm{O}_{2}$ bands: $6120-6280 \mathrm{~cm}^{-1}$.

\begin{tabular}{|c|c|c|c|c|c|c|c|c|}
\hline \multirow[t]{2}{*}{ Band } & \multicolumn{4}{|c|}{ Upper State Rotational Constants in $\mathrm{cm}^{-1}$} & \multicolumn{4}{|c|}{ Intensity Constants } \\
\hline & $G^{\prime}-G^{\prime \prime}$ & $B^{\prime}$ & $D^{\prime} \times 10^{7}$ & $H^{\prime} \times 10^{12}$ & $s_{V} \times 10^{24}$ & $a_{1} \times 10^{4}$ & $a_{2} \times 10^{5}$ & $a_{3} \times 10^{9}$ \\
\hline $30013 \leftarrow 00001$ & $\begin{array}{l}6227.9166155(19) \\
6227.916540(1)^{a}\end{array}$ & $\begin{array}{l}0.3867110194(78) \\
0.386711076(98)^{\mathrm{a}}\end{array}$ & $\begin{array}{l}1.715717(88) \\
1.715489(20)^{\mathrm{a}}\end{array}$ & $\begin{array}{c}10.234(26) \\
0.99(13)^{\mathrm{a}}\end{array}$ & $440.610(13)$ & $+3.104(8)$ & $+1.8624(22)$ & $-0.871(81)$ \\
\hline $\begin{array}{l}31113 \leftarrow 01101 e \\
31113 \leftarrow 01101 f\end{array}$ & $6196.176079(23)$ & $\begin{array}{l}0.386922173(120) \\
0.388334478(121)\end{array}$ & $\begin{array}{l}1.217528(135) \\
1.486159(155)\end{array}$ & $\begin{array}{l}-1.930(19) \\
-1.205(50)\end{array}$ & $32.654(5)$ & $+3.26(5)$ & $+1.087(26)$ & 0.0 Fixed \\
\hline $\begin{array}{l}32213 \leftarrow 02201 e \\
32213 \leftarrow 02201 f\end{array}$ & $6170.10837(43)$ & $\begin{array}{l}0.38860954(182) \\
0.38861009(184)\end{array}$ & $\begin{array}{l}1.608(15) \\
1.458(15)\end{array}$ & $\begin{array}{l}0.0 \text { fixed } \\
0.0 \text { fixed }\end{array}$ & $1.254(4)$ & 0.0 Fixed & 0.0 Fixed & 0.0 Fixed \\
\hline $40014 \leftarrow 10002$ & 6175.11377 (17) & $0.38734765(57)$ & $1.9797(37)$ & 0.0 fixed & $2.247(4)$ & $-7.97(43)$ & 0.0 Fixed & 0.0 Fixed \\
\hline $40013 \leftarrow 10001$ & $6205.51034(28)$ & $0.38555187(165)$ & $0.792(24)$ & $-12.80(88)$ & $1.485(4)$ & 0.0 Fixed & 0.0 Fixed & 0.0 Fixed \\
\hline & \multicolumn{4}{|c|}{ Lower State Constants } & & & & \\
\hline 00001 (fixed) & 0. & 0.39021894900 & 1.334088000 & 0.01918 & & & & \\
\hline $\begin{array}{l}01101 e \text { (fixed) } \\
01101 f \text { (fixed) }\end{array}$ & 667.3798265 & $\begin{array}{l}0.39063910900 \\
0.391254698 \\
\end{array}$ & $\begin{array}{l}1.3539300 \\
1.3616060 \\
\end{array}$ & $\begin{array}{l}2.967 \\
3.040\end{array}$ & & & & \\
\hline $\begin{array}{l}02201 e \text { (fixed) } \\
02201 f \text { (fixed) }\end{array}$ & 1335.1313992 & $\begin{array}{l}0.3916667620 \\
0.3916667620 \\
\end{array}$ & $\begin{array}{l}1.373660 \\
1.381250 \\
\end{array}$ & $\begin{array}{l}-3.765 \\
0.7380 \\
\end{array}$ & & & & \\
\hline $\begin{array}{l}10001 \text { (fixed) } \\
10002 \text { (fixed) }\end{array}$ & $\begin{array}{l}1388.1840918 \\
1285.4081123\end{array}$ & $\begin{array}{l}0.3901889160 \\
0.3904708290\end{array}$ & $\begin{array}{l}1.149427 \\
1.57157070\end{array}$ & $\begin{array}{l}1.86596 \\
2.33398\end{array}$ & & & & \\
\hline
\end{tabular}

\begin{tabular}{|c|c|c|c|c|c|c|c|c|c|c|c|c|}
\hline \multirow[t]{2}{*}{ Band } & \multicolumn{6}{|c|}{ Correlation Coefficients for Upper State Constants } & \multicolumn{6}{|c|}{ Correlation Coefficients for Intensity Constants } \\
\hline & $G^{\prime}-G^{\prime \prime} \& B^{\prime}$ & $G^{\prime}-G^{\prime \prime} \& D^{\prime}$ & $G^{\prime}-G^{\prime \prime} \& H^{\prime}$ & $B^{\prime} \& D^{\prime}$ & $B^{\prime} \& H^{\prime}$ & $D^{\prime} \& H^{\prime}$ & $s_{V} \& a_{1}$ & $s_{V} \& a_{2}$ & $s_{V} \& a_{3}$ & $a_{1} \& a_{2}$ & $a_{1} \& a_{3}$ & $a_{2} \& a_{3}$ \\
\hline $30013 \leftarrow 00001$ & -0.704 & -0.540 & -0.432 & +0.938 & +0.826 & +0.958 & -0.037 & -0.635 & +0.058 & +0.051 & -0.809 & -0.072 \\
\hline $\begin{array}{l}31113 \leftarrow 01101 e \\
31113 \leftarrow 01101 f\end{array}$ & $\begin{array}{l}-0.765 \\
-0.764\end{array}$ & $\begin{array}{l}-0.583 \\
-0.582\end{array}$ & $\begin{array}{l}-0.460 \\
-0.459\end{array}$ & $\begin{array}{l}+0.931 \\
+0.930\end{array}$ & $\begin{array}{l}+0.817 \\
+0.816\end{array}$ & $\begin{array}{l}+0.958 \\
+0.959\end{array}$ & -0.017 & -0.756 & & +0.069 & & \\
\hline $\begin{array}{l}32213 \leftarrow 02201 e \\
32213 \leftarrow 02201 f\end{array}$ & $\begin{array}{l}-0.784 \\
-0.779\end{array}$ & $\begin{array}{l}-0.604 \\
-0.600\end{array}$ & & $\begin{array}{l}+0.928 \\
+0.927\end{array}$ & & & & & & & & \\
\hline $40014 \leftarrow 10002$ & -0.829 & -0.654 & & +0.928 & & & -0.021 & & & & & \\
\hline $40013 \leftarrow 10001$ & -0.862 & -0.758 & -0.658 & +0.966 & +0.892 & +0.975 & & & & & & \\
\hline
\end{tabular}




\begin{tabular}{|c|c|c|c|c|c|c|c|c|c|c|}
\hline \multirow[t]{2}{*}{ Band } & \multicolumn{10}{|c|}{ Correlation Coefficients for additional Upper State Constants not listed above } \\
\hline & $\begin{array}{l}B^{\prime}(e) \& \\
B^{\prime}(f)\end{array}$ & $\begin{array}{l}B^{\prime}(e) \& \\
D^{\prime}(f)\end{array}$ & $\begin{array}{l}B^{\prime}(e) \& \\
H^{\prime}(f)\end{array}$ & $\begin{array}{l}D^{\prime}(e) \& \\
H^{\prime}(e)\end{array}$ & $\begin{array}{l}D^{\prime}(e) \& \\
B^{\prime}(f)\end{array}$ & $\begin{array}{l}D^{\prime}(e) \& \\
D^{\prime}(f)\end{array}$ & $\begin{array}{l}D^{\prime}(e) \& \\
H^{\prime}(f)\end{array}$ & $\begin{array}{l}B^{\prime}(f) \& \\
H^{\prime}(e)\end{array}$ & $\begin{array}{l}D^{\prime}(f) \& \\
H^{\prime}(e)\end{array}$ & $H^{\prime}(e) \& H^{\prime}(f)$ \\
\hline $31113 \leftarrow 01101$ & +0.585 & +0.443 & +0.346 & +0.958 & +0.443 & +0.331 & +0.255 & +0.348 & +0.256 & +0.195 \\
\hline $32213 \leftarrow 02201$ & +0.611 & +0.471 & & & +0.471 & +0.363 & & & & \\
\hline
\end{tabular}

Notes: The uncertainties reported in parentheses under the various columns correspond to one-sigma internal statistical errors in units of the last quoted digit of the measured values. For example, 6227.9166155 (19) $\mathrm{cm}^{-1}$ corresponds to $6227.9166155 \pm 0.0000019 \mathrm{~cm}^{-1}$.

Contribution due to vibrational partition function for the lower vibrational levels was applied in computing the band strengths listed in the Table above.

The rotational partition function for ${ }^{12} \mathrm{C}^{16} \mathrm{O}_{2}=263.87063$ [43]. A value of 263.60 has been used in this Table to enable comparison with values reported in [18] (see Table 7).

The band centers and rotational constants are in $\mathrm{cm}^{-1}$. The rotational constants for the lower states (ground state, 01101, 02201, 10001, 10002) are from Refs. [29-30]. Note that $L^{\prime \prime}(10001)=0.5663 \times 10^{-18}$ and $L^{\prime \prime}(10002)=-0.9928 \times 10^{-18}$.

The intensity constants are the same for the $e$ and $f$ levels of the $31112 \leftarrow 01101$ and the $32212 \leftarrow 02201$ bands.

The band strengths $\left(S_{V}\right)$ are in $\mathrm{cm}^{-1} /\left(\right.$ molecule $\left.\cdot \mathrm{cm}^{-2}\right) \times 10^{-24}$ at $296 \mathrm{~K}$.

${ }^{a}$ These ro-vibrational constants are from Ref. [27].

The value of $S_{v}\left(4.4061 \times 10^{-22} \mathrm{~cm} /\right.$ molecule at $\left.296 \mathrm{~K}\right)$ reported under intensity constants correspond to the vibrational band strength $\left(\mathrm{S}_{\mathrm{v}}\right)$ and differs from the sum of all line intensities $S_{\text {band }}=4.4959 \times 10^{-22} \mathrm{~cm} /$ molecule at $296 \mathrm{~K}$ (see the text for details). 
Table 7

Comparison of measured band intensity ${ }^{\mathrm{a}}$ parameters for the $30013 \leftarrow 00001$ and $31113 \leftarrow 01101$ bands of ${ }^{12} \mathrm{C}^{16} \mathrm{O}_{2}$.

\begin{tabular}{|c|c|c|c|c|}
\hline \multirow{2}{*}{$\begin{array}{l}\text { Para- } \\
\text { meter }\end{array}$} & \multicolumn{2}{|c|}{$30013 \leftarrow 00001$ band } & \multicolumn{2}{|c|}{$31113 \leftarrow 01101$ band } \\
\hline & Present Study ${ }^{b}$ & Toth et al. [13] & Present Study ${ }^{b}$ & Toth et al. [13] \\
\hline $\mathrm{S}_{\mathrm{v}}$ & $\begin{array}{l}4.40610(13) \times 10^{-22} \\
4.4133(5) \times 10^{-22}\end{array}$ & $4.420(4) \times 10^{-22}$ & $\begin{array}{l}0.32654(5) \times 10^{-22} \\
0.32545(19) \times 10^{-22}\end{array}$ & $0.3281(3) \times 10^{-22}$ \\
\hline$a_{1}$ & $\begin{array}{l}0.3104(8) \times 10^{-3} \\
0.2880(11) \times 10^{-3}\end{array}$ & $0.2782(80) \times 10^{-3}$ & $\begin{array}{l}0.326(5) \times 10^{-3} \\
0.372(6) \times 10^{-3}\end{array}$ & $0.2308(248) \times 10^{-3}$ \\
\hline$a_{2}$ & $\begin{array}{l}0.18624(22) \times 10^{-4} \\
0.1711(4) \times 10^{-4}\end{array}$ & $0.1826(26) \times 10^{-4}$ & $\begin{array}{l}0.1087(26) \times 10^{-4} \\
0.1213(31) \times 10^{-4}\end{array}$ & $0.0482(98) \times 10^{-4}$ \\
\hline$a_{3}$ & $-0.871(81) \times 10^{-9}$ & & & \\
\hline $\mathrm{N}$ & 74 & 60 & 136 & 74 \\
\hline$J_{\max }$ & 74 & 67 & 60 & 53 \\
\hline
\end{tabular}

${ }^{a}$ Intensities are expressed in units of $\mathrm{cm}^{-1} /\left(\right.$ molecule $\left.\cdot \mathrm{cm}^{-2}\right)$ at $296 \mathrm{~K}$. The uncertainties reported in parentheses under columns 2-5 correspond to one-sigma internal statistical errors in units of the last quoted digit(s) of the measured values. For example, $4.4133(5) \times 10^{-22}$ corresponds to $(4.4133 \pm 0.0005) \times 10^{-22}$.

${ }^{b}$ The upper values in each row under columns 2 and 4 (labeled Present Study) correspond to those from the present study, and the lower values correspond to those determined in Ref. [18]. Note that the Herman-Wallis $a_{3}$ parameter was not determined in Ref. [18] or in Ref. [13].

It may be recalled that in the present study the rotational partition function $\left(Q_{r}\right)$ used was $0.12 \%$ higher than the value used in [18]. 


\section{Table 8}

Off-diagonal relaxation matrix element coefficients, $W_{i j}$, and their temperature dependence exponents for $\mathrm{CO}_{2}-\mathrm{CO}_{2}$ and $\mathrm{CO}_{2}$-air mixing in the $30013 \leftarrow 00001$ band of ${ }^{12} \mathrm{C}^{16} \mathrm{O}_{2}$.

\begin{tabular}{|c|c|c|c|c|}
\hline $\begin{array}{l}\left(W_{i j}\right) \\
\text { between }\end{array}$ & $\begin{array}{l}\left(W_{i j}\right)^{\mathrm{a}} \\
\mathrm{CO}_{2}-\mathrm{CO}_{2}\end{array}$ & $\begin{array}{l}n_{2}\left(W_{i j}\right)^{\mathrm{b}}\left(\mathrm{CO}_{2^{-}}\right. \\
\left.\mathrm{CO}_{2}\right)\end{array}$ & $\begin{array}{l}\left(W_{i j}\right)^{\mathrm{a}} \\
\mathrm{CO}_{2} \text {-air }\end{array}$ & $\begin{array}{l}n_{1}\left(W_{i j}\right)^{\mathrm{b}} \\
\left(\mathrm{CO}_{2} \text {-air }\right)\end{array}$ \\
\hline $\mathrm{P} 2$ \& P4 & $0.00762(11)$ & & $0.00807(13)$ & \\
\hline P4 \& P6 & $0.01252(11)$ & & $0.01340(14)$ & \\
\hline P6 \& P8 & $0.01481(12)$ & $1.002(41)$ & $0.01642(25)$ & $0.883(47)$ \\
\hline P8 \& P10 & $0.01784(13)$ & $0.897(42)$ & $0.01951(29)$ & $0.807(48)$ \\
\hline P10 \& P12 & $0.02054(14)$ & $0.834(45)$ & $0.02127(31)$ & $0.823(47)$ \\
\hline P12 \& P14 & $0.02284(15)$ & $0.889(39)$ & $0.02265(32)$ & $0.815(47)$ \\
\hline P14 \& P16 & $0.02510(15)$ & $0.814(37)$ & $0.02230(32)$ & $1.005(47)$ \\
\hline P16 \& P18 & $0.02672(16)$ & $0.734(35)$ & $0.02241(33)$ & $1.030(46)$ \\
\hline P18 \& P20 & $0.02716(17)$ & $0.900(31)$ & $0.02311(34)$ & $0.924(45)$ \\
\hline P20 \& P22 & $0.02739(18)$ & $0.849(26)$ & $0.02313(32)$ & $0.895(38)$ \\
\hline P22 \& P24 & $0.02752(19)$ & & $0.02347(26)$ & \\
\hline P24 \& P26 & $0.02750(21)$ & & $0.02226(30)$ & \\
\hline P26 \& P28 & $0.02709(24)$ & & $0.02042(34)$ & \\
\hline P28 \& P30 & $0.02625(27)$ & & $0.01664(39)$ & \\
\hline P30 \& P32 & $0.02409(30)$ & & $0.01452(44)$ & \\
\hline P32 \& P34 & $0.02225(35)$ & & $0.01128(51)$ & \\
\hline P34 \& P36 & $0.02059(41)$ & & $0.01071(57)$ & \\
\hline P36 \& P38 & $0.01852(48)$ & & $0.00497(63)$ & \\
\hline P38 \& P40 & $0.01920(56)$ & & & \\
\hline P40 \& P42 & $0.01952(65)$ & & & \\
\hline P42 \& P44 & $0.01986(75)$ & & & \\
\hline P44 \& P46 & $0.02073(86)$ & & & \\
\hline P46 \& P48 & $0.02002(92)$ & & & \\
\hline P48 \& P50 & $0.01447((3)$ & & & \\
\hline
\end{tabular}




\begin{tabular}{|c|c|c|c|c|}
\hline$R 0 \& R 2$ & $0.00540(7)$ & & $0.00249(9)$ & \\
\hline $\mathrm{R} 2$ \& R4 & $0.01672(11)$ & & $0.01041(13)$ & \\
\hline $\mathrm{R} 4$ \& R6 & $0.02226(11)$ & & $0.01634(13)$ & \\
\hline R6 \& R8 & $0.02640(11)$ & $0.833(19)$ & $0.01988(21)$ & $0.733(31)$ \\
\hline R8 \& R10 & $0.02970(12)$ & $0.814(20)$ & $0.02114(22)$ & $0.913(32)$ \\
\hline$R 10$ \& R12 & $0.03159(12)$ & $0.784(20)$ & $0.02227(23)$ & $0.913(33)$ \\
\hline R12 \& R14 & $0.03222(12)$ & $0.794(20)$ & $0.02268(23)$ & $0.914(33)$ \\
\hline R14 \& R16 & $0.03273(12)$ & $0.822(20)$ & $0.02254(23)$ & $0.973(32)$ \\
\hline R16 \& R18 & $0.03239(12)$ & $0.769(20)$ & $0.02300(23)$ & $0.914(31)$ \\
\hline R18 \& R20 & $0.03193(13)$ & $0.731(18)$ & $0.02342(23)$ & $0.830(29)$ \\
\hline R20 \& R22 & $0.03078(13)$ & $0.676(16)$ & $0.02271(21)$ & $0.855(25)$ \\
\hline R22 \& R24 & $0.02894(13)$ & & $0.02308(17)$ & \\
\hline R24 \& R26 & $0.02800(14)$ & & $0.02313(18)$ & \\
\hline R26 \& R28 & $0.02681(15)$ & & $0.02225(20)$ & \\
\hline R28 \& R30 & $0.02592(16)$ & & $0.02107(22)$ & \\
\hline R30 \& R32 & $0.02512(17)$ & & $0.01981(25)$ & \\
\hline R32 \& R34 & $0.02229(18)$ & & $0.01746(28)$ & \\
\hline R34 \& R36 & $0.02104(20)$ & & $0.01708(31)$ & \\
\hline R36 \& R38 & $0.01978(21)$ & & $0.01555(34)$ & \\
\hline R38 \& R40 & $0.01796(23)$ & & $0.01213(35)$ & \\
\hline R40 \& R42 & $0.01579(24)$ & & $0.00824(33)$ & \\
\hline R42 \& R44 & $0.01155(26)$ & & & \\
\hline R44 \& R46 & $0.00911(26)$ & & & \\
\hline R46 \& R48 & $0.00642(24)$ & & & \\
\hline
\end{tabular}

Notes: The values given in parentheses represent one sigma internal measurement error in units of the last quoted digit.

anits are $\mathrm{cm}^{-1} \mathrm{~atm}^{-1}$ at $296 \mathrm{~K}$.

${ }^{\mathrm{b}}$ Temperature dependence exponents, $n_{1}$ and $n_{2}$, have no units (see the text for details). 